\title{
PNNL-12139
}

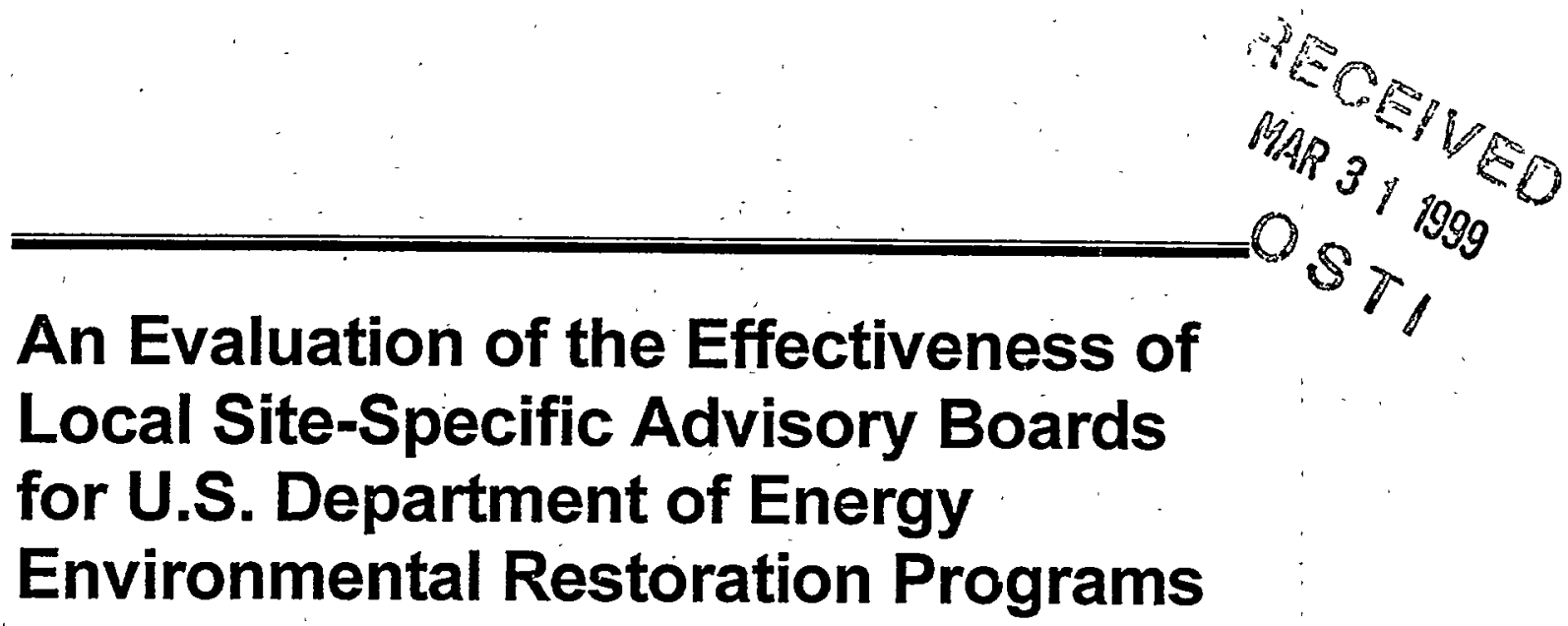

Judith A. Bradbury

Kristi M. Branch

Pacific Northwest National Laboratory

February 1999 


\section{STANDARD DISCLAIMER}

This report was prepared as an account of work sponsored by an agency of the United States Government. Neither the United States Government nor any agency thereof, nor Battelle Memorial Institute, nor any of their employees, makes any warranty, express or implied, or assumes any legal liability or responsibility for the accuracy, completeness, or usefulness of any information, apparatus, product, or process disclosed, or represents that its use would not infringe privately owned rights. Reference herein to any specific commercial product, process, or service by trade name, trademark, manufacturer, or otherwise does not necessarily constitute or imply its endorsement, recommendation, or favoring by the United States Government or any agency thereof, or Battelle Memorial Institute. The views and opinions of authors expressed herein do not necessarily state or reflect those of the United States Government or any agency thereof.

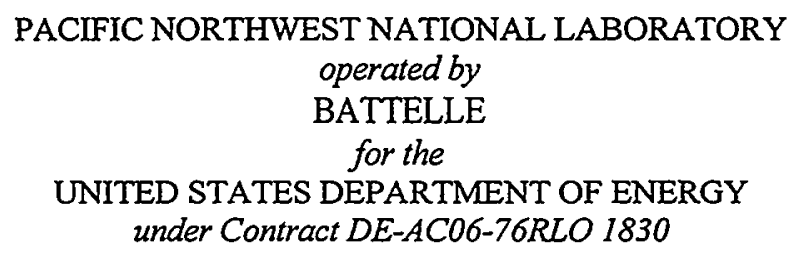




\section{DISCLAIMER}

\section{Portions of this document may be illegible in electronic image products. Images are produced from the best available original document.}




\section{FOREWORD}

In the early 1990s, the U.S. Department of Energy (DOE) undertook a major new effort to involve community stakeholders in decisions that would affect them and their communities and interests. An important component of this effort was the establishment of local Site-Specific Advisory Boards (SSABs) at $12 \mathrm{DOE}$ environmental remediation sites. These boards were a formal representation of a change in the way DOE conducts its missions, adding consideration of community concerns and values to the Department's decision-making processes. DOE's purpose in creating the SSAB Initiative was to obtain broadly based, independent, consensus advice and recommendations on issues that have the potential to affect communities surrounding DOE sites, so that it could formulate policies that could be implemented with community consent.

Because the boards represented a significant commitment by DOE to change its relationships with community stakeholders, the Department has conducted several assessments of the boards. In 1996 and 1997 a survey was administered to board members and others involved in the work of the boards (DOE/EM 0311, 1996; DOE/EM, 1997). As part of the first survey, $D O E$ and the boards established a set of performance criteria. The surveys provided data that revealed wide variations in board performance and significant change over time. To gain a better understanding of the factors affecting board performance, DOE initiated a more in-depth, qualitative study of nine of the boards across the complex. This study focused on identifying and analyzing the factors affecting board performance and presenting that information in a format that helped the boards and DOE gain insight into their strengths and weaknesses and learn from one another.

This report presents the results of this in-depth study. It begins with an overview report that identifies and discusses the six factors that were found to affect board performance. The overview report provides the framework and rationale for the information presented in the nine individual site reports, which follow in alphabetical order. The individual site reports describe each of the boards in terms of the six factors affecting board performance, beginning with a brief summary of the history and setting for the local SSAB. They end with a list of issues raised by members and the researchers' assessment of the key accomplishments and challenges facing the board. 


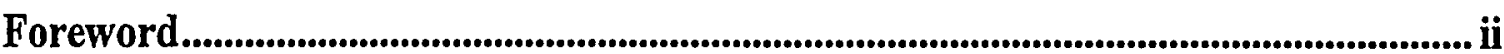

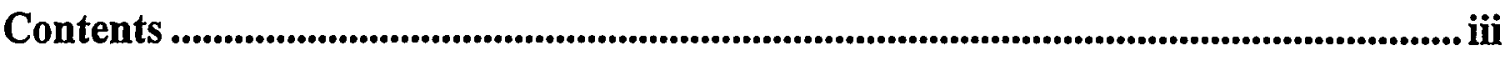

Overview Report ................................................................................................................... 1

Individual Site Reports:

Hanford Advisory Board

Idaho National Engineering and Environmental Laboratory Citizens Advisory Board

Nevada Test Site Community Advisory Board

Northern New Mexico Citizens' Advisory Board

Oak Ridge Reservation Environmental Management Site-Specific

Advisory Board

Paducah Gaseous Diffusion Plant Site-Specific Advisory Board

Pantex Plant Citizens' Advisory Board

Rocky Flats Citizens Advisory Board

Savannah River Site Citizens Advisory Board 
PNNL-12139

An Evaluation of the Effectiveness of Local SiteSpecific Advisory Boards for U.S. Department of Energy Environmental Restoration Programs:

\section{Overview Report}

Judith A. Bradbury

Kristi M. Branch

Pacific Northwest National Laboratory

February 1999 


\section{OVERVIEW REPORT}

\section{Executive Summary}

In 1998, DOE initiated a study of its local Site Specific Advisory Boards (SSABs) organized under the Environmental Management SSAB Charter. Building on the findings of surveys conducted in 1996 and 1997, this study focused on the quality of board discourse and interaction at three levels: among board members, between board members and the broader public, and between board members and DOE and the regulators. Where the quality of board discourse and interaction was weak, boards were found to be less able to achieve their basic purpose of seeking consensus among diverse views, providing independent advice to DOE reflecting that consensus, and providing a channel of communication with the surrounding community.

The study identified six key factors that affect the quality of discourse. It then developed a description of each local SSAB in terms of those factors. The report thus provides an outsider's perspective, based on a review of the range of board experience across the complex, that is intended to help the boards learn about their own and the other boards' strengths and weaknesses.

The data used to characterize board performance and identify these factors were obtained through observations of board and subcommittee meetings, in-person interviews with board members and staff, telephone interviews with board members unavailable for in-person interviews, and a review of documentation relating to each board.

Boards that are most aligned with DOE's purpose of benefiting from community viewpoints have members who reflect the diversity of viewpoints in the community, who work with one another to clarify the purpose of the board, and who establish processes that facilitate true consensus building. Although not all boards have community contexts or initial conditions that are favorable to their effectiveness, many boards have worked hard and patiently, often with the help of a facilitator, to build processes that bring out and include diverse views in independent, consensus recommendations to DOE.

The six factors that affect the problems and issues encountered by the boards in achieving effective dialogue include community context; board composition; purpose, goals, and commitment to consensus; internal process and functions; public engagement; and DOE and regulator engagement.

Community Context: Existing conditions affect the challenges of recruiting members who can create a diverse board and work effectively together. For example, boards in communities with a history of involvement are more likely to find recruits with experience working in diverse groups and on contentious issues than those in communities without such a history. Boards at sites with a mission limited to cleanup are likely to have an easier time than those boards at sites with controversial defense programs. Boards in communities with 
longstanding, unresolved social conflicts are likely to have more difficulty than those in communities where such conflicts are less prominent or where they have been previously resolved.

Board Composition: The composition of the board affects both the quality of discourse and the credibility of the board and its recommendations. Boards should reflect the diversity in the surrounding communities-both the demographic diversity (e.g., gender, ethnicity, education, and socioeconomic status) and the diversity in viewpoints. Boards without members who represent demographic groups and viewpoints in the community jeopardize their ability to achieve the goal of providing advice that reflects the diversity of community views and hence the validity and credibility of their recommendations. As mentioned above, community context can make it more or less difficult to recruit a diverse board.

Purpose, Goals, and Commitment to Consensus: A definition that has been established and agreed on among board members concerning the basic purpose of the board has a major impact on board procedures and board effectiveness. Boards that have made a commitment to including a wide range of community viewpoints (including those critical of DOE) and to finding areas of agreement among those viewpoints are better able to meet DOE's intent than those that have not made such a commitment. The commitment of individual board members is important, often assisted by effective facilitation.

Internal Process and Functions: Quality dialogue is more likely to occur (and member diversity to be maintained) when leadership understands the purpose of the SSAB Initiative and focuses on finding bases for agreement among different viewpoints. Effective leaders (both formal and informal) set a conducive atmosphere for work and ensure that processes are put in place that enhance the board's ability to achieve quality dialogue and enlarge members' area of agreement. For example, they encourage development of a focused agenda; provide facilitation, team-building, and an open agenda-building and issues management process; ensure that adequate administrative support is in place; and encourage networking within and outside the board. Clarifying the goals of the board and adjusting internal process elements often represent the best opportunities for a board to initiate shortterm changes.

Public Engagement. Obtaining input and providing feedback to the broader public concerning board activities are key responsibilities of the boards. Where this dialogue is weak or missing, DOE and the boards can take deliberate steps to improve it, for example, by conducting surveys to assess community views and conducting outreach activities such as newsletters, media coverage, and networking.

DOE and Regulator Engagement: An effective board depends in part on high-level DOE staff and regulators to become sufficiently involved to understand, value, and act on board advice and to empower the board to make independent judgments. When this does not occur, or when DOE and the regulators do not provide positive feedback, board members may conclude that their efforts are not worthwhile. They may then become hostile or apathetic, or leave the board. 


\section{Table of Contents}

Executive Summary ............................................................................................................. ii

Table of Contents ............................................................................................................... iv

Introduction ......................................................................................................................................... 1

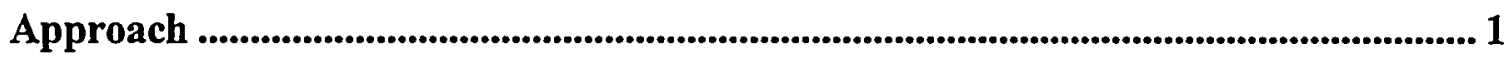

Factors Affecting SSAB Performance Across All Sites ........................................................ 2

Community Context................................................................................................................... 4

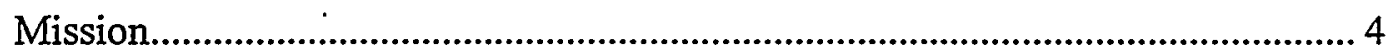

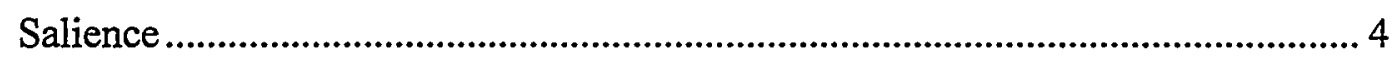

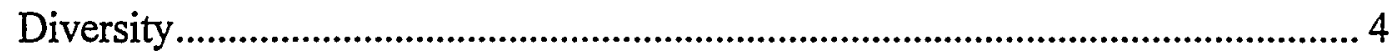

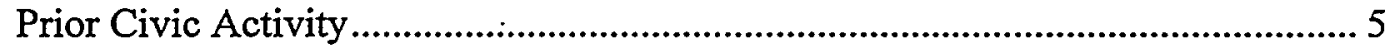

Board Composition ................................................................................................................................. 5

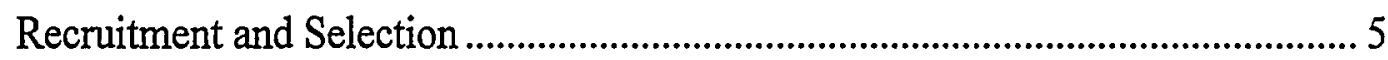

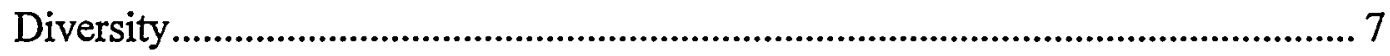

Goals, Purpose, and Commitment to Consensus ……....................................................... 7

Internal Process and Functions .................................................................................... 8

Agenda Building, Issues Management, and Decision Making ................................ 9

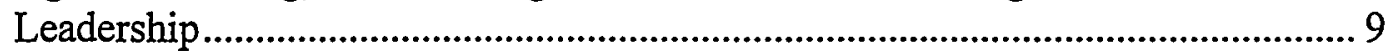

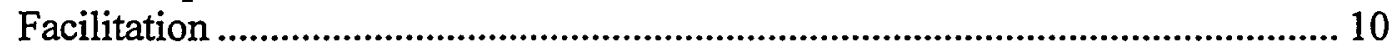

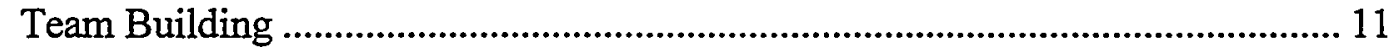

Administrative and Technical Support .................................................................. 12

Public Engagement ............................................................................................................................... 12

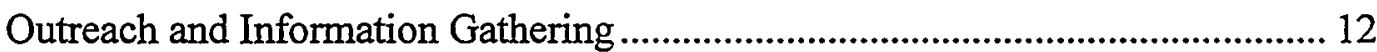

Opportunities for Participation in Board Activities .............................................. 13

DOE and Regulator Engagement ......................................................................................... 13

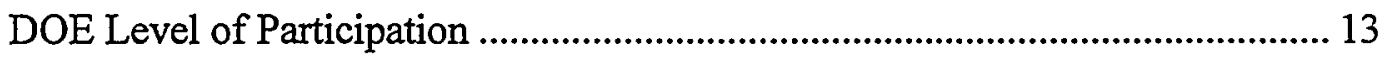

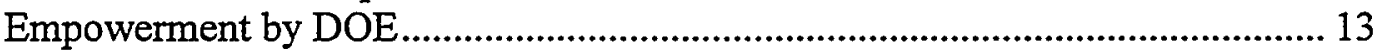

DOE Responsiveness ......................................................................................... 14

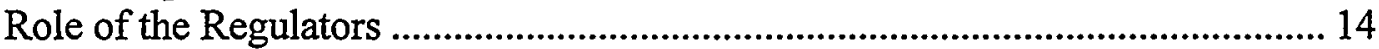




\section{Introduction}

Local Site-Specific Advisory Boards (SSABs), known in some locations as Community or Citizen Advisory Boards (CABs), were established at 12 U.S. Department of Energy (DOE) sites between 1993 and 1996. The purpose of the boards is to draw on the full diversity of community views to provide independent, consensus advice and recommendations to DOE on issues of environmental remediation and waste management that have the potential to affect the surrounding community. Such broad-based, independent advice helps DOE formulate policies that can be implemented with community consent.

In 1995, a steering committee of board and DOE representatives developed a set of six goals to serve as the basis for evaluating the boards' progress and performance in terms of achieving this basic purpose. In 1996 and 1997, board members and others involved in the work of the board, as DOE liaisons and federal and state regulators, participated in a survey focused on those goals (DOE/EM-0311, 1996; DOE/EM, 1997). The surveys revealed wide variation in the performance of the boards, and provided information of use to DOE as well as to the boards themselves. However, in 1998, DOE wished to examine the details behind the reported phenomena and performance measures and to develop information that would help the boards, $\mathrm{DOE}$, and the regulators improve their effectiveness in providing advice to that reflects the diversity of community views and a channel of communication with the surrounding community. Hence, in 1998 DOE initiated this study, which involved a series of site visits to the boards by researchers with extensive experience in public participation and program evaluation.

The purpose of the study was to:

- Validate the set of goals established by the steering committee that were used in previous DOE surveys of the boards

- Identify key factors affecting local SSABs' performance

- Describe how each local SSAB was operating in relation to these factors

- Provide a basis for boards to reflect on their own performance and processes and to learn from one another.

\section{Approach}

Building on previous surveys and further review of the literature, the researchers developed a research design and interview guide. Ten of the 12 environmental remediation sites having a $S S A B$ or $C A B$ were selected for visits by a research team. These sites were Hanford, Idaho, Los Alamos, Nevada, Oak Ridge, Paducah, Pantex, Rocky Flats, Sandia, and Savannah River. Because of scheduling constraints, two sites - Fernald and Monticello - were not visited. The report represents a snapshot of nine boards at a point in 
time, beginning in March 1998 with a visit to the Savannah River Site Citizens Advisory Board and ending in December 1998, following a visit to the Northern New Mexico Citizens Advisory Board.

The researchers observed the boards, reviewed documentation, and conducted interviews during site visits. At some sites, the schedule also allowed observation of subcommittee meetings. At Oak Ridge, a special administrative meeting of the board was also observed. The researchers examined documentation relating to each board, including meeting minutes and records of board recommendations and ex-officio responses.

The researchers conducted in-depth, in-person interviews of approximately one hour duration with board chairs and co-chairs and as many of the board's officers and members (including former members) as was possible in a three to five day site visit. Where professional facilitators and/or administrators were retained by the board, they were also interviewed. In several cases, additional interviews were conducted by telephone in an effort to speak with board members whose schedules did not allow in-person interviews. It was not possible to speak with all board members; however, the interviewers talked with persons representing different viewpoints in an effort to ensure a balanced report of board functioning. In addition, regulators, DOE, and DOE contractor staff with responsibilities pertaining to the establishment and operation of the board were also interviewed.

In evaluating the performance of the boards, the researchers recognized that the context and specific challenges facing each board would vary. Similarly, the performance of all of the boards would be uneven: some would excel in areas where others did not; all would have strengths and weaknesses. The goal of the study was to encourage the boards to reflect on their accomplishments and challenges, learn about their own strengths and weaknesses, and learn from one another's successes and challenges. It was specifically not intended to encourage competition among the boards or single any out for criticism or praise.

\section{Factors Affecting SSAB Performance Across All Sites}

The study was designed to assist DOE and the boards in assessing whether the boards were fulfilling DOE's overarching purpose of obtaining independent, consensus advice and recommendations from the range of local and regional stakeholders' perspectives in order to make decisions that would be more acceptable to those affected (and hence more likely to be implemented). DOE's initial guidance to the local SSABs drew both on the Federal Advisory Committee Act (FACA) and also on the conceptual framework and recommendations of the Federal Facilities Environmental Restoration Dialogue Committee (commonly referred to as the Keystone Dialogue), that emphasized the value of a "forum for discussing citizens' issues and concerns," to enable development of "a more complete or satisfactory plan or decision."

\footnotetext{
' Federal Facilities Environmental Restoration Dialogue Committee, Consensus Principles and Recommendations for Improving Federal Facilities Cleanup, April 1996, Keystone Center, Keystone, CO, p. 50.
} 
In compliance with the FACA regulations requiring that the boards "be fairly balanced in terms of points of view represented" (41 CFR Chapter 101-6.7), DOE emphasized the need for the local SSABs to include representation "of all persons and groups who see themselves as affected" (SSAB Guidance, Interim-Final, November 1994, p.2). A recent memo from the Secretary of Energy provides a reminder of DOE policy (DOE M 510.11) that "consideration shall also be given to such interests as geographic regions of the country; minority groups; women's organizations; public and private academic institutions, including Historically Black Colleges and Universities; physically challenged individuals and groups; and the public at large."2

Also included in DOE's initial guidance was the understanding that the desired approach was for the boards to seek consensus in developing their advice to DOE. However, this was never explicitly stated; ${ }^{3}$ nor was the underlying rationale for a consensus-seeking approach discussed. Nevertheless, the assumption was generally accepted by the boards as well as by the members of the Steering Committee that developed the goals on which previous evaluations were based. The expectation was that advice which reflected agreement among very different viewpoints would also be more likely to be acceptable to nearby communities. It would thus provide a firm basis for developing policies that were not only technically sound but also could be implemented. ${ }^{4}$

This study focused on processes that enhanced the boards' ability to develop broadly based policy advice, while also providing a channel of communication with the surrounding community. It examined the dialogue among the three participating groups as they worked to develop their recommendations to DOE: among board members, between the board and DOE and regulators; and between the board and the community. Six factors emerged as exerting a strong influence upon the ability of the boards to establish and maintain an effective dialogue:

\section{- Community context}

- Board composition

- Goals, purpose, and commitment to consensus

\footnotetext{
${ }^{2}$ Memorandum from Bill Richardson to Heads of Department Elements, November 6, 1998.

${ }^{3}$ The guidance does not state that the boards should use consensus. However, the list of Field Office responsibilities states that : "[Field Offices should] encourage the Board to make every attempt to reach consensus" (DOE Office of Environmental Management, Site-Specific Advisory Board Guidance, Interim Final, November 14, 1994, DOE, Washington, DC, p. 8). A suggestion is also included under Section 2, Basic Principles, that "a facilitator could be used to ensure that board members set and reach meeting objectives, maintain focus, work as a team, and reach consensus" (p.2). FACA is also not explicit. The definition of an advisory committee does not specify a requirement for consensus advice (41 CFR 1016.1003); however, a subsequent section states that a group is not covered under the Act when a federal official initiates a meeting to obtain the advice of individual attendees and "not for the purpose of utilizing the group to obtain consensus advice" (41 CFR 101-6.1004). The language included in the background discussion included in the federal register notice was not included in the regulation, although it provides additional persuasory evidence of the intent that advice reflect consensus ( 52 FR 45926, December 2 , 1987).

${ }^{4}$ For this reason, the focus of the study was not on the products themselves (e.g., the number of recommendations and their use by DOE), but on the boards' composition and the processes that enhanced boards' ability to provide broadly based, independent policy advice.
} 
- Internal processes

- Public engagement

- DOE and regulator engagement.

\section{Community Context}

Existing conditions affect the challenges of recruiting a diverse board of members who can work together. Thus, the composition and structure of the community, including DOE's past and present place in that structure, appear to play a significant role in shaping both the development and impact of a board. Sites with a mission limited to cleanup are likely to have an easier time than those with controversial defense programs. Boards also have an easier time becoming effective if the issues of the site are already known and salient (i.e., of central importance) to the community, if a wide range of institutions and interest groups already exist, and if the community has a history of active citizen engagement.

\section{Mission}

The scope and nature of the DOE mission is a key factor affecting board functioning. At sites where production activities continue and site restoration is not the sole mission, local SSABs face a particular challenge. Under these circumstances, a board's scope and agenda are more likely to be disputed and community controversy over the pros and cons of a continuing DOE mission is more likely to spill over into board discussions and relationships - especially if the continuing mission is weapons-related. Boards appear to be more likely to agree on the scope and focus and to be able to provide strong consensus advice when the mission is limited to or concentrated on site restoration. Disagreement appears to be more likely when the board must clarify and agree on how to address DOE activities that are split among different $\mathrm{DOE}$ divisions and when the restoration agenda is competing with other issues for the attention of the community, as well as the attention and resources of the DOE site office. This is especially likely when the issues are controversial, such as new missions involving weapons or receipt of additional wastes.

\section{Salience}

Boards seem to have an easier time defining their role and organizing effectively to fill it when they are confronted with issues that are already known and of central importance to the affected community. Some boards have been implemented where site issues and remediation are not regarded as a high priority by the surrounding community but where DOE desired to be proactive in soliciting community advice. In these cases, it has proven difficult to recruit, engage, and retain members, and boards have tended to focus a greater proportion of their energy on matters of internal organization and agenda setting.

\section{Diversity}

A diverse economic base can moderate concerns that site restoration may adversely affect ongoing production activities to the detriment of the local economy. Where such concerns 
are present, they may give rise to polarization of views on the board, thus increasing the difficulties in reaching consensus. Also presenting a challenge is the existence of longstanding social and cultural conflict among different community stakeholders that is likely to carry over into discussions about DOE environmental and waste management issues. However, these are not the sole dimensions of community diversity. When it is effectively represented on a board, civic diversity - the presence of a wide range of institutions and interest groups - and demographic diversity in the community seem to reduce the likelihood of the board becoming polarized around opposing (critical and defensive) views of DOE and its restoration efforts. When a board becomes polarized, effective dialogue and the search for areas of agreement become more difficult.

\section{Prior Civic Activity}

Communities that have a history of active citizen engagement in environmental, economic, and community development issues appear to be at an advantage in establishing and operating a local SSAB. In part this may reflect social learning by the community about how to organize and deal with strongly held differences. Also, existing social networks may provide benefits for recruitment and transmission of information around the community that support the board's operation and shape its choice of activities. Where past experience also included public or stakeholder involvement in other DOE activities, the stakeholders may already have become knowledgeable about the policy implications of key technical issues, identified community values in relation to $\mathrm{DOE}$ issues, and forged a foundation for future relationships. A comparable experience among DOE personnel about the methods and benefits of public involvement may have enabled them to interact effectively with the board and help it operate effectively.

Other aspects of community context may also be significant in particular locations. However, salience, mission, diversity, and prior civic activity seem to be influential across all of the SSABs that we studied.

\section{Board Composition}

A key requirement for the local SSAB is to meet the FACA mandate to be "fairly balanced in its membership in terms of the points of view represented and the functions to be performed" (41 CFR 101-61029(c)). Recruitment and selection of board members should therefore reflect concerns for demographic diversity and diversity of viewpoints and accountability to the community.

\section{Recruitment and Selection}

Although all boards are designed to recruit and select according to established categories to ensure diversity, considerable variation exists in the specific way this FACA requirement is implemented. A fair, open recruitment and selection process that ensures representation of the diversity of community viewpoints provides the essential foundation for boards to achieve the basic purpose of the SSAB Initiative. Absence (through exclusion, refusal, or withdrawal) of particular viewpoints affects both the operation of the board and the credibility of board recommendations to DOE, the regulators, and the public. 
Most boards use several methods to recruit candidates-advertising in local media, written requests and visits to community organizations, and personal networks. Responsibility for recruitment is usually assigned to administrative staff, under direction from the board and a membership committee.

Analytically, the selection approach can be classified according to two cross-cutting dimensions:

- What viewpoint does the member represent? Representation may be by (1) individual viewpoint, (2) category viewpoint, or (3) organizational interest viewpoint. In the first approach, individuals are selected from identified categories to represent their own viewpoints - the assumption is that the representation of the various categories will ensure diversity of views. In the second approach, members are selected to represent the views of people in the particular category from which they are drawn. In this approach, the implication is that members will take responsibility for informing themselves about the views of other people in this category and reporting back to them about board activities. In the final approach, members are selected to represent particular organizations and institutions that speak for community interests. In practice, board selection approaches fall along a continuum from individual (e.g., Savannah River Site, where members are selected from various categories to reflect the demographic diversity of the community) to organizational (e.g., Hanford, where the majority are selected from existing community interest groups).

- Who selects the member? Although DOE has final responsibility for approving members, four methods of selecting members from among potential candidates are used. Members may be selected by (1) the board; (2) a third-party or independent body; (3) organizations, through designation of their representative; or (4) DOE. Most boards select their own members, relying on a membership committee to solicit, screen, and recommend candidates for board approval. The Oak Ridge Board, which relies on an independent panel, provides an example of the second selection process. Hanford primarily requests organizations to designate their own representative (the board also includes some at-large members of the public who are recruited and selected by EPA and the State regulators). At Los Alamos, DOE assumed sole responsibility for selecting members in its 1997 restructuring of the board; this responsibility was shared with the board Chair in the recruitment and selection process conducted at the end of 1998.

The approach used by a board has implications for the relationship of the board to the community. Theoretically, it may be easier for board members who are selected explicitly to represent the interests of organizations and institutions in the community to become prepared for discourse within the board as well as for dialogue between the board and the community - particularly when they have had prior experience in collaborative problem solving. Whether members are actually appointed by participating 
organizations, or invited to join the board because of their membership in a community organization, their memberships in these organizations provide an existing channel for the exchange of information with the public.

Some boards have had difficulty with recruitment and selection, particularly when civic organizations do not play a major role in community life, when certain constituency groups have declined to participate in the boards, or when the board has set specific goals for diversity in demographic representation. In some cases, boards have relied on the personal networks of existing members to recruit new members. However, personal networks, if used alone, may not tap into all segments of the community and may create particular problems where boards have become highly polarized. In these cases, each side may view the recruitment efforts of the other as a way to stack the board with their supporters.

\section{Diversity}

However members are recruited, a key requirement is that board membership be diverseincluding both demographic diversity (e.g., gender, ethnicity, education, and socioeconomic status) and diversity of viewpoints. It is important that members reflect the range of community perspectives, including members with a critical perspective on DOE policies, if the board is to fulfill its role of providing independent, broad-based policy advice to DOE. The participation of community members who are critical of DOE and/or the regulators is important not only to enrich the deliberations of the board and their value to DOE and the regulators, but also to enhance the credibility of the board to the public. In addition, broad diversity seems to be the best insurance against a board becoming polarized into critical and defensive factions that find it very difficult to agree on an approach and agenda and to develop consensual recommendations that expedite effective site remediation.

The selection process can be used to ensure that members are authentic representatives of diverse viewpoints and community constituencies. However, changes in the composition of the board through strategic recruitment and selection may need to occur over a number of years as existing members' terms expire and may not be possible where the community itself does not have strong, diverse civic organizations and constituencies.

\section{Goals, Purpose, and Commitment to Consensus}

As our study progressed, it became increasingly apparent that the definition established and agreement reached among board members on the basic purpose of the SSAB Initiative have had a major impact on the quality of the dialogue at all three levels, and thus on board effectiveness. Boards that have made a commitment to including a wide range of community viewpoints (including viewpoints critical of DOE) and to finding areas of agreement among those viewpoints were more likely to achieve the goal of developing broadly based policy advice and recommendations. The key was commitment to searching for areas of agreement (both technical and non-technical) rather than focusing on areas of disagreement, and the establishment of procedures that enhanced their ability to do this successfully. Where this commitment was weak or lacking, or where such procedures had not been established, problems were particularly likely to be reflected in the dialogue among members. 
Members of boards such as Idaho, Hanford, and Rocky Flats that were strongly committed to seeking consensus on substantive policy and procedural decisions (administrative decisions are typically made by a majority vote) frequently emphasized to us the central importance of this decision-making approach. For many, the process of striving for consensus both reinforced and demonstrated members' commitment to the essential goal of providing advice to DOE and the regulators that would have broad-based support.

A shared commitment to consensus may be particularly important for keeping SSABs from devolving into a technical advisory board, especially at sites where the complexity and technical aspects of the issues afford an opportunity for members with technical training and familiarity with DOE and regulatory terminology and procedures to dominate board dialogue, albeit unintentionally. Devolution of the local SSABs into technical advisory boards is counter to DOE's intent: in establishing the advisory boards, DOE sought to obtain help from a broad range of affected publics in developing policies that would be acceptable to these publics, in addition to being technically sound. Board commitment to consensus (frequently the product of influential members' personal commitment and assisted by effective facilitation) can serve as a means of enabling members with diverse backgrounds and training to play an active role in policy discussions and the development of board advice.

\section{Internal Process and Functions}

Our study indicated that boards have used a variety of approaches to ensure performance of the functions that facilitate effective discourse. The specific approach does not seem to be as important as ensuring that the necessary functions are performed and, most critically, that these functions are designed to enhance the board's ability to achieve the purpose of the local SSABs. Adjusting internal processes may represent the best opportunity for boards to initiate short-term changes. However, implementing process changes is unlikely to result in more effective performance, unless the changes are preceded by a clear articulation of goals to assist the members in gaining insight into the assumptions that underlie the perceived need for change.

It is difficult to say whether the processes and procedures a board adopts for agenda building and decision making are the cause or outcome of a board's performance. Typically, however, the success with which these functions are performed is reflected in the quality of the discussion that occurs in board meetings. Important functions include:

- Open agenda-building, issues management, and decision-making processes that emphasize search for common areas of agreement among diverse views and that are informed by DOE and regulator needs

- Team-building processes, which may be formal or informal

- Leadership, particularly by the Chair and/or Executive Committee

- Facilitation, both for meeting planning and implementation and for brokering technical and interpersonal issues 
Administrative and technical support, including technical assistance to facilitate participation by nontechnical members and reduce members' workload.

\section{Agenda Building, Issues Management, and Decision Making}

Local SSABs that are seen as effective by both board members and DOE and regulatory officials devote significant resources to building a consensual agenda for the board's operations, following that agenda in a sustained fashion, and making decisions by consensus.

$\mathrm{DOE}$ and the regulators can help the agenda-building process by providing information about problems and issues that are most important to them. Once an agenda and work plan are developed, boards require functional subcommittees and/or issue managers to prepare information for the rest of the board and provide continuity of focus on an issue over time. Boards have adopted a variety of ways to maintain focus: by adhering to a formal work plan (e.g., Hanford, Idaho, Oak Ridge, Rocky Flats, and Savannah River); by dividing issues into "awareness" categories for staff to monitor and "focus areas" for members to address, as at Rocky Flats; and referring back to values and principles to guide their selection of priorities, as at Hanford. All of the boards reported to us that becoming and keeping focused is an ongoing problem. The process demands considerable leadership and internal networking and is difficult to achieve given the voluntary nature of board service and the many issues to be addressed.

\section{Leadership}

Leadership that focuses on enhancing the effectiveness of board discourse seems to be highly beneficial to the functioning of a board. Clearly, the Chairperson is the focal point for ensuring effective performance of the leadership function and promoting effective board discourse. Leadership support by other group leaders (who typically gravitate to leadership roles on the Executive Committee) is an added advantage. Effective leaders model desired behaviors. They may or may not be good meeting facilitators (see below), but they do:

- Place highest priority on improving the effectiveness of the board as a whole

- Emphasize values and the search for agreement, maintaining a balance between technical and policy orientations

- Encourage the development of a focused agenda

- Set a conducive atmosphere for work, orchestrating productive meetings, ensuring that other organizational functions are performed, and motivating and encouraging members

- Expend considerable effort networking with other members of the board outside of meetings to develop a sense of the group as well as maintaining an independent stance while interfacing with DOE.

Sometimes, boards have adopted strategies to provide balance among different factions by appointing co-chairs with opposing viewpoints. While this measure may be implemented to 
address concerns that the board may be dominated by one or the other viewpoint, and may be necessary initially to obtain participation of diverse viewpoints, it may exacerbate divisions among the board and/or preempt the emergence of an authentic consensus builder. Provided that the two co-Chairs work collaboratively together to provide unifying leadership, however, such an approach may work well - at Pantex, for example, the co-chair structure is currently proving effective. However, it may be beneficial for boards that started out with this requirement to revisit it periodically to determine whether it is helping or hindering their efforts to work together in a collaborative manner.

\section{Facilitation}

DOE's initial guidance to the local SSABs recognized the value of a facilitator to "ensure that board members set and reach meeting objectives, maintain focus, work as a team, reach consensus, and operate at maximum efficiency." Our visits to the boards reinforced the value of effective facilitation of board discussions. Our observations indicated that effective facilitation helped the boards: establish and maintain a fair process; pay attention to the contributions of both technical and nontechnical members in working toward consensus decisions; and ensure that board discussions were focused and productive. In addition, the facilitators (and/or other board members) often played a mediator role outside of board discussions.

- Establishing and maintaining a fair process. An impartial facilitator plays an important role in establishing and maintaining a process where every member feels that his or her perspective is protected, i.e., protected against bias in the process because the person running the meeting has no agenda, and protected against personal attack from other participants in the process. These general attributes are especially valuable when, as in the SSAB Initiative, diverse groups are expected to work together in a problem-solving and consensus mode. They are particularly important when many board members and ex-officio members are unfamiliar with this way of addressing differences and reaching decisions. In this situation, the facilitator can assist and reinforce members' commitment to consensus decision making and ensure that the process is not used in a destructive rather than a constructive way, for example, allowing a minority to block decisions.

- Encouraging participation by both technical and nontechnical members. An independent facilitator provides particular value to boards that have a strong contingent of technically oriented members and/or a technical Chairperson. Here, the facilitator can help prevent domination by a technical perspective, including the logical-rational form of discourse that may effectively exclude those untrained in this mode of argumentation. A facilitator's training and attention to process and participation can provide an important complement to a Chairperson who is strongly oriented toward the technical aspects of site issues.

- Ensuring that board discussions are focused and productive. Effective facilitation of meetings is also important in retaining membership. Board service is voluntary and unpaid. If members perceive that their time is not being well spent because discussions are getting bogged down or if they believe that they do not receive a 
fair hearing for their views, they are likely to become obstructive or withdraw. The facilitator's role is to keep the meeting focused and on track and to guide discussions toward productive results. When a board is polarized, the role of an independent facilitator becomes essential.

Fulfilling a broker role. A broader interpretation of the facilitation function includes the mediator or broker role - addressing interpersonal issues and/or interpretations of technical and policy issues - among board members, between the board and community, or between the board and DOE and the regulators. In some boards, this function is performed by the facilitator. In others, the Chairperson and/or individual board members perform this function as part of their networking across different groups or interests. In yet others, administrative staff, including the technical coordinator/assistant, act as brokers. The key is effective performance of this function by one or a number of persons.

\section{Team Building}

Self evaluation, group retreats, consensus training, and workshops are examples of the various formal techniques that boards have employed to promote team building and reflexivity, i.e., the process of reflecting critically on successes and problems. Such techniques help to provide self-correction and redirection where needed, and promote a sense of shared identity and purpose. Even where time and distance cause difficulties for additional meetings, boards that conduct a self-evaluation find that it helps them identify problem areas and make self-corrections where needed. The self-evaluation need not be complex. For example, the Idaho board allocates a short time on each meeting agenda for a flip-chart evaluation in which members discuss what went well or not well at that meeting and where changes may be needed.

Some boards conduct more extensive team building efforts: (1) the Oak Ridge board scheduled a one-day meeting to discuss decision-making approaches and planned another retreat to focus on process issues; (2) Rocky Flats holds an annual retreat, which includes a self evaluation process as well as prioritization of issues, to reflect on past events and activities and establish future directions; (3) the Hanford Board has scheduled several special sessions, including a one-day workshop last year to discuss their agenda, focus, and workload; (4) the Northern New Mexico (Los Alamos) board held a retreat at the beginning of the current fiscal year to regroup and discuss how to proceed with the reconstituted board; and (5) Savannah River site also recently instituted a retreat. Cross-site seminars, such as the one recently hosted by Nevada on low-level waste, and regular cross-site conference calls and board Chair meetings provide additional opportunities for team building and networking.

These techniques seem to be effective when they are reinforced by informal networking that provides on-going and real-time support of communication and problem-solving. A variety of less formal approaches can be effective. For example, meeting together for a meal, either before or after a meeting, provides an opportunity for informal interaction. The informal discussions, especially across groups, that occur when boards meet away from the site and stay overnight in a hotel (e.g., Idaho, Hanford, Savannah River, and Los Alamos), can be very beneficial to a board's effectiveness. 


\section{Administrative and Technical Support}

A well-functioning administrative team provides the infrastructure essential for supporting board operations. The bottom line is: do the administrative staff make the board and Chairperson's job easier, or do they become just another problem to manage? Board members are volunteers and, as frequently observed in interviews, the workload is heavy. Consequently, the more staff members are able to lessen the load, the more effectively board members are able to function and the more effort they are able to apply to substantive issues facing the board.

Various administrative functions need to be fulfilled. They include, at a minimum, the dayto-day administrative and meeting-related tasks such as staffing the board office, distributing information, arranging meeting logistics and notes, and performing various types of recordkeeping. Administrative staff that can fulfill more than these minimum requirements can help promote more effective board discourse. For example, providing executiveassistant help such as coordinating meetings and agendas, coaching members and also presenters, and acting as the eyes and ears of the Chair may reduce the workload on the Chair and Executive Committee. Some boards (e.g., Nevada) have appointed a technical assistant or coordinator to help synthesize, distill, and explain key technical issues and monitor emerging issues and activities. This type of support can be invaluable both for enhancing nontechnical members' ability to contribute to substantive discussions and for simplifying and lightening the reading burden on all members.

\section{Public Engagement}

Ultimately, the effectiveness of the local SSABs depends on their ability to represent the diversity of views among the public. An important function of the board is to let the public know that DOE is being advised by a citizen committee. Obtaining input and providing feedback to the broader public are key responsibilities of the boards.

\section{Outreach and Information Gathering}

One of the most straightforward methods of public outreach is available where board members actually represent constituencies and organizations within the community and can report back directly to those organizations about the SSAB's activities in the course of their normal organizational activities. Members who have been recruited through demographic profiling or personal networking, or who have the responsibility to represent a "category" of the public, frequently report difficulty in developing a strategy for linking to "the public."

There is considerable variation in the extent to which boards commit resources to direct communication with the public and in the focus of that communication. Some boards do not believe that they have a responsibility to conduct public outreach. However, other boards are concerned that their communities are almost entirely unaware of the existence and operation of the local SSAB. To address this problem, most boards prepare and circulate their own newsletter within their communities, advertise events in local newspapers, and seek to inform the local media about their activities. Others, e.g., Pantex and Rocky Flats, have engaged in specific information-gathering activities such as 
community surveys to improve their understanding of their communities' views and needs.

\section{Opportunities for Participation in Board Activities}

Another way of fulfilling the board's responsibility of serving the public interest is to encourage members of the public to participate in board meetings and, as is the case with some boards, inviting nonmembers to serve on subcommittees. A productive application of the latter approach is at Oak Ridge, where the board sponsored the establishment of an End Use Working Group that provided an opportunity for wider community involvement in a process to examine a particularly complex and salient issue. Special attention needs to be paid to the possibility of bias in selecting and defining issues, however, if these extra participants result in over-representation of a particular viewpoint.

\section{DOE and Regulator Engagement}

Opportunities to enhance local SSAB performance also lie with the DOE site offices and regulators who have an important influence on board performance and member satisfaction. The quality of DOE engagement and sense of responsibility for encouraging Board effectiveness as well as the importance and value the local site office places on the board's recommendations are important. Attitudes of DOE staff at the sites range across a spectrum from reluctant acceptance that begrudges the diversion of resources from technical activity to enthusiastic support that places a high value on the board's discussions and recommendations. At some sites, the support provided to the boards by DOE and contractors at the day-by-day working level is extensive and invaluable. However, the support of top management is also critically important in signaling to board members that their contributions are valued.

\section{DOE Level of Participation}

The extent of DOE participation in the work of the board and the level of DOE management that is actively engaged with the board seem to be significant factors in board effectiveness for a variety of reasons. First, DOE participation affects the quality and timing of information the board receives from DOE. Second, DOE participation affects the benefit DOE receives, in terms of understanding stakeholder issues and viewpoints as well as the agency's ability to respond. Third, the participation of DOE management signals to board members the value placed on their participation and effort. Generally, when a DOE site manager is an active advocate of the board, regularly attends and encourages staff to attend board meetings, and is personally responsive to information and resource requests, there is a beneficial impact on the board's operations.

\section{Empowerment by DOE}

Board members generally express the view that they should be able to operate and need to be seen by the public to operate at a high level of independence from DOE and contractor supervision. There is variation among the boards, however, in the emphasis placed on independence: at Rocky Flats, an example of one of the most independent boards, the board 
was established as a nonprofit organization. Likewise, boards place differential emphasis on indicators of independence such as having an independent office or control of their budget and hiring of staff. Most, however, emphasize the need for access to independent technical review and/or assistance. Concern is voiced about being dependent on DOE and/or former site-related employees for technical information.

\section{DOE Responsiveness}

DOE's willingness to be open in providing information and in responding to local SSAB recommendations provide an important source of feedback to the board about its effectiveness and the worth of its efforts. At some sites, DOE and the board make a determined effort to track recommendations, act on board recommendations, and follow up with technical staff. Some boards keep elaborate tracking records showing the recommendation, date it was given, and the status of the response (Hanford, Savannah River). Others, for example Idaho and Pantex, allocate a time-slot at each board meeting for DOE to report verbally, in addition to its written responses. At the Savannah River Site, DOE staff members are assigned to follow up and coordinate meetings with technical staff within a specified time period. Some boards assign the tracking task to administrative staff, encouraging DOE to be more responsive.

The quality and timeliness of DOE feedback are identified as key factors in board satisfaction and sense of effectiveness. If DOE is seen to act on SSAB recommendations and/or take time to explain the rationale for nonacceptance, the board members have an enhanced sense that their commitment of time and energy is worthwhile. However, if DOE responds in a perfunctory manner and merely records recommendations, this can have a demoralizing effect on the board.

\section{Role of the Regulators}

Tremendous variation occurs among sites in the role played by regulators, as illustrated by the extremes of Hanford and Nevada. At the former site, DOE is bound by the Tri-Party Agreement, and EPA and State regulators play a very active role, both in the formal meetings and informal networking that occurs outside of meetings. At that site also, the State regulators are responsible for screening and recommending membership candidates for DOE approval. At the latter site, in contrast, regulators play a very limited role; for example, DOE activities are not regulated by EPA, and EPA is not included in an ex-officio role.

Where they are active, regulators can play a very positive role in providing the perspective of a key player in environmental cleanup and in supporting and empowering the board. Factors that appear to be of particular importance in influencing the degree of engagement by regulators (and whether or not they regard the board as a joint enterprise or "DOE's Board") include their relationship with one another and with DOE; the existence of a written agreement that specifies the responsibilities of each agency in remediating the site; and whether or not the board's by-laws require recommendations to be provided to the 
regulators as well as to DOE. Additional factors include the importance of the site to the regulators and the local presence of regulators. 


\section{Individual Site Reports}

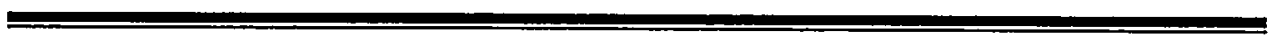


PNNL-12139

An Evaluation of the Effectiveness of Local SiteSpecific Advisory Boards for U.S. Department of Energy Environmental Restoration Programs

\section{Hanford Advisory Board}

Judith A. Bradbury

Kristi M. Branch

Pacific Northwest National Laboratory

February 1999 


\section{HANFORD ADVISORY BOARD}

\section{Table of Contents}

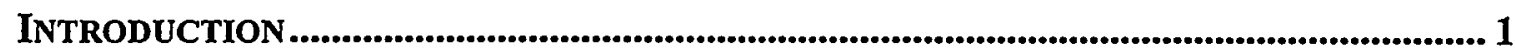

COMMUNITY CONTEXT ......................................................................................................... 2

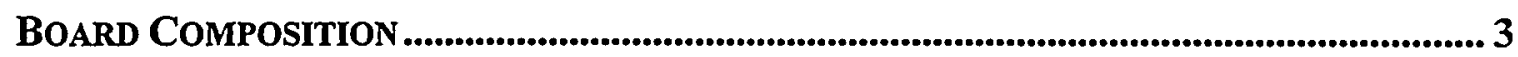

PURPoSe, GoAls, AND CoMmitMENT TO CONSENSUS ............................................................ 4

INTERNAL PROCESS AND FUNCTIONS............................................................................................5

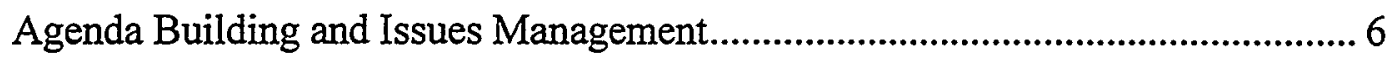

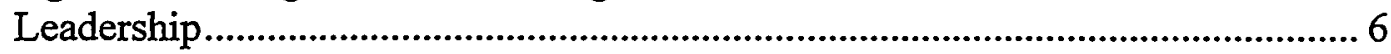

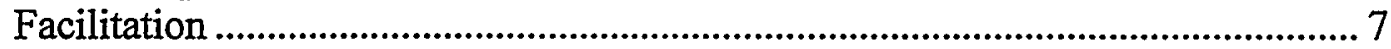

Team Building ................................................................................................... 8

Administrative and Technical Support ................................................................. 8

Process Summary ............................................................................................. 8

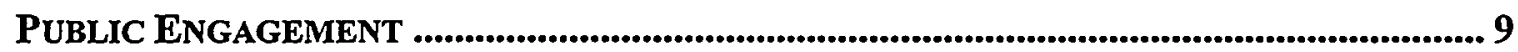

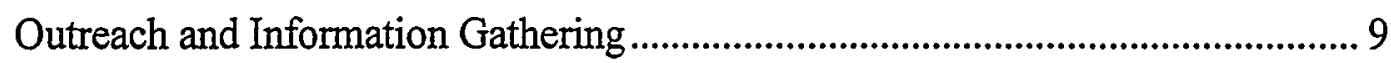

Opportunities for Public Participation in Board Activities...................................... 10

DOE AND REGULATOR ENGAGEMENT.................................................................. 10

DOE Level of Participation ................................................................................. 10

Empowerment by DOE......................................................................................... 10

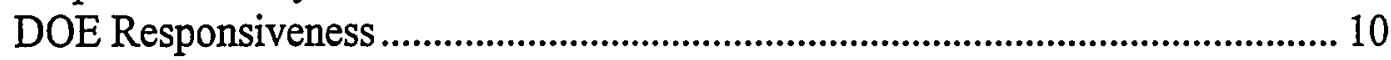

Role of the Regulators .................................................................................. 11

ISSUES AND OBSERVATIONS ................................................................................................... 11

Issues Raised by Members Concerning the HAB ................................................. 11

Researchers' Assessment of Primary Accomplishments and Challenges

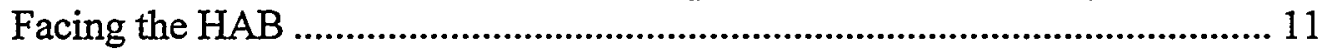




\section{HANFORD ADVISORY BOARD}

\section{Introduction}

This report details the results from the Hanford portion of a U.S. Department of Energy (DOE) study that was initiated to understand factors contributing to the effectiveness of the DOE local Site-Specific Advisory Boards (SSABs) and to provide information useful for the boards and DOE in their continuing efforts at improvement. The Overview report that accompanies the individual site reports discusses findings across nine DOE sites and provides background on the goals, methodology, and rationale for the framework used in the study. It also serves as a template for the findings presented in this site report.

The report for Hanford Advisory Board (HAB) is thus structured according to the six factors that were found to be important in assessing local SSAB effectiveness. As emphasized in the Overview, the study was designed to assist DOE and the boards in assessing how well the boards were fulfilling DOE's basic purpose in establishing the boards, and to provide information that would be useful to DOE and the boards in achieving this purpose. Specifically, DOE established the boards to obtain independent, consensus, policy advice and recommendations that drew on the range of local and regional stakeholder perspectives. The underlying rationale was that advice that reflected agreement among very different viewpoints would also be more likely to be acceptable to nearby communities and thus would provide a firm basis for developing policies that were not only technically sound but also could be implemented. Accordingly, the focus of the study was on board processes that enhanced the boards' ability to provide independent, broadly based policy advice, rather than on the recommendations per se.

This report describes the $\mathrm{HAB}$ as it was operating at the time of the researchers' visit in June 1998. The description is provided in terms of the six factors found to contribute to board effectiveness (community context; board composition; purpose, goals, and commitment to consensus; internal processes and functions; public engagement; and $\mathrm{DOE}$ and regulator engagement). It begins by highlighting key features of the site context that posed particular challenges facing the HAB. The two subsequent sections discuss the board's composition, including diversity of viewpoints represented on the board, and the board's sense of purpose, goals, and commitment to consensus. The next section examines the board's internal processes and functions, including how board members accomplish agenda building, issues management, and team building; how facilitation, brokering, and leadership roles are taken and performed; and how administrative and technical support is provided. The following section, on public engagement, details the board's effectiveness in providing opportunities for public participation and in outreach and information gathering. The next section discusses the relationship between the board and DOE, and between the board and site regulators. The final section lists important issues that members mentioned and provides the researchers' assessment of the accomplishments and challenges facing the HAB. 
As emphasized in the Overview report, the purpose of this study is to provide an outsider's perspective, based on a review of boards across the complex, and to encourage the boards to reflect on their own strengths and weaknesses and learn from one another's accomplishments and challenges.

\section{Community Context}

The 560 square mile Hanford site, managed by the Richland Operations Office (DOERL), is located in Benton, Franklin, and Grant counties in southeastern Washington near the communities of Richland, Kennewick, and Pasco. The Columbia River flows through the site. The reservations of the Yakima, the Confederated Tribes of the Umatilla, and Nez Perce, who have treaty interests in the site, are located in the surrounding area.

In 1990 , the three county area had a population of 204,791 people, 150,033 of whom lived in the Richland-Kennewick-Pasco ("Tri-Cities") metropolitan area. The population in the three-county area is predominately white, with approximately 14 percent of Hispanic origin. Interest in the Hanford site extends throughout the State of Washington and into Oregon, and thus includes the cities of Spokane, Seattle, Olympia, and Portland as well as an extensive rural, agricultural area.

Several aspects of the Hanford site and mission provide a favorable, yet challenging context for the development of a local SSAB. Hanford's current mission is focused primarily on waste management and environmental restoration, environmental research and technology development, and energy research. However, it also includes nuclear research and some defense program activities, and the possibility of new missions and activities are periodically raised (such as MOX fuel and FFTF restart). The environmental and safety issues associated with the site are massive and salient. However, they are also multifaceted and complex, with some problems and solutions not yet well articulated (for example, high-level tank waste).

The site has a long history of public involvement, including previous collaborative problem-solving efforts that have engaged a variety of local, regional, and national stakeholder organizations and laid a foundation for effective public involvement, such as the Future Site Uses Working Group and the Tank Waste Task Force. However, the affected tribes, whose standing as sovereign nations assured of a government-togovernment relationship with DOE made them initially reluctant to participate as stakeholders in an advisory board, represent an essential interest and viewpoint. The size and economic and social diversity of the impacted area provides a broad base for recruitment of participants with a rich diversity of interests, capabilities, and viewpoints. However, it requires assembling and coordinating the participation of members from a large geographic area, multiple political jurisdictions, and with strongly held and wellarticulated opposing viewpoints.

The site's cleanup strategy is governed by an agreement signed in 1989 among DOE, EPA, and the Washington State Department of Ecology, known as the Tri-Party

Agreement (TPA). The TPA established milestones and the legal framework for cleanup. 
Hanford issues are important to the regulators, who have established local offices to oversee this work. The state of Washington has established a memorandum of agreement with the state of Oregon, thus facilitating participation of Oregon state representatives.

Hanford site activities have high local, regional, and national salience. Hanford was one of the principal producers of nuclear materials for the defense program from 1943, when the first plutonium production reactor was built, until 1991, when the all of the site's nine plutonium production reactors were retired. The site's nuclear weapons material production activities have left behind massive amounts of radioactive materials, unique radiation hazards, vast volumes of contaminated water and soil, and many contaminated structures ranging from reactors to chemical plants to evaporation ponds.

Many aspects of the Hanford cleanup effort pose extraordinary technical and management challenges. The hazards posed by the waste stored on the site, the history of contamination and airborne releases, and the proximity of the Columbia River have created considerable public and regulatory concern. A wide array and variety of organizations have been actively involved in Hanford issues over the past decade (and longer) including, among others, the Washington League of Women Voters, Greenpeace, Hanford Education Action League, Hanford Watch, Heart of America Northwest, Physicians for Social Responsibility, Sierra Club, local unions, and the Tri-Cities Development Corporation.

Hanford is also salient because of its economic importance to the local area and region. Employing about 11,000 workers in 1997, DOE-RL and its contractors are the single most important component of the local economy, accounting, directly and indirectly, for an estimated $36 \%$ of all local non-farm employment and up to $67 \%$ of local wage income (including farm income) in Benton and Franklin counties. Anticipated workforce and budget reductions as site cleanup progresses are important local issues. DOE, in collaboration with the local governments and economic development organizations in Benton and Franklin counties, has a program to support economic diversification of the local economy. The interest and participation of residents from both inside and outside the local area have helped the board obtain the diversity of viewpoints needed for an effective board and provide balance to the board's discussions.

The HAB is the only DOE-related community-based advisory body active in the local area, although other bodies bring together various combinations of parties with an interest in the Hanford site (for example, the Hanford Communities, the Tri-City Technical Council, the Hanford Health Information Network, and the Vadose Zone Expert Panel). A number of technical review committees have also been formed to examine Hanfordrelated issues.

\section{Board Composition}

The HAB was formed in 1993-1994, the first of the SSABs. Prior to that time, DOE-RL solicited advice from a number of citizen advisory bodies, starting with the committee formed to provide advice on the Defense Waste Environmental Impact Statement (1985), 
and including the Future Site Uses Working Group (1990) and the Tank Waste Task Force (1993). Many of the organizations and individuals involved in the HAB participated in these earlier efforts. Interviews, as well as the $\mathrm{HAB}$ web page, indicate that this experience, for both DOE and the public, had a very important impact on the $\mathrm{HAB}$. Primary impacts were establishing a familiarity and confidence in the consensusseeking process, building relationships, and establishing a set of underlying principles and values for the overall cleanup of Hanford that had widespread support. The HAB adopted these values and principles and used them as a base for its deliberations.

The board is currently composed of 31 members and their alternates, representing ten different interest areas. DOE-RL, EPA, and Washington State Departments of Ecology and Health, and the Confederated Tribes of the Umatilla are ex-officio members. The Nez Perce and Yakama Nations now have members on the board. The current chairperson, an Oregon resident, is a former vice president of the League of Women Voters of the United States. The size of the board and the inclusion of alternates seems to reduce the potential for members representing minority viewpoints to be isolated or marginalized.

In 1993, the Tri-Party agencies initiated the effort to form an advisory board, and contracted with an independent facilitation/mediation team from the Keystone Center to serve as convenors. A call for comments, followed by a series of interviews and meetings, identified a number of issues and concerns that potential participants in an advisory board felt needed to be addressed. Based on this information, the convenors made recommendations and suggested guidelines for proceeding with the establishment of the advisory group. They developed a three-tiered structure of involvement in the board, delineated ten interests to be represented, and grouped the interests into three categories $(\mathrm{A}, \mathrm{B}$, and $\mathrm{C})$ as a way to achieve a balance of interests and representation on the board. They then worked with the Tri-Party agencies and the interested public to implement the recommended selection process. ${ }^{1}$

Organizations within most of the ten interest areas are responsible for recruiting and nominating their representatives, subject to the balance and diversity criteria established in the HAB Charter, and consultation with EPA and the Washington Department of Ecology. EPA and Ecology have responsibility for recruiting and nominating at-large members, who are to be individuals with an expressed interest in Hanford cleanup and who contribute to ethnic, gender, and racial diversity, as well as non-union, nonmanagement cleanup contractor representatives. With the exception of at-large members, the HAB members are to "represent the interests and concerns of the organizations, institutions, or constituencies that have appointed them." This process has established a board that is broadly representative of the viewpoints of the community and that has maintained its diversity over time.

\footnotetext{
${ }^{1}$ Mealey, Tim and Barbara Stinson. (nd). Convening Report on the Establishment of an Advisory Board to Address Hanford Cleanup Issues. The Keystone Center.
} 


\section{Purpose, Goals, and Commitment to Consensus}

The HAB agreed that the board would make decisions by consensus, with rare exceptions. This agreement has been kept with the board demonstrating considerable skill in working within the consensus process, recognizing the importance of laying the groundwork through informal discussions before decisions are brought before the board and of distributing the work among the board members. Board members seem to recognize the legitimacy of blocking proposals that do not adequately address an interest.

Independence, early and open access to information, and the ability to make a difference have been key priorities and concerns of board members. As a condition of participation, the initial board members obtained early commitments from the Tri-Party agencies that the $\mathrm{HAB}$ would have the freedom to uncover the issues, set its own agenda, control its own expenditures and have some independent staffing, as well as be listened and responded to by the highest levels of management. The early days of the board were difficult, even with the benefit of past experience with the task force and working group. Through this process, the board forged a shared sense of purpose and approach that it has sustained over time, though with a continuing undercurrent of tension created by the strength of the opposing viewpoints.

Despite this shared sense of purpose, the complexity of the site and the differences of interest among board members have created an ongoing challenge for the $\mathrm{HAB}$ to uncover the priority issues and set a manageable agenda. The board's Charter and Operating Ground Rules note that the board will have to work closely with the Tri-Party agencies to identify major policy issues and reflect requests for advice from the agencies and that are of concern to its members. The HAB members take pride in the amount of work they do. They are proud of the HAB's ability to take on complex issues, understand them, apply the core principles and values, and develop consensus advice that makes a difference in site cleanup. The $\mathrm{HAB}$ commitment to consensus and to working through important problems permeated both the board meeting's discussions and the site visit interviews with members.

\section{Internal Process and Functions}

A number of functions must be fulfilled for a group of people to work together effectively, particularly when they are convened to represent different perspectives. These include agenda-building and issues management processes that emphasize searching for common areas of agreement among diverse views; leadership, particularly by the chair(s) and executive committee; facilitation, both for meeting planning and implementation and for brokering technical and interpersonal issues; team building processes, which may be formal or informal; and administrative and technical support, including technical assistance to facilitate participation by non-technical members and to reduce members' workload. 


\section{Agenda Building and Issues Management}

An agenda that meets the priorities of the members and focuses the work of the board makes an essential contribution to the board's effectiveness. The HAB members view agenda setting as a critical function, a collaborative process, and an ongoing challenge for the board. They devote considerable time and effort to ensure that they are focusing on important and timely issues. Recognizing the breadth of the environmental issues within its scope and the need to simultaneously maintain flexibility and achieve focus, the board developed a series of mechanisms to build its agenda and manage issues - and to stop and remind themselves that their impact will be greatest if they focus on major policy issues and don't get diverted by or bogged down in technical details.

Standing committees were established, despite initial resistance, to serve as the primary locus of issue identification, framing, and analysis. The committees select their own chairs, who serve on the executive committee. A committee member is identified to serve as the issue manager for each major issue. Members can volunteer or be asked to serve by the committee chair. The standing committees meet on a regular schedule, in locations that rotate around the region. Committee meetings are open to the public, but membership is limited to board members and their alternates. The committees frame issues, gather information, provide progress reports to the board, and develop draft recommendations, which they bring to the full board. The contractor support staff and facilitators help the committee chairs obtain the necessary information and arrange for presentations from the Tri-Party agencies and Hanford contractors. The board has implemented a tracking system that facilitates information sharing and helps the board maintain its focus and schedule. The system is maintained by the administrative and facilitation staff. Committees have the ability to request and obtain independent technical assistance, if needed.

At the time of the study, the HAB's executive committee was composed of the chair, vice-chair, chairs of each of the standing committees, one or two ad hoc members, and representatives of the Tri-Party agencies. The executive committee serves a coordinating and integrating role to develop issues and the agenda for the full board and to ensure that the board is functioning effectively. The executive committee has strong administrative support (see below) to assist with this process.

The full board sets aside one meeting each year to discuss the upcoming agenda and to develop a work plan. The Tri-Party agencies are asked to give a status report and identify major policy issues. The work plan is adjusted to accommodate fast-breaking and emerging issues. To keep track of what they have done, as well as to provide easily accessible information about the board (see below), each year an annual report is prepared, posted on the board's web page, and distributed by members to their constituencies.

\section{Leadership}

The Charter and Ground Rules of the HAB specify that the chair will be appointed by the sponsoring Tri-Parties, based on the advice and recommendations of Hanford 
stakeholders. The vice-chair is selected by the board. The current HAB chairperson is highly skilled and experienced at chairing consensus-based boards. Without exception, board members and ex-officio representatives commended the leadership provided to the board by the chairperson, commenting on her dedication and skill in guiding the board to find consensus where none was originally evident, emphasizing and reminding the board about the core values, and knowing when to push for or defer decisions.

The $\mathrm{HAB}$ has both the benefit and challenge of having a number of strong leaders, whose skills and experience have often been developed through their roles in their sponsoring organizations. Collectively these leaders have helped the board develop and maintain a balance between the technical and policy orientations, and have often modeled desired behaviors, and set a conducive atmosphere for work and networking. They have been assisted in this by leadership from the Tri-Party agencies, and by strong support and facilitation staff. Given its size and diversity, this has allowed the HAB to focus a large proportion of its time and energies on substantive issues, though without neglecting attention to procedural and process issues when necessary. This leadership has also been effective in presenting the board to the external world, including testifying before Congress. The chairperson has succeeded in gaining the trust and confidence of all parties, in part by paying scrupulous attention to the ground rule of not speaking for the board on topics other than where it has produced consensus advice. Similar positive evaluation was given to the leadership provided at the committee level.

\section{Facilitation}

The board has always had professional facilitation support, considered essential to help the chair manage the meetings and the committee chairs manage the working sessions. Although DOE formally manages the $\mathrm{HAB}$ budget, the chair and other key members have a key role in procuring facilitation services, again in order to ensure independence. The HAB is large; meetings frequently involve more than 50 people. The facilitators support the chair, who runs the board meetings. The current facilitation team has technical expertise that the board has found helpful.

Board meetings have a clear agenda and keep to schedule, with some flexibility to accommodate the status of discussion. The majority of interactions, though sometimes heated, are civil and orderly although the inability of some members to refrain from personal attacks was identified as a significant irritant and problem. Once clarified, issues requiring further work during the board meeting are frequently referred to a small group (often those with the most clearly opposing views) to address off-line and bring back to the whole board. Proposed recommendations are put up on a viewgraph, and the facilitator expedites the "wordsmithing" process. It is clear that the facilitators serve the board and its work.

The HAB has many members and support staff who assist with informal communications, problem solving, and "working" of issues. Particular note was made of the important role played by DOE and contractor support staff in facilitating communication between the board and DOE program managers and in helping to broker issues on a wide range of topics. A number of $\mathrm{HAB}$ members also serve on other DOE- 
related committees and have multiple opportunities for networking. The HAB probably has a greater ability to work issues outside of formal meetings than any other board, since so many of its members work for organizations that support their involvement at Hanford, thus bringing them into frequent contact and increasing the amount of time they can devote to board work.

\section{Team Building}

$\mathrm{HAB}$ members expressed a strong sense of membership and pride in the board. Although explicitly representing organizations/institutions, board members nevertheless demonstrated a commitment to the success of the board and recognition of their fellow board members as part of a team. The HAB conducts an annual self-evaluation and has commissioned feedback on its performance in a variety of ways in order to identify problems and improve effectiveness.

The board has succeeded in developing informal positive relationships among the members, though concern was expressed that the corrosive effect of personal attacks by some members on others has not been completely resolved. The board holds its two-day meetings (and its committee meetings) at different locations around the two-state region, which provides additional opportunities for informal social interactions among the members.

The $\mathrm{HAB}$ has developed a rather elaborate record-keeping system to ensure that existing and new members can access the previous work and advice of the board. New members receive a structured orientation and all members go through orientation on a yearly or biyearly basis. A number of special sessions have been held to focus on understanding the common interests of the members and to consider the value of a region-wide consensus on Hanford issues, and to reexamine the agenda, focus, and workload of the board.

\section{Administrative and Technical Support}

Funding for the HAB is provided by DOE (initially by DOE-EM-HQ, but now by DOE$\mathrm{RL})$. This arrangement was considered important to assure independence of the board and timely access to funds. Some funding is used for administrative and technical support, obtained as part of the facilitation/mediation contract. DOE, EPA, Washington State Department of Ecology and contractor staff provide additional administrative support, who help with record maintenance and distribution, meeting planning and logistics, information gathering, coordination, and general troubleshooting. Although the $\mathrm{HAB}$ does not have an office, per se, it maintains its address and telephone in the office of the facilitator, as a demonstration of the board's independence from DOE.

According to all reports, the administrative support provided to the board by both its own staff and by the Tri-Party agencies, is excellent, considerably lightening the load on board members, particularly the chairs. Many of those interviewed commended the helpful, capable, and diligent efforts of the support staff. 


\section{Process Summary}

$\mathrm{HAB}$ meetings are held for two consecutive days, eight times per year. The board has begun to schedule a presentation and open forum session the evening of the first day, on topics of current interest to the board and the public. These sessions are designed specifically to be of interest and accessible to the public as well as board members. The $\mathrm{HAB}$ is a work-oriented board; members are expected to come prepared to both board and committee meetings. Because of the duration of the meetings, there is time for presentations, committee reports, and board action. Pertinent (and background) information is made available to the board members and the public.

The observed meeting was well run, with good teamwork between the chair and the facilitator. Meeting logistics appeared smooth. Adequate support personnel were available to address emerging needs. Board discussions demonstrated integration of technical and policy considerations, with participation by a large proportion of members. A substantial number of topics were covered, but without a sense of superficiality or preemption of discussion. Procedural matters were dealt with expeditiously. The size, diversity, and intensity of the board create a continuing demand for process management and facilitation.

\section{Public Engagement}

The board initially established a committee on public involvement, which was unable to resolve how the board wanted to address the issue of engaging the public in Hanford and board deliberations. For a period, the committee was put in abeyance, with its members distributed among the other committees to ensure that they were addressing public involvement issues associated with the substantive issues. The committee has been reinstated, but a recent committee meeting indicated that the original uncertainty still pertains. The board is divided about whether it should be advising DOE and the regulators about their public involvement program and approach, or focusing on how the board itself can engage the public. Despite this, the board is attentive to the need to be visible to the public and to make its activities and recommendations accessible to and known by the public.

\section{Outreach and Information Gathering}

The board has explicitly stated that DOE and the regulators have responsibility for public involvement and that the board should neither duplicate nor substitute for them in this role, although it was prepared to advise them and participate in some of their outreach activities. The board has advised DOE and the regulators to incorporate stakeholder values in their plans. It has been a strong and persistent advocate of the need for a National Equity Dialogue to focus on the totality of DOE waste management and disposition issues. Although the board is attentive to the need to prepare materials that are accessible to the public and that summarize and present board activities, boardinitiated public outreach does not seem to be a high priority for the HAB. This may be because board members (aside from members-at-large), as representatives of organizations or institutions, have built-in channels of communication to interest groups 
through their sponsoring organizations/institutions. Several board members mentioned specific outreach activities they were undertaking with their organizations. Based on discussions and review of the board documentation, it appeared that many board members take seriously their responsibility to report back to their organizations and to use their organization's communication channels to distribute the information to their broader constituency. No evaluation of the effectiveness of this outreach strategy has been conducted.

\section{Opportunities for Public Participation in Board Activities}

The $\mathrm{HAB}$ meetings and committee meetings are organized as working sessions for a very busy board. Although they are open to the public, well advertised, and provide a formal period for public comment, they are not structured to facilitate public engagement. As with other boards, the $\mathrm{HAB}$ meetings are generally not well attended by the public. This does not appear to be a particular concern for the board. Although all written materials are made available to the public, the public comment period is structured like a public hearing (where public statements are received and recorded), rather than as a dialogue. The public is treated as a visitor at or observer of the board's meeting. The board has taken the initiative, as mentioned earlier, to structure an evening session of presentations that is designed for the public.

\section{DOE and Regulator Engagement}

The HAB is clearly chartered to provide advice to the Tri-Party Agencies and has received assurances from DOE, EPA and Washington State Department of Ecology that they will provide information to the board, have senior managers attend board meetings and interact with the board, and receive board advice, with a requirement to provide a written response to the board's advice. Because of the Tri-Party Agreement, the regulators are daily involved in Hanford issues and place a high priority on resolving environmental policy issues.

\section{DOE Level of Participation}

Within the framework of independence, the $\mathrm{HAB}$ has structured a close working relationship with Tri-Party agencies, recognizing the importance of close engagement for understanding, access to information, and impact. DOE-RL has been a visible and public supporter of the HAB. The DOE Designated Federal Official/Deputy Designate Federal Official for the board was the Deputy Site Manager (until he relocated out of the area) and is currently the Chief Financial Officer; both senior managers consistently attended board meetings and participated actively in them. The Site Manager has frequently attended portions of many meetings. In addition, senior DOE-RL program managers and representatives from the other Tri-Party agencies often work closely with the HAB committees.

\section{Empowerment by DOE}

The Site Manager has made it clear to his direct reports and others that the board is to be 
taken seriously and that they are to respond to board requests. Board members generally agree that the commitment made by the Tri-Party agencies to provide the board independence and support has been honored.

\section{DOE Responsiveness}

Board members generally agreed that DOE's ability and willingness to provide predecisional information to the board has improved, and that the Tri-Party agencies are diligent about responding to board inquiries and advice. However, a number expressed serious reservations about DOE's commitment to take board advice seriously, citing several recent examples of where the board's advice on major policy and management decisions had not been followed.

\section{Role of the Regulators}

More than most other boards, the regulators take ownership and responsibility for the success of the board. As with DOE, the regulators have sent senior managers to interact with the board, and have demonstrated that the board's discussions and advice were heard at the highest management level. Interviews with board members gave high marks to the constructive approach and useful assistance provided by the representatives from the regulators.

\section{Issues and Observations}

\section{Issues Raised by Members Concerning the HAB}

- On a number of major, far-reaching policy and management issues, such as privatization, DOE has not followed board advice.

- A number of board members expressed concern about how to prepare for transition of leadership if the current chairperson retires.

- Despite the length of time the board has been in existence and the procedures that have been put in place, several members commented that personal attacks have not ceased and are not controlled adequately.

- The amount of work and scope of the problems threaten board members with fatigue.

- At-large members are not sure how to link back to their "constituency."

- Board members continue to struggle with the challenge of focusing the board's agenda to be both manageable and impactful. 


\section{Researchers' Assessment of Primary Accomplishments and Challenges Facing the $H A B$}

\section{Accomplishments}

- The scope, complexity, and severity of the problems at the Hanford site posed a tremendous challenge for priority setting and focus. The quality and depth of leadership on the board has been essential to its effectiveness.

- Previous experience with the Future Site Uses Working Group and the Tank Waste Task Force, which were well structured and expertly facilitated, provided a solid platform for the $\mathrm{HAB}$. The HAB capitalized on this platform. It also drew on the extensive knowledge base of members who had been involved with Hanford issues for many years.

- The HAB has forged an effective working relationship among the diverse interests and developed a shared sense of purpose that is critical to its productivity.

- This board undertakes an incredible workload, probably only possible because a large proportion of its members are representatives of organizations that support their work.

- DOE-RL and the regulators, who initiated the formation of the HAB before directed to by $\mathrm{DOE} / \mathrm{HQ}$, have taken responsibility for the board and developed an effective relationship with the board, though responsiveness on the tough issues is an ongoing question.

- Adherence and reference to core values has helped the board provide coherent and impactful advice.

\section{Challenges}

- The size, diversity, and strength of the members poses an ongoing challenge and unceasing requirement for strong leadership.

- Lack of civility, and indulgence in personal attacks during board meetings can erode personal relationships and reduce the effectiveness of board deliberations. Despite a variety of efforts, the board has not managed to adequately control this problem. 
PNNL-12139

An Evaluation of the Effectiveness of Local SiteSpecific Advisory Boards for U.S. Department of Energy Environmental Restoration Programs

\section{Idaho National Engineering} and Environmental Laboratory Citizens Advisory Board

Judith A. Bradbury

Kristi M. Branch

Pacific Northwest National Laboratory

February 1999 


\section{IDAHO NATIONAL ENGINEERING AND ENVIRONMENTAL LABORATORY CITIZENS ADVISORY BOARD}

\section{Table of Contents}

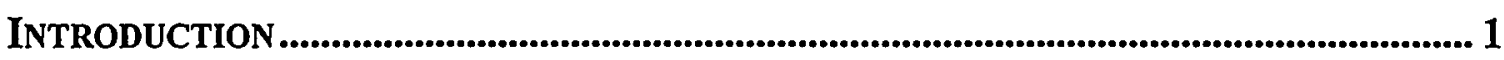

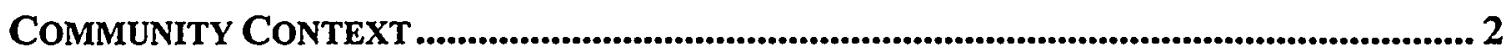

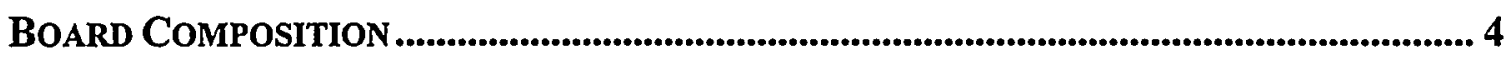

PURPOSE, GoALS, AND COMMITMENT TO CONSENSUS............................................................... 4

INTERNAL PROCESS AND FUNCTIONS.................................................................................. 5

Agenda Building and Issues Management.......................................................... 6

Leadership................................................................................................ 7

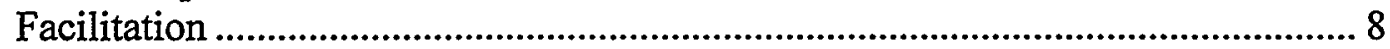

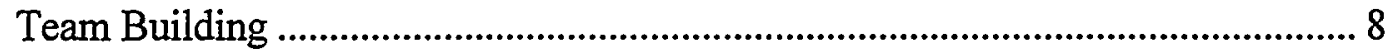

Administrative and Technical Support ................................................................. 9

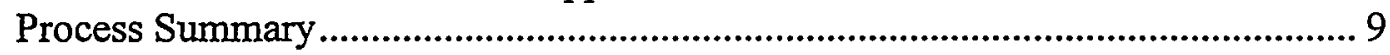

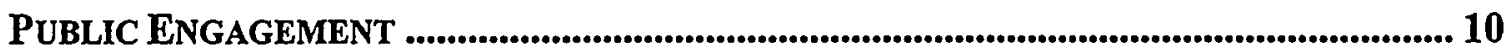

Outreach and Information Gathering .......................................................... 10

Opportunities for Public Participation in Board Activities..................................... 10

DOE AND REGULATOR ENGAGEMENT .......................................................................... 11

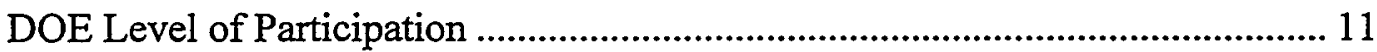

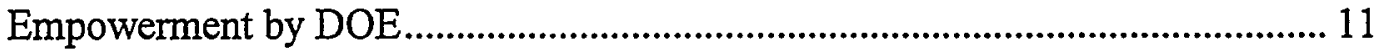

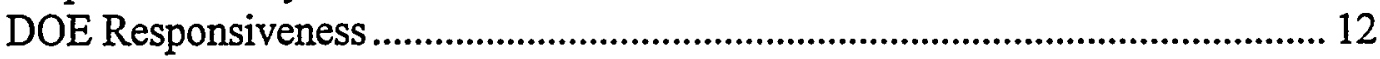

Role of the Regulators .......................................................................................... 12

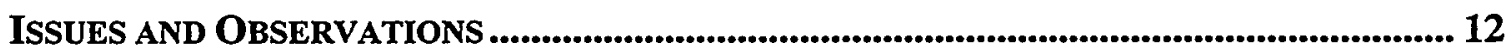

Issues Raised by Members Concerning the INEEL Citizens Advisory Board..... 12 Researchers' Assessment of Primary Accomplishments and Challenges

Facing the INEEL Citizens Advisory Board ................................................... 13 


\section{IDAHO NATIONAL ENGINEERING AND ENVIRONMENTAL LABORATORY CITIZENS ADVISORY BOARD}

\section{Introduction}

This report details the results from the Idaho National Engineering and Environmental Laboratory (INEEL) Citizens Advisory Board portion of a U.S. Department of Energy (DOE) study that was initiated to understand factors contributing to the effectiveness of the DOE local Site-Specific Advisory Boards (SSABs) and to provide information useful for the boards and DOE in their continuing efforts at improvement. The Overview report that accompanies the individual site reports discusses findings across nine DOE sites and provides background on the goals, methodology, and rationale for the framework used in the study. It also serves as a template for the findings presented in this site report.

The report for the INEEL Citizens Advisory Board (CAB) is thus structured according to the six factors that were found to be important in assessing local SSAB effectiveness. As emphasized in the Overview, the study was designed to assist DOE and the boards in assessing how well the boards were fulfilling DOE's basic purpose in establishing the boards, and to provide information that would be useful to DOE and the boards in achieving this purpose. Specifically, DOE established the boards to obtain independent, consensus, policy advice and recommendations that drew on the range of local and regional stakeholder perspectives. The underlying rationale was that advice that reflected agreement among very different viewpoints would also be more likely to be acceptable to nearby communities and thus would provide a firm basis for developing policies that were not only technically sound but also could be implemented. Accordingly, the focus of the study was on board processes that enhanced the boards' ability to provide independent, broadly based policy advice, rather than on the recommendations per se.

This report describes the Idaho $\mathrm{CAB}$ as it was operating at the time of the researchers' visit in May 1998. The description is provided in terms of the six factors found to contribute to board effectiveness (community context; board composition; purpose, goals, and commitment to consensus; internal processes and functions; public engagement; and $\mathrm{DOE}$ and regulator engagement). It begins by highlighting key features of the site context that pose particular challenges facing the $\mathrm{CAB}$. Two subsequent sections discuss the board's composition, including diversity of viewpoints represented on the board, and the board's sense of purpose, goals, and commitment to consensus. The next section examines the board's internal processes and functions, including how board members accomplish agenda building, issues management, and team building; how facilitation, brokering, and leadership roles are taken and performed; and how administrative and technical support is provided. The following section, on public engagement, details the board's effectiveness in providing opportunities for public participation and in outreach and information gathering. The next section discusses the relationship between the board and DOE, and between the board and site regulators. The final section lists issues that 
members raised in their discussions and provides the researchers' assessment of the accomplishments and challenges facing the $\mathrm{CAB}$.

As emphasized in the Overview, the purpose of this study is to provide an outsider's perspective, based on a review of boards across the complex, and to encourage the boards to reflect on their own strengths and weaknesses and learn from one another's accomplishments and challenges.

\section{Community Context}

The Idaho Operations Office (DOE-ID) oversees the operations of the INEEL, which occupies an 890 square mile site in Southeastern Idaho. The eastern border of the site is approximately 23 miles west of Idaho Falls. Some INEEL research and support facilities are also located in Idaho Falls, the nearest town of any size (a 1990 population of approximately 44,000 ) in this desert region. The site employs about 8,000 workers, playing an important role in the economy of this sparsely populated area. In 1990, only about 120,000 people lived within a 50-mile radius of the site. The population is predominately Caucasian ( $96 \%$ in Idaho Falls). The Shoshone-Bannock Tribes are located on the Fort Hall Reservation, southeast of the site.

Established in 1949 as the National Reactor Testing Station, the site has historically specialized in nuclear reactor testing. The first reactor using nuclear fission to produce electricity and the Navy's first prototype nuclear propulsion plant were both located at INEEL. Most of the site's 52 reactors, many first-of-a-kind facilities, are now phased out and many have been dismantled, though the Advanced Test Reactor and the Advanced Test Reactor Critical Facility Reactor are still operable. INEEL now has nine major facilities that support the site's major activities: site cleanup and environmental management, nuclear materials disposition and interim storage, applied engineering, and technology commercialization. Seven of these facilities are managed by DOE-ID, one (Argonne National Laboratory West) is managed by DOE-Chicago, and one (Naval Reactors) is managed by DOE-Pittsburgh. The site's focus has shifted from reactor development and defense-related work toward hazardous and radioactive waste management, cleanup, and environmental technology, although Argonne-West continues research on reactors and reactor safety. The Laboratory is actively searching for additional missions, particularly those related to environmental technology.

A Tri-Party agreement, called the Federal Facilities Agreement/Consent Order (also known as FFA/CO), governs CERCLA activities at all nine facilities on the site. In addition, a consent order signed in 1996 by the Governor, DOE and the Navy, popularly known as the Governor's Agreement or the Settlement Agreement, provides additional stipulations beyond the FFA/CO requirements, and restricts DOE from bringing more waste into Idaho until certain requirements are met. The Settlement Agreement is very specific and very firm.

Our study has found that a number of contextual factors - mission, salience of the issues, diversity of the population, and previous civic engagement - can affect the challenges 
local SSABs face in recruiting members, defining their goals and purpose, and establishing effective working relationships among members with different viewpoints and values. A primary factor that has posed a challenge to the development of effective dialogue at several boards has been disagreement over scope and agenda. INEEL has a number of attributes that could have led to this type of disagreement. It is a multiprogram laboratory that combines environmental restoration with an active search for additional nuclear energy and energy research missions. In addition, some of the most controversial decisions about the site's activities, for example, receipt, storage, and transport of high-level and TRU waste, involve national policies that are not controlled solely by DOE-ID, another source of potential dispute about scope and agenda. The involvement of multiple DOE organizations and locations, only some of which the board is chartered to advise, increases the potential for complications, difficulty with communication, and controversy. Finally, INEEL's regional economic and political importance could have created issues of dependence and tension between those concerned about economic stability and development and those opposed to future site activities. Nevertheless, despite these attributes, the INEEL CAB members did not report intense disagreement over scope and agenda.

INEEL is a Superfund site, on the National Priorities List. INEEL is one of the primary interim storage sites for government-owned spent nuclear fuels and transuranic wastes. A principal concern is potential contamination of the Snake River Plain Aquifer, a sole source aquifer and valued state resource. Some INEEL issues have high local, regional, and national salience (of central importance), an aspect that has increased the ability of the INEEL CAB to recruit multiple candidates for each available position on the board and to maintain representatives from throughout the state.

Issues related to disposal of the nuclear waste in interim storage at the site have gained national and state attention as a consequence of the governor's pressure on DOE for progress in removing the waste from Idaho. Activist groups opposed to nuclear power and nuclear weapons and to the receipt of additional radioactive wastes at the site have focused attention on these issues. A local pro-DOE/Laboratory grassroots organization has also been established. This has resulted in a limited number of organizations and individuals, some unaffiliated with DOE or the Laboratory, with extensive knowledge about the site and its management and regulatory context. The INEEL CAB is the only citizen-based advisory group chartered by DOE in the local area, although other federal, state, and local agencies have involved state residents in a variety of advisory boards and involvement activities.

\section{Board Composition}

The INEEL CAB, with 15 citizen members, held its first meeting in May 1994 after a lengthy design and selection process. A Design Committee (25 volunteers, including the site regulators) determined that the board should geographic and viewpoint diversity. The Committee insisted that the DOE administrative link be through the Program Office in order to tie the board more closely to site decision makers. The Committee then created a seven-member Selection Panel to choose the initial board members. The 
INEEL CAB now recruits (through advertisements), screens, and selects its own members, with DOE approval.

The INEEL CAB follows an individual approach in its recruitment and selection process, overseen by a Member Selection Committee. With the exception of the member representing the Shoshone-Bannock Tribes, who is appointed by the appropriate Tribal authorities, and the member representing organized labor, members are selected as individuals, with the recruitment and selection process designed to create a board with the mix of perspectives specified by the Design Committee. The recruitment application emphasizes the importance of the ability to work productively with others. Candidates themselves identify the categories or perspectives they match. The selection process has been attentive to the need to maintain diversity and to limit the number of members with past or present employment or economic links to the site. The board expends considerable effort recruiting new members and has succeeded in maintaining a strong pool of candidates and a board with members who do represent the range of perspectives set out by the Design Committee.

At the time of the site visit in early spring of 1998, the board had broad geographic representation, with members from throughout the state. Older white males, many of whom were retired from management positions, were heavily represented on the board. Almost half the board members were retirees. A local governmental official was a member of the board, and the board had succeeded in working out a way to have the viewpoints of the Shoshone-Bannock represented, through a board member selected by the Tribes. The board members generally indicated that they felt responsible for reflecting their own viewpoints, as opposed to the viewpoints of a particular constituency or public. Although the board has members who represent an environmental perspective, two members who were affiliated with environmental groups opposed to nuclear activities withdrew from the board in 1996. Although most of those whom we interviewed agreed that these members simply decided that they could best use their time and efforts elsewhere, some felt that their withdrawal was also due to a perception that the board was fundamentally hostile toward the activist point of view. A number of members mentioned that the board had a reputation in some quarters of being "in DOE's pocket," which they generally felt was undeserved. They felt the board was acting to address this perception.

\section{Purpose, Goals, and Commitment to Consensus}

The INEEL CAB is chartered to provide informed recommendations and advice to DOEIdaho, EPA (Region 10), and the State of Idaho "regarding the full scope of INEEL issues, including environmental restoration, waste management, and economic aspects." Although the board's charter does not cover the Argonne-West (DOE-Chicago) or Naval Reactors (DOE-Pittsburgh) activities, the board has reviewed material and provided recommendations concerning these areas.

The INEEL CAB operates with a strong emphasis on thorough analysis of the technical aspects of the issues it is addressing in order to give informed advice. The board's 
members include a number with strong technical backgrounds and several with extensive and in-depth knowledge of the site, including current and ex-site employees and university professors, who play a lead role in the technical analyses. There is general agreement among board members that the basic goals of the board are to identify and understand site problems, analyze priority problems from multiple technical perspectives, and to find areas of agreement that provide the basis for board advice. Some members emphasized the importance of bringing public values and issues to DOE, while others emphasized the importance of helping develop a more informed public. This variability in characterization of purpose, though not necessarily reflecting a conflict, was seen by some as an indication that a reexamination of the board's goals and purpose might be beneficial.

In general, the board members we interviewed reflected a desire to be constructive, focusing not on finding fault with DOE, but rather on reviewing and offering specific, technically focused recommendations that provide the citizen's perspective on site cleanup issues. Credibility with DOE is important to the board, and credibility with the public was identified as important by several board members.

The board has agreed to use a consensus process for making recommendations and reaching most administrative decisions. Some administrative decisions, such as the nomination of new members, are made by super majority vote, although the facilitator emphasizes the importance of not making decisions that leave some members angry and frustrated. Recognizing that most members have not had prior experience with consensus decision making, the board has had several half-day training sessions to help them become more comfortable and skilled in this approach. Several members commented that their experience with consensus decision making has been personally very valuable and rewarding. In addition, the facilitator consistently models and coaches the members in the practice and value of consensus seeking.

\section{Internal Process and Functions}

A number of functions must be fulfilled for a group of people to work together effectively, particularly when they are convened especially to represent diverse perspectives. These include decision-making, agenda building and issues management, team building, leadership, facilitation, and administrative and technical support.

\section{Agenda Building and Issues Management}

An agenda that meets the priorities of the members and focuses the work of the board makes an essential contribution to effectiveness. The INEEL CAB process includes a request to $\mathrm{DOE}$ and the regulators for a prioritized list of their upcoming decisions and need for advice. Semi-annually this information is provided to the board members prior to a meeting at which the issues are prioritized. Once issues have been identified as priorities, they are referred to one of several issues committees, which decides how to proceed. According to the board's charter, the chair is responsible for ensuring that agendas are prepared in a timely fashion and are consistent with the needs of the issue committee. The chair and support staff prepare a work plan and documents designed to 
facilitate management of the board's agenda, issues, and schedule. The board chair, vicechair, and facilitator work as a team to support the committees and their chairs. Over the last year, the board has been working out internal issues about roles and responsibilities relative to the chair and vice-chair, the committee chairs, the committee members, and the facilitator.

DOE-ID has developed a system for tracking the board's recommendations and how they are responded to, but the board has not, although the topic has been discussed and the chair had maintained a personal tracking system. An analysis conducted by the board to evaluate the effectiveness of their efforts concluded that many of their recommendations were not framed in a way that allowed clear demonstration of response. An effort has been made to learn from this finding in the formulation of board recommendations. A noteworthy feature of the Idaho $\mathrm{CAB}$ is its survey of recipients of board recommendations. For example, earlier this year, a set of 18 questions was drafted to gather information on the perspectives of DOE program managers and the ex-officio members on the relative merits of policy recommendations and detailed/specific recommendations and the importance of consensus. This issue had been the subject of considerable board discussion in previous board meetings. Input from the survey provides valuable feedback to members in helping them be effective as an advisory board to DOE and its regulators.

The board uses a system of standing committees and issues committees to conduct its detailed work. Standing committees, designed to include at least three board members, deal primarily with operational issues such as member selection, public communications, and procedures. Any stakeholder can be invited to serve on standing committees by the board chair, who is to pay attention to diversity considerations. Substantive issues are addressed by issues committees. Members identify which committees they want to join, based primarily on what interests them. Membership is fluid. The committees select their own chairs, prompted by the board chairperson, if necessary.

Overall, the board members reflect a sense of pride in their achievements and work hard to meet the goals they have set for themselves and the board. This has required some creative solutions to the logistics problem, given the dispersed location of the board members across the entire state. Most committee meetings are conducted by conference call. Committees tend to meet frequently, and meetings are announced to committee members by phone, fax, or e-mail.

There has been some discussion about whether the board is focusing so much on technical matters that policy issues are not receiving the attention they deserve. One comment about this noted that "the problem with making policy recommendations is that you don't see the immediate cost savings you can from specific technical recommendations." However, a number of board members also expressed concern that they might be spending too much time providing detailed technical review of DOE's documents. Others acknowledged that finding the right balance between technical detail and broader policy discussions was very difficult. It is clear that the board members pride themselves on becoming well informed about the issues on the agenda and give 
considerable thought to how the board can be most effective.

In a recent attempt to deal with this, the board has moved to separate the policy aspects from the technical aspects of an issue and to focus on reaching consensus agreement on the policy aspects. The board assigns a committee responsibility for discussing and addressing the technical details and bringing a recommendation, with explanations, to the full board, which may or may not attempt to reach consensus on every technical detail.

The board does not have an executive committee, though since the last election the chair and vice-chair have functioned as an executive committee. The chair, with the assistance of the facilitator and support staff, had been participating in all (or almost all) committee meetings that he felt were crucial to the board's activities. Recently, the chair and vice chair have divided up responsibility for the committees, and each interacts with them as they see necessary. The chair derives objectives for the board meetings from the activities of the committees: the objectives are reviewed by the vice-chair and the DOE coordinator. The facilitator then pulls together an agenda influenced by the priorities and decision schedule.

\section{Leadership}

The INEEL CAB has strong technical leadership, provided with extraordinary energy by the chair and supported by a number of members with extensive, pertinent academic training and professional experience. The effectiveness of this technical leadership is reflected in the pride members take in the quality and soundness of advice produced by the board and the credibility the board has gained with DOE for its sound and timely advice on complex technical issues. The chair and other members have built effective networks that benefit the board's work and have put in place procedures and obtained and managed support services that keep the board operating efficiently. Since the election of officers in May, the chair and vice-chair have been working together to improve the functioning of the whole board, focusing more attention on managing the complex human interactions of the board, and standing back a bit from some of the technical work. The facilitation team reinforces these efforts, working effectively during the meetings and behind the scenes to set a conducive atmosphere for work, build relationships, encourage members, broker solutions, and develop avenues for progress. However, some aspects of this leadership function, in particular, helping the board establish, and then reaffirm, board goals and values; balancing the technical/policy focus; and modeling behavior that places the interests of the board above one's personal interests need to be provided by board members.

Because of his strong interest and background, and his high energy, the chair also plays a prominent role in many of the technical analyses undertaken by the committees, often providing leadership in the substantive discussions of the board. The particular dynamics and personal styles of the board members, which includes a reluctance to raise interpersonal issues directly with the individuals involved, has resulted in some members expressing concern about domination of the board's deliberations by a single viewpoint, but a reluctance to raise these issues directly. Changes that have occurred in roles and responsibilities on the board over the past year, along with a conscious effort by the chair 
and the facilitator to address these concerns, appear to have lessened this perceived problem.

\section{Facilitation}

The board has had a number of different facilitators over the course of its history and has learned the value of a strong, capable facilitator and support team. The current facilitator, selected by and dedicated full-time to the board, is rated very highly by those we interviewed and recognized as a key resource for the board members, who are quick to acknowledge were inexperienced with consensus decision making before coming on the board. The CAB's facilitation team provides the full range of services: helping the chair plan the agendas for the meetings, promoting civility and courtesy, structuring the discussion to ensure that all viewpoints are presented and heard, making sure that everyone has an opportunity to speak, drawing out quiet members, and heading off or mediating conflicts. The facilitator also works behind the scenes to gather information and build relationships, playing a key role in assuring that issues are identified early, understood, and addressed. The DOE board coordinator plays an important role in facilitating communication between DOE and the board, suggesting strategies, and providing insight. He is credited with helping ensure that the board is well informed and kept up to date about emerging issues.

\section{Team Building}

Under the guidance of their facilitator, the board is very diligent about conducting selfevaluations at the end of every meeting to assess its performance and identify problems so that they can be corrected before they affect board performance. It has also conducted several annual self-assessments, including a particularly extensive one in 1996. The interviews indicate that the board members feel productive. Frustration levels among members generally seem to be low.

Board members report enjoying their work on the board and their interactions with other board members. The two-day meetings, involving travel to various locations around the state are used as opportunities for members (including ex-officios) to get together informally. Members from the local community frequently host evening social events for the board. The board has not conducted retreats, although it has organized training sessions for members. The Membership Selection Committee has developed a new member orientation packet, and the facilitator has a set of materials addressing both the content and process of board activities that she is responsible for communicating to new members. The facilitator is attentive to the need for team building and helps structure board meetings and associated activities to promote member interactions and cooperative relationship building. Several of the technically trained board members are teachers, and a number of comments were made about the willingness of the technically trained members to structure discussions and presentations to help the non-technical members understand the issues the board is addressing.

In addition, there is an attempt to organize a site tour at least once a year to provide orientation for new members and an opportunity for existing members to see additional 
aspects of the site. The orientation process, which also includes presentations and discussions with staff and the Membership Committee, typically takes between one and one and one-half days.

\section{Administrative and Technical Support}

Administrative support is provided by the facilitation team and the DOE board coordinator. The two FTE staff coordinated through the facilitator perform the day-today administrative tasks, oversee and support meeting logistics, maintain board records and web page, and coordinate various board functions such as the committee conference calls. Additional support is provided by the board coordinator, if necessary.

Collectively, these services ease the burden on board members, especially the board and committee chairs. They also maintain the board's mailing list, prepare and distribute the newsletter, and generally make sure that what needs to be done is done. These services were much praised and appreciated.

The board has only infrequently sought outside technical support, though some of the members interviewed indicated that it might be worth considering the value of independent technical input. One member noted that the committees serve as "technical advisor" to the rest of the board, and another commented that those with technical expertise were available and willing to mentor the non-technical members upon request. There is some confusion about the ability of the board, or the willingness of DOE, to hire technical consultants, though they do have the ability to pay for speakers.

\section{Process Summary}

Board meetings are scheduled for two days every other month at a location that rotates around the state. At the meeting the researchers observed in May 1998, the skill of the facilitator and the role assigned to the facilitator in running the meeting resulted in a well run, civil, and energetic meeting in which all board members were encouraged to participate, desirable behavior was modeled, and the agenda was completed on time. It was clear that substantial committee work had proceeded the board meeting. Both technical and non-technical members participated in the discussion, which involved give and take in an orderly and respectful manner. Members appeared to have come to the meeting prepared and ready to work.

Board members demonstrated familiarity with the consensus process, which followed well-facilitated discussions. The board's agenda had been well planned, with careful thought to the timing and structure of potentially tense activities, such as the election of officers. The meeting was designed skillfully to provide structure and information to the board members in an unobtrusive and respectful way. Prior to the election, the function and responsibilities of the positions up for election were reviewed and discussed, thus providing an opportunity for board learning. Throughout the meeting, members were engaged, interacted energetically, civilly, and with good humor. The facilitator was careful to check with the board and the chair concerning decisions, for example extending the amount of time devoted to an agenda item, thus making it clear that she was serving, not directing, the board. There was a high degree of informal, congenial interaction 
during breaks and lunch. The board has established a clear understanding among the members that they are not to represent board positions to the public unless the board has established a consensus position on that topic.

\section{Public Engagement}

The board has not developed a clear sense of purpose regarding its efforts to link with the broader public, although a number of members interviewed noted that this was an important area that needed more attention. There is growing awareness that board credibility, in the long term, depends upon credibility with the public and that this will require some effort on the part of the board. This is seen as a significant challenge, since most members believe that the public knows little or nothing about the board, and some express the view that the broader public will not be able to understand the essential technical aspects of the site problems. At this time, the board's primary focus is on providing informed input to $\mathrm{DOE}$ (and its regulators) from the variety of perspectives the board members personally represent: providing a forum for public opinion and representing public views, though identified by several as an important function of the board, has not been a priority.

\section{Outreach and Information Gathering}

Board members have a general sense that the public is not aware of the board or its recommendations. A number of board members indicated that before they had applied for board membership they had been generally unaware of the existence or operation of the board. Several members commented that the majority of the public was ill-informed about INEEL issues, and some questioned whether there was strong interest on the part of the public in the site or the board. Some also questioned whether it was appropriate or feasible for the board to attempt to understand and/or try to reflect public sentiment and viewpoints, given the fact that the board is drawn from the entire state. The board has not conducted any systematic information gathering, such as a survey, to determine the public's viewpoints and awareness, though various members did report conversations with the public in their role as board members, in which they attempted to raise awareness and increase the visibility of the board. The board has started trying to schedule a luncheon presentation at a local civic organization in association with the board meetings. During the meeting we attended, such a presentation was made at the local Rotary club.

The board does have a newsletter and a web site, designed specifically for public outreach. To facilitate the provision of information about the board to the public, the facilitator prepares an Annual Report and press releases about board activities and events.

\section{Opportunities for Public Participation in Board Activities}

The board has recently made several changes to its procedures for public participation that have been implemented since observation of the meeting. In part because of past negative experience with confrontational interactions between the board and members of the public attending board meetings, board meetings and interaction guidelines had 
previously provided limited opportunities for the public to participate in board activities. At the time of the site visit, board meetings were not designed to facilitate interaction with members of the public who might attend: meeting materials were not shared with the public; comment periods were scheduled at specific times often distant from presentations or board discussion's of substantive issues; and the public comment period was structured formally, more like a public hearing (statements can be made, but they are not responded to) than a dialogue. Rules governing the public's interactions with the board were prominently posted and were framed in a defensive tone.

Since the site visit, the board has included more frequent, fifteen-minute comment periods that allow public input more closely linked to presentations and to the board's discussion of particular topics. The location of the microphone for the public speakers has been moved from behind to in front of the board, and the chair of the public communications committee presides over each session. In addition, the board is discussing how they can use public comment to inform themselves about public viewpoints.

Because the board has members scattered over a large geographic area, committee meetings are most frequently conducted through conference calls, which are not publicly announced. This makes much of the substantive work of the board inaccessible to the public. Somewhat counteracting this inhospitable message, members of the public indicated that the facilitator and support staff had been very gracious, helpful, and efficient in providing requested information and materials.

\section{DOE and Regulator Engagement}

\section{DOE Level of Participation}

Board members reported strong, consistent DOE participation in board activities, with high-level representation at board meetings and informal access to the site manager and other key managers on an as-needed basis. It was emphasized that the DOE site manager voluntarily expanded the scope of the board's charter to include all aspects of the INEEL operations, and several members commented that the board had been encouraged to address those issues and areas that they felt were important. Several board members emphasized that they had given harsh recommendations to DOE that not only did not evoke a defensive or aggressive response, but were followed. For example, the board had advised DOE that the CERCLA proposed plan for WAG1 was unacceptable and needed to be rewritten. Board members believed that they were making an important contribution to key site decisions and that their work was highly valued by DOE. DOE frequently, and in a variety of venues, has expressed appreciation for the board and its value. The board members believed that they were trusted by DOE, and that they are gaining access to more information at an earlier stage than had previously been available. 


\section{Empowerment by DOE}

DOE has indicated that the value of the board and its advice is enhanced when the board is seen by the public as independent and credible. As indicated above, the board is administered through the Program Office rather than Public Affairs in a specific effort to reinforce the board's access to DOE decision makers and pertinent information. The senior DOE-ID manager has made clear his support for the board and his willingness for the board to address the issues they feel are most important. DOE has assigned staff to ensure that the board has the resources it needs to do its job. The facilitation team sees itself, and is seen by board members, as serving the board.

\section{DOE Responsiveness}

DOE regularly reports at each board meeting, in addition to providing formal written responses to recommendations and other formal board requests. DOE has made a commitment to respond to advice from the board within 30 days whenever possible. As part of this discussion, DOE has instituted a formal tracking system. The board has made an effort to ask DOE how it can provide advice that is most useful.

\section{Role of the Regulators}

Both the FFA/CO and the "Governor's Agreement" structure and specify the role of the regulators. The INEEL Oversight Program Director was involved in the Design Committee for the board. Some board members were unclear about the board's status relative to the regulators. Some believed that the board was not formally authorized to advise the regulators but that it sends them copies of their advice, for their information. The State regulators view the board as being chartered and funded by DOE to give advice to DOE; it is not an advisor to the regulators, although they say that they take board input into account along with other input they receive from the State's citizens. Similarly, the State's role is not to ask the board to give recommendations on a specific topic, but to indicate State priorities and the timeframe during which input is appropriate.

The EPA staff responsible for INEEL are located in Seattle (Region 10), and consequently have some distance to travel to attend board meetings. In the past, the board had criticized EPA for poor attendance. However, this problem has been solved, and a number of board members indicated that EPA had been more willing than the state to provide information to the board. Discussions with board members indicates that the board has avenues of communication with state and EPA ex-officio members that enable them to follow up on board issues.

\section{Issues and Observations}

\section{Issues Raised by Members Concerning the INEEL CAB}

- In general, the INEEL CAB members seemed quite satisfied with the board and their participation on it. 
- Concern was expressed that the chair is too involved in every aspect of board activities, exerting a disproportionate influence on the board's agenda, approach, and recommendations. At the same time, respect and appreciation for the technical expertise and amount of work contributed by the chair was also expressed.

- Several board members commented that the board has acquired a reputation of being "in DOE's pocket." Though undeserved, they emphasized that the board needs to ensure that it is taking the actions needed to establish its independence and gain public credibility, which is seen essential for the board to maximize its value to DOE.

- There was a widely held belief that the board is not well known in the broader community and does not have a clear strategy for communicating with the public or raising its visibility.

- Board members noted that the board is not representative of the public: members are considerably better educated, as well as better informed and more interested in INEEL than the broader public. There is currently no clear concept or mechanism for the board to ensure that it understands the perspectives of this broader public, and it is not possible for individual board members to represent the viewpoints of everyone in the state.

\section{Researchers' Assessment of Primary Accomplishments and Challenges Facing the INEEL CAB}

\section{Accomplishments}

- The board has developed a number of mechanisms to build informal relationships among board members. This, combined with the unceasing efforts of the facilitator, have led to a board with good relationships among members.

- The board has made a deliberate and consistent effort to learn and apply the concept of consensus decision making, obtaining training and contracting with a facilitator who models and coaches the board in this. The board recognizes that this approach does not come naturally to members.

- The board makes a special effort to conduct evaluations that will help improve its performance. Evaluations include self-evaluations conducted as part of each meeting; analysis of recommendations; and a survey of recipients' opinions of past recommendations.

- The board has built a good and constructive relationship with DOE-ID and has provided a substantial number of consensus recommendations to DOE and the regulators. 


\section{Challenges}

- The board has a very high proportion of whites (consistent with the state population, which is $96 \%$ white), and a predominance of retirees and white males. Although this composition has allowed the board to focus a large amount of time and effort on site issues rather than being required to spend a lot of time learning how to communicate and work with one another, it may be inconsistent with the guidelines for diversity and limit the board's ability to address issues from multiple perspectives.

- The strong personality, extraordinary familiarity with the site, interest, high energy, time availability, and technical orientation of the chair can dominate the board unless balanced by equally strong, committed members. The chair, vicechair, the board, and the facilitator are working to achieve this balance.

- The board's natural orientation is to challenge the technical aspects of DOE (or regulator) decisions but to accept the underlying management structure, problem definition, decision framework, and decision criteria. This can make it difficult for the board to engage those who feel it is important to challenge these aspects of the situation. 
PNNL-12139

An Evaluation of the Effectiveness of Local Site-Specific Advisory Boards for DOE Environmental Restoration Programs:

\section{Nevada Test Site Community Advisory Board}

Judith A. Bradbury

Kristi M. Branch

Pacific Northwest National Laboratory

February 1999 


\section{NEVADA TEST SITE \\ COMMUNITY ADVISORY BOARD}

\section{Table of Contents}

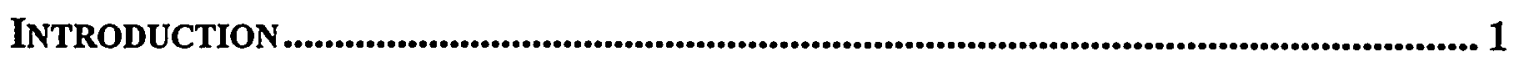

COMMUNITY CONTEXT ........................................................................................................... 2

BOARD COMPOSITION .............................................................................................................. 3

PuRPoSe, Goals, AND Commitment to ConSENSUS........................................................... 4

INTERNAL PROCESS AND FUNCTIONS ............................................................................... 5

Agenda Building and Issues Management..........................................................

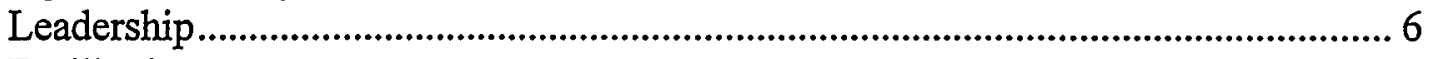

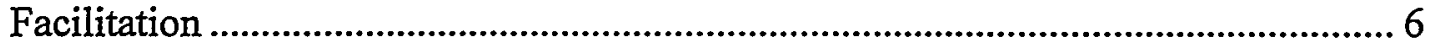

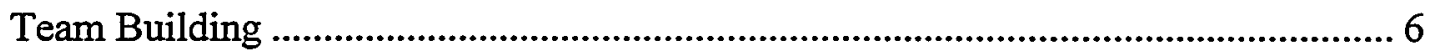

Administrative and Technical Support ....................................................................... 7

Process Summary ....................................................................................................... 7

PUBLIC ENGAGEMENT ................................................................................................ 8

Outreach and Information Gathering .................................................................. 8

Opportunities for Public Participation in Board Activities........................................... 8

DOE AND REGULATOR ENGAGEMENT......................................................................... 9

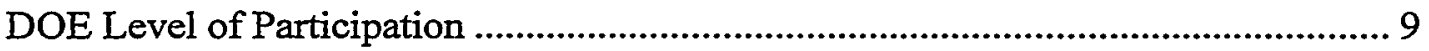

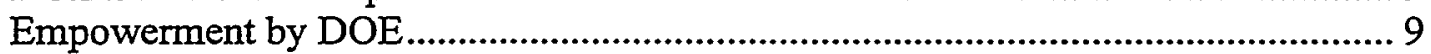

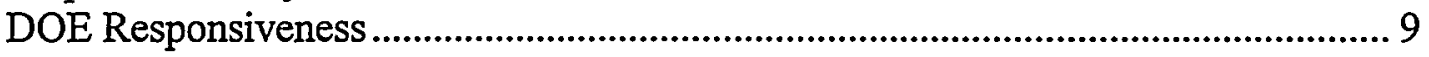

Role of the Regulators .................................................................................................... 9

ISSUES AND OBSERVATIONS ................................................................................................. 10

Issues Raised by Members Concerning the Nevada CAB....................................... 10

Researchers' Assessment of Primary Accomplishments and Challenges

Facing the Nevada $\mathrm{CAB}$................................................................................ 10 


\section{NEVADA TEST SITE \\ COMMUNITY ADVISORY BOARD}

\section{Introduction}

This report details the results from the Nevada portion of a U.S. Department of Energy study that was initiated to understand factors contributing to the effectiveness of the DOE local Site-Specific Advisory Boards (SSABs) and to provide information useful for the boards and DOE in their continuing efforts at improvement. The Overview report that accompanies the individual site reports discusses findings across nine DOE sites and provides background on the goals, methodology, and rationale for the framework used in the study. It also serves as a template for the findings presented in this site report.

The report for the Nevada Test Site Community Advisory Board (NTSCAB or Nevada $\mathrm{CAB}$ ) is thus structured according to the six factors that were found to be important in assessing local SSAB effectiveness. As emphasized in the Overview, the study was designed to assist DOE and the boards in assessing how well the boards were fulfilling DOE's basic purpose in establishing the boards, and to provide information that would be useful to DOE and the boards in achieving this purpose. Specifically, DOE established the boards to obtain independent, consensus policy advice and recommendations that drew on the range of local and regional stakeholder perspectives. The underlying rationale was that advice that reflected agreement among very different viewpoints would also be more likely to be acceptable to nearby communities and thus would provide a firm basis for developing policies that were not only technically sound but also could be implemented. Accordingly, the focus of the study was on board processes that enhanced the boards' ability to provide independent, broadly based policy advice, rather than on the recommendations per se.

This report describes the Nevada $\mathrm{CAB}$ as it was operating at the time of the researchers' visit in July 1998. The description is provided in terms of the six factors found to contribute to board effectiveness (community context; board composition; purpose, goals, and commitment to consensus; internal processes and functions; public engagement; and $\mathrm{DOE}$ and regulator engagement). It begins by highlighting key features of the site context that pose particular challenges to the $\mathrm{CAB}$. The two subsequent sections discuss the board's composition, including diversity of viewpoints represented on the board, and the board's sense of purpose, goals, and commitment to consensus. The next section examines the board's internal processes and functions, including how board members accomplish agenda building, issues management, and team building; how facilitation, brokering, and leadership roles are taken and performed; and how administrative and technical support is provided. The following section, on public engagement, details the board's effectiveness in providing opportunities for public participation and in outreach and information gathering. The next section discusses the relationship between the board and $\mathrm{DOE}$, and between the board and site regulators. The final section lists important 
issues members identified and provides the researchers' assessment of the accomplishments and challenges facing the CAB.

As emphasized in the Overview, the purpose of this study is to provide an outsider's perspective, based on a review of boards across the DOE complex, and to encourage the boards to reflect on their own strengths and weaknesses and learn from one another's accomplishments and challenges.

\section{Community Context}

The Nevada Test Site (NTS) is located in an isolated area in Nye County, approximately two hours by road from Las Vegas. Nye County is large and sparsely populated. The only communities within an hour's drive of the NTS are Amargosa Valley (1990 population: 761), Beatty (1990 population: 1,623), and Pahrump (1990 population: 23,425 , currently estimated to be 25,000). The DOE Nevada Operations Office, contractor offices, and the CAB office, are all located in Las Vegas, in Clark County (1990 population: 741,459 , currently estimated to be 1.2 million). The CAB deals primarily with DOE and contractor personnel from Las Vegas, and the majority of CAB meetings take place there.

Several aspects of the NTS context pose a challenge for the CAB:

- The scope and agenda of the CAB are restricted to cleanup issues at the NTS, despite the existence of other, overlapping issues of high salience (i.e., central importance), such as the proposed high level radioactive waste repository at Yucca Mountain, that influence board operations.

- The secret nature of activities at the NTS has limited community access to information about the site and provided little opportunity for the community to build a foundation for collaborative problem-solving with DOE.

- Supportive regulatory relationships are lacking.

- The long distances between communities and the wide dispersal of the population make communication among $\mathrm{CAB}$ members difficult and time consuming.

Although the work of the CAB is limited to NTS cleanup, other DOE activities on or adjacent to the site affect the $\mathrm{CAB}$ and its ability to operate effectively. Agreement on scope and agenda is made more difficult by the competition these other activities create for the attention and resources of both DOE and the public. The fact that the site's mission-related activities are controversial at the national level further complicates the challenge facing the board. DOE activities at the NTS, which has played a central role in the weapons program, have formerly been the target of highly visible opposition by antinuclear, peace activists. While controversy over the NTS has diminished with reductions in weapons activity, sustained controversy and state opposition to the proposed Yucca Mountain repository overshadow issues related solely to NTS cleanup activities. Although some of the larger policy issues related to cleanup of the DOE complex (e.g., transportation of low-level waste to be disposed on site) and remediation of the NTS 
(potential groundwater impacts) overlap, they are likely to be managed by separate $\mathrm{DOE}$ offices only one of which (the Nevada Operations Office of Environmental Management division) the $\mathrm{CAB}$ advises.

The salience of NTS cleanup activities to the local population varies by jurisdiction. In Nye County, the economic salience of all DOE activities is high - increases or decreases in employment opportunities (at the NTS or potentially at the repository) are a serious concern for residents. In addition, potential groundwater impacts are a concern for the local communities. In Las Vegas, the size of the city and the dominance of tourism and gaming lessen any potential impact on the economy from DOE employment; however, the potential impact of transportation concerns on tourism and gaming have long had high political salience. Other than transportation, the cleanup mission is not a central concern in Las Vegas and Clark county where tourism issues, water availability, and the impacts of rapid area growth dominate the agenda.

Previous DOE/local community interactions have provided little positive experience in collaborative problem solving. These interactions have been strongly influenced by the secrecy surrounding NTS activities and by citizen opposition to the repository both at the state level and in Las Vegas. While the $\mathrm{CAB}$ provides an important opportinity for individual and community learning, the learning process has started later than at some other sites where a foundation of citizen organization and interavtion has already been laid. The difficulties imposed by the local physical and political geography add to the challenge.

The small, widely dispersal population of the rural counties closest to and most impacted by site activities is numerically and politically dominated by the large, metropolitan population of Las Vegas. The small population and large distances between the more impacted rural communities, combined with the location of $\mathrm{DOE}$ and contractor offices in Las Vegas, have led to a Las Vegas orientation in CAB membership and activities. Meetings are seldom held in the rural communities, requiring the most directly affected public and $C A B$ members to drive long distances to participate.

Relationships with the regulators, which are a source of support and positive influence at some sites, provide limited assistance for the Nevada CAB. EPA is not included as an ex-officio member of the board. The NTS, which is not a CERCLA site, does not fall within the EPA's jurisdiction, although the State has been delegated responsibility under the Federal Facility Agreement and Consent Order and participates instead of EPA. Meanwhile, longstanding state opposition to the Yucca Mountain repository tends to spill over on to state-DOE relationships in working with the $\mathrm{CAB}$.

\section{Board Composition}

The board, which had 18 members at the time of the site visit, was formed in 1993 by DOE after consultation with a working group of interested citizens and representatives from local governments, Indian Tribes, the university system, and others. Members were recruited through a mix of the individual and organizational approaches. A list of 
nominees was forwarded to the State of Nevada Division of Environmental Protection for review. The State's recommendations were submitted to DOE for final approval. Members are now recruited, screened, and selected by the board, on the recommendation of the Diversification Committee.

Board membership, as constituted in the summer of 1998, provided a sound foundation for the expression of diverse views. The board included a broad cross-section of viewpoints, with local government and activist environmental group participation. Site and ex-site workers participated but did not dominate the group. The board was broadly representative of the area's demographic diversity, although with a Las Vegas orientation and lacking Tribal representation. The majority of members were from Las Vegas; five members came from Nye, Lincoln and Esmeralda Counties. Tribal representatives have declined to participate, although the board does take the initiative in maintaining communication with the Tribes. At the time of the site visit, the chair was from Pahrump in Nye County; since then a new chair from Las Vegas has been elected. The low proportion of members from the rural counties most affected by NTS cleanup was an issue for some members.

The board does follow guidelines in recruiting members. Although members emphasized their individual orientation (i.e., they believe that they should speak for themselves and not for members of the category from which they were recruited), the categories are broadly applied and particular organizations may be used as selection categories. Several members noted that the board had difficulty recruiting members, especially from the rural areas. Difficulty recruiting rural members was attributed to the long drive required for meeting attendance; difficulty recruiting Las Vegas and Clark County residents was attributed to the low salience of NTS cleanup compared with the other problems faced by the rapidly growing area.

\section{Purpose, Goals, and Commitment to Consensus}

Although some members expressed frustration that the $\mathrm{CAB}$ was not mandated to address high level waste or nuclear testing issues, and others focused on technical goals, many of the board members emphasized the need for policy input to DOE. For many, the primary goal of the CAB is to provide the public's perspective on environmental cleanup and related issues, such as low-level waste disposal and transportation. The board was characterized as "a mediator between DOE and the public" and "a surrogate" for the public. Several members also pointed to the need for an oversight role "to keep DOE honest," in view of DOE's self-regulation.

Members spoke with pride of the pioneering role they had played in promoting inter$\mathrm{SSAB}$ discussion of issues that required complex-wide agreement. They emphasized their recent hosting of a low-level waste seminar for all site boards as a particular achievement. This seminar set a precedent for the SSABs to tackle intersite issues.

However, this sense of achievement was moderated by concern about the board's lack of focus and direction. Overall, a sense of shared purpose and board identity did not appear 
to be well-developed, and members did not emphasize the importance of searching for areas of agreement. The board does not use a consensus approach to conducting meetings and making decisions; majority voting is used for decisions on recommendations and advice to DOE.

Several members pointed to the difficulty of agreeing on scope and agenda and limiting discussion just to NTS issues when discussing problems that were linked to broader DOE-wide site issues. In addition to transportation, for example, a particular concern was expressed about the lack of a comprehensive DOE approach to groundwater studies and the compartmentalization into separate Yucca Mountain and NTS groundwater models.

\section{Internal Process and Functions}

Our study of board processes across the complex highlights the importance of providing for the functions that, in combination with diversity on the board, contribute to effective discourse. These functions include agenda-building and issues management, leadership, facilitation, team building, and administrative and technical support. As described below, problems with provision of some of these functions limited the CAB's ability to reach its full potential.

\section{Agenda Building and Issues Management}

The technical advisor plays a strong role in issue identification and management for the Nevada $C A B$. Agenda setting is initiated during workshops for members, which are held twice a year. Issues are prioritized by members and developed into an informal work plan. DOE provides a list of its priorities and participates in the workshop but not in the prioritization process. The state regulator does not participate. Issues are assigned to committees for more detailed review, with the committee chair responsible for issue management, including bringing the issue to the board for approval. Members reported that the majority of the board's work is done in committee and that there is usually little additional discussion when recommendations are brought to the whole board. Committee structure and membership is fluid and members, plus non-members, may attend. Few non-members attend committee meetings, which are announced only at board meetings and do not appear to be widely advertised.

A major concern expressed by almost all SSAB members was their difficulty maintaining focus on key issues and their sense of issue overload. They frequently pointed out that these were volunteer boards whose members could not be expected to devote full time to board issues. The difficulties were compounded at Nevada, where their Administrative Committee (originally envisaged as an Executive Committee to provide direction) evolved into a general meeting open to all and serving as an overflow meeting for items not covered in board meetings. At the time of the site visit, the board was discussing the issue of the Administrative Committee's function and the possibility of changing the schedule of board meetings to address the problem of issue overload. The problem of issue overload is common to many boards, who have addressed it in a variety of ways by explicitly agreeing on how priority issues will be established; by adhering to a formal 
work plan, once an initial list has been established, with prior agreement on how new issues will be approved; by referring back to a set of previously established values and principles to guide their work; or by the chair, supported by an Executive Committee and reinforced by extensive, informal networking and a clear sense of direction.

\section{Leadership}

Observations during the site visit indicated that the roles and responsibilities of the chair, committee chairs, and administrative committee were not clearly defined and assigned. Because of the blurring of the functions of the administrative committee, the chair did not appear to have an executive committee to support him in his tasks. This lack of clarity in roles and responsibilities was reflected in an apparent lack of overall board strategy and meeting management. There seemed to be clear agreement that the chair was responsible for external coordination functions; however, other expectations were not explicitly spelled out. This made it difficult for the chair to delegate tasks effectively and difficult for board members to identify how to participate effectively. It has also made it difficult for the technical advisor to focus on his primary responsibility.

\section{Facilitation}

Allocation of responsibility for meeting facilitation was shared between a recently appointed facilitator and the technical advisor. Overall, facilitation was problematic. The meeting was not kept to schedule and was variable in level and approach. As a result, discussion and exchange among members was constrained rather than facilitated. As discussed below, DOE recognized the need to make changes in facilitation responsibilities as part of an overall approach to providing improved administrative and technical support.

The broker role was played primarily by the technical advisor, who interacts extensively with members and DOE, particularly on technical issues. The chair and other board members also played behind-the-scenes coordination roles.

\section{Team Building}

The long distance separating members poses a challenge to the Nevada $C A B$ in initiating team-building exercises, which can help both in establishing and maintaining a shared sense of purpose and board identity. Opportunities for informal social interaction are limited by the short meeting time and the meeting location, which does not facilitate informal interaction. New members are provided a handbook and operating procedures. Twice a year, workshops are held to discuss the work plan. However, other activities such as retreats or training on the purpose, meaning, and methods of consensus decision making have not been conducted. The board also does not use a self-evaluation process, either as part of the meeting discussion or at time set aside for reflection on progress and problems. To enhance members' communication capabilities, DOE earlier provided laptop computers; however, problems with server and internet access and obtaining service have limited their utility for rural area members for whom it is most needed. 


\section{Administrative and Technical Support}

Support functions are provided by the technical support services contractor, located near the DOE office. DOE also has a contract with a technical advisor through the University of Nevada, Las Vegas - this person is located in the university rather than at the site. At the time of the site visit, DOE was evaluating how to restructure and provide additional support to the $C A B$. Since then, several changes have been made: a new facilitator has been hired and a new position has been created to provide executive/administrative support and free the technical advisor to focus on technical support to the board.

The support services staff personnel perform day-to-day administrative tasks. These include providing staff support, overseeing meeting logistics and minutes, and keeping the board's records. The primary administrative services support person, who had been appointed, several months before the site visit, was widely praised for the good quality of her support.

At the time of the site visit, the technical advisor filled several functions for the board. In the role for which he was originally hired, he reviewed technical documents; identified new issues and monitored on-going issues; prepared and distilled information for nontechnical members; identified needed presentations for the board and helped DOE staff with their preparation; explained and answered members' questions; and mentored new members. Almost without exception, members spoke highly of the technical assistance he had provided. They praised, in particular, his help in keeping them abreast of key issues and providing assistance to non-technical members that enabled them to contribute more effectively to substantive discussions.

Over time, the technical advisor's role had expanded to include additional functions that were not otherwise explicitly provided for by the board. For example, until very recently, the technical advisor had sole responsibility for facilitating the board meeting (although his role had been reduced, he continued to be responsible for the larger proportion of the meeting). More particularly, he had also stepped in to perform a variety of executive functions, the responsibility for which had been left undefined. Similarly undefined was the distinction between staff and board member roles. These issues had resulted in work overload for the advisor and contributed to members' concerns over board direction and focus.

\section{Process Summary}

The effectiveness of discourse among members appeared to have been constrained by problems that had arisen in providing for essential board functions. Both the chair and the technical advisor expressed frustration with the situation. This raised the question whether increased administrative and facilitation support accompanied by clarification of leadership, members, and support staff roles would be helpful.

Board meetings are scheduled for one evening per month for approximately four hours. Observation of the board meeting, which permitted only a one-shot view of board processes, showed that interactions were civil and respectful; however, observation of 
board discussion was limited by the high proportion of time taken up with presentation, which ran beyond schedule. Several members expressed concern that active participation in board activities is limited to five or six core members, and that it is difficult to maintain interest and attendance for the entire meeting. One member also complained about the amount of meeting time spent on "mundane things" instead of substantive discussion.

\section{Public Engagement}

Consistent with their views that the CAB's goal is to act as a mediator between $D O E$ and the public, a substantial proportion of board members interviewed for this study expressed a strong sense of their responsibility to the public. They envisaged their role as one of providing a forum for public input and of representing the public's views to DOE. A new chair, who has experience in radio communication, had been selected for the Public Outreach Committee and was planning to expand its activities.

\section{Outreach and Information Gathering}

The extent of seeking input and reporting back to civic organizations by members is variable, depending both on the individual and whether he or she has a discrete group with which to interact. A public outreach committee is responsible for outreach planning and implementation. At the time of the site visit, the newly appointed committee chair was developing plans for expanding outreach activities. Outreach activities included:

- Advertisements of monthly meetings in local newspapers

- Mailing list

- Website

- The CAB Advisor, a one or two-page handout inserted in the EM Update, which is published quarterly.

The $\mathrm{CAB}$ does not publish an Annual Report. To date, there has been no information gathering about public views.

\section{Opportunities for Public Participation in Board Activities}

The meeting was held in the auditorium of the DOE Nevada Operations Office. Information was readily available for public attendees and opportunities provided for comment and board response throughout the meeting. Committee meetings (which were not observed) are open to the public; however, these meetings are not advertised except at the monthly board meeting.

Several members expressed concern that holding meetings in the DOE site office discourages public attendance and raised the possibility of meeting in other Las Vegas locations had been examined but not followed up. Others pointed out, however, that public attendance had not been greater when the $\mathrm{CAB}$ had met at other locations (hotel, conference center, several high schools) and that reduced cost and consistency of meeting 
location were advantages. A number of members emphasized the need to systematically rotate meetings among rural areas, where members of the public closest to the site had shown interest in NTS issues.

\section{DOE and Regulator Engagement}

DOE managers expressed strong appreciation for the value of the board in providing a public perspective. The CAB is DOE's main mechanism for pulsing the public. DOE indicated that the informal discussions, as well as the formal meetings, provide useful feedback and help DOE prioritize and focus its other involvement efforts where they are most needed. Several members expressed concern about the board's effectiveness and gave more hesitant views of their value to $\mathrm{DOE}$.

\section{DOE Level of Participation}

The Assistant Manager for Environmental Management is responsible for the board and attends board meetings. His attendance has been consistent, and he plays an active role in the meetings - at the meeting observed during the site visit, he made the initial introductions and actively participated in discussions. Technical staff, especially those who are involved in issues of importance to the board, are expected to attend board meetings. DOE and contractor staff also attend committee meetings.

\section{Empowerment by DOE}

A number of members who were interviewed expressed concern about their overdependence on DOE. Particular issues of concern were the DOE meeting location and their board's limited role in staff hiring decisions and responsibility for the $C A B$ budget. Several members complained that they had not been involved upfront in decisions to restructure the administrative and support functions of the board, including technical support and facilitation.

\section{DOE Responsiveness}

DOE responds to board recommendations in writing. No tracking system is maintained by the board or DOE. Some members expressed concern about the extent of DOE's responsiveness, in particular the limitations on the local DOE office's ability to respond to the broad nature of issues that are important to the local communities beyond Las Vegas.

\section{Role of the Regulators}

EPA does not have jurisdiction over NTS and does not participate as an ex-officio member. Relationships between DOE and the State regulator are influenced politically by Yucca Mountain activities. State engagement in $\mathrm{CAB}$ activities appears to be low.

Cleanup activities are governed by an Interagency Agreement between DOE/NV and the State of EPA. The CAB provides advice to DOE and the State. However, 
recommendations appear to be provided primarily to DOE. The State regulator did not attend the August meeting that was observed. According to members interviewed for the study, the State regulator participates in the board discussions but often leaves early.

\section{Issues and Observations}

\section{Issues Raised by Members Concerning the Nevada CAB}

- The major issue of concern, expressed almost unanimously by interviewees, was the board's lack of focus and direction.

- Many members also expressed concern about the extent and effectiveness of the board's interaction with the public, which for many members was viewed as an important part of the board's role. Of particular concern was the need to increase interaction with rural communities affected by the site.

- An additional common issue was the constraint on the board's scope and agenda. Members emphasized the problem of DOE's "compartmentalization" of issues such as groundwater impacts and transportation and the difficulty of limiting discussion to NTS issues when these were linked to broader, DOE-wide site issues.

- Several members expressed concern about the lack of board empowerment.

- Communication difficulties, including problems with internet access (server and service) were frequently mentioned.

\section{Researchers' Assessment of Primary Accomplishments and Challenges Facing the Nevada CAB}

\section{Accomplishments}

- The $C A B$ is providing a prototype for community dialogue and a valuable opportunity for personal, agency, and community learning in the face of difficult challenges in terms of context (mission and scope, as well as prior civic experience in collaborative problem solving).

- The board includes members from a range of perspectives and emphasizes policy issues.

- Members displayed a strong sense of responsibility to the public. An enthusiastic chair had been appointed to the outreach committee shortly before the site visit.

- The Nevada board has played a key role in promoting and setting a precedent for inter-SSAB discussions. 


\section{Challenges}

- Several problems in fulfilling board functions were apparent at the time of the site visit. (A number of changes to address these problems have since been instituted):

- Meeting facilitation was problematic.

- A lack of clarity was evident concerning roles and responsibilities of the leadership (chair, administrative committee, committee chairs) and of support staff.

- The role of staff vs. support staff was a key issue that needed to be addressed.

- Plans for increased administrative support needed to be accompanied by clarification of leadership, members, and support staff roles. Involvement of board members in such clarification was also needed.

- The $C A B$ faces particular constraints related to scope and agenda that are organizationally and politically difficult, if not impossible, for the Assistant Manager for Environmental Management to address.

- The $C A B$ also faces particular difficulties in terms of population dispersal and distance; communication is a more difficult problem than at most sites because of limitations with computer access. 
PNNL-12139

An Evaluation of the Effectiveness of Local SiteSpecific Advisory Boards for U.S. Department of Energy Environmental Restoration Programs:

\section{Northern New Mexico}

Citizens' Advisory Board (Los Alamos)

Judith A. Bradbury

Kristi M. Branch

Pacific Northwest National Laboratory

February 1999 


\section{Northern New MeXico Citizens' AdVISORY BoARd}

\section{Table of Contents}

INTRODUCTION ............................................................................................................................................. 1

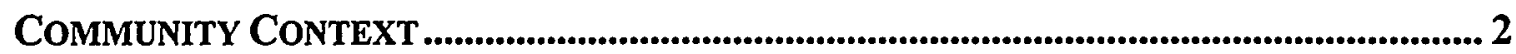

BOARD COMPOSITION ........................................................................................................ 4

PuRPOSE, GoALS, AND COMMITMENT TO CONSENSUS........................................................ 6

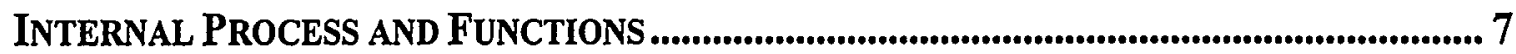

Agenda Building and Issues Management............................................................ 7

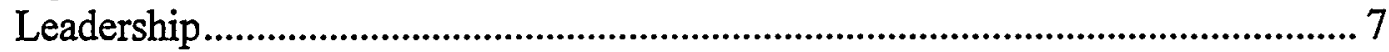

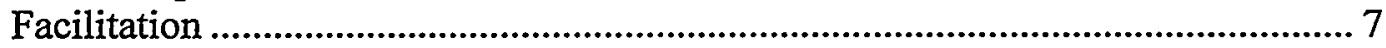

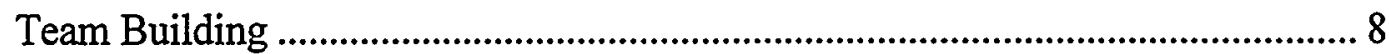

Administrative and Technical Support .................................................................. 8

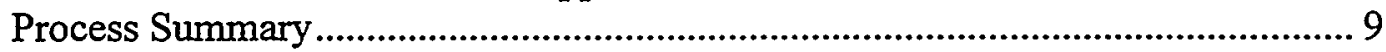

PUbLIC ENGAGEMENT ........................................................................................................ 9

Outreach and Information Gathering .................................................................... 9

Opportunities for Public Participation in Board Activities....................................... 9

DOE AND REGULATOR ENGAGEMENT.............................................................................. 10

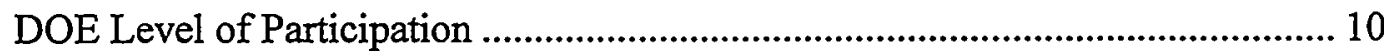

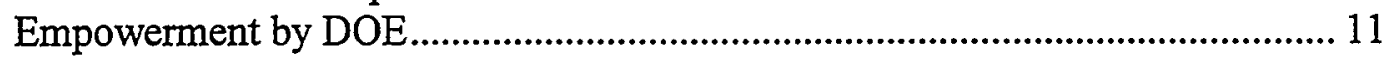

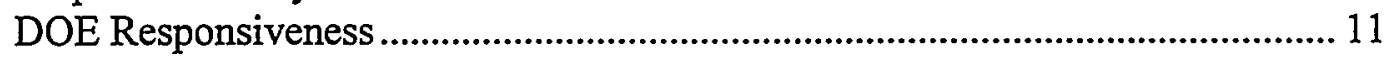

Role of the Regulators ............................................................................................ 11

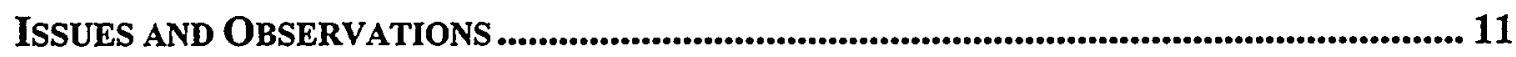

Issues Raised by Members Concerning the Northern New Mexico CAB ............. 11

Researchers' Assessment of the Primary Accomplishments and Challenges

Facing the Northern New Mexico CAB ........................................................... 12 


\section{Northern New MeXico Citizens' AdVISORY BoARd}

\section{Introduction}

This report details the results from the Los Alamos portion of a U.S. Department of Energy (DOE) study that was initiated to understand factors contributing to the effectiveness of the DOE local Site-Specific Advisory Boards (SSABs) and to provide information useful for the boards and DOE in their continuing efforts at improvement. The Overview report that accompanies the individual site reports discusses findings across nine DOE sites and provides background on the goals, methodology, and rationale for the framework used in the study. It also serves as a template for the findings presented in this site report.

The report for the Northern New Mexico Citizens' Advisory Board (CAB) is thus structured according to the six factors that were found to be important in assessing local SSAB effectiveness. As emphasized in the Overview, the study was designed to assist $\mathrm{DOE}$ and the boards in assessing how well the boards were fulfilling DOE's basic purpose in establishing the boards, and to provide information that would be useful to DOE and the boards in achieving this purpose. Specifically, DOE established the boards to obtain independent, consensus, policy advice and recommendations that drew on the range of local and regional stakeholder perspectives. The underlying rationale was that advice that reflected agreement among very different viewpoints would also be more likely to be acceptable to nearby communities and thus would provide a firm basis for developing policies that were not only technically sound but also could be implemented. Accordingly, the focus of the study was on board processes that enhanced the boards' ability to provide independent, broadly based policy advice, rather than on the recommendations per se.

This report describes the Northern New Mexico CAB as it was operating at the time of the researchers' visits in October and December 1998. The description is provided in terms of the six factors found to contribute to board effectiveness (community context; board composition; purpose, goals, and commitment to consensus; internal processes and functions; public engagement; and $\mathrm{DOE}$ and regulator engagement). It begins by highlighting key features of the site context that pose particular challenges facing the $\mathrm{CAB}$. The two subsequent sections discuss the board's composition, including diversity of viewpoints represented on the board, and the board's sense of purpose, goals, and commitment to consensus. The next section examines the board's internal processes and functions, including how board members accomplish agenda building, issues management, and team building; how leadership, facilitation, and brokering roles are taken and performed; and how administrative and technical support is provided. The following section, on public engagement, details the board's effectiveness in providing opportunities for public participation and in outreach and information gathering. The next section discusses the relationship between the board and DOE, and between the board and site regulators. The final section lists issues that members raised in their 
discussions and provides the researchers' assessment of the accomplishments and challenges facing the $\mathrm{CAB}$.

As emphasized in the Overview, the purpose of this study is to provide an outsider's perspective, based on a review of boards across the complex, and to encourage the boards to reflect on their own strengths and weaknesses and learn from one another's experiences.

\section{Community Context}

The Los Alamos National Laboratory (LANL) is managed by the University of California under a management and operations contract for the DOE Los Alamos Area Office, Albuquerque Operations Office. The LANL is located in Northern New Mexico, 90 miles north-northeast of Albuquerque, 35 miles northwest of the city of Santa Fe, and 20 miles southwest of Espanola in Rio Arriba County. It covers an area of almost 28,000 acres or approximately 43 square miles, of which $86 \%$ lies within Los Alamos County and 14 percent within Santa Fe County. The closest population centers are the communities of Los Alamos (a 1990 population of approximately 12,000) and White Rock (a 1990 population of approximately 8,000). Santa Fe, which is further from the site, is the closest large population center.

LANL was first established as Manhattan Project Y to design, develop, and test nuclear weapons in World War II. Its missions have expanded beyond national security, and it is now a multidisciplinary, multipurpose institution engaged in theoretical and experimental research related to all four of DOE's missions (national security, energy resources, environmental quality, and science). LANL has played and continues to play a major role in national security and in the regional and State economy; currently, approximately 9,200 full-time contract staff and 68 Federal employees work at the site. Defense program funding provides over two-thirds of major DOE funding, and the Office of Defense Programs (DP) is the LANL site landlord. Because of its national security mission, LANL is actively involved in research and development related to weapons production and stockpile and nuclear materials stewardship and management. This mission dominates other LANL activities, including the Environmental Management Program, which the $\mathrm{CAB}$ is authorized to advise - requested Fiscal Year 1999 funding for the latter program was approximately $\$ 78$ million or $6 \%$ of the LANL budget compared with $\$ 893$ million or $71.5 \%$ for Defense Programs. ${ }^{1}$

Nearby jurisdictions affected by laboratory operations include six counties (Los Alamos, Mora, Rio Arriba, San Miguel, Sandoval, and Santa Fe) and ten Pueblos (Cochiti, Jemez, Nambe, Picuris, Pojoaque, San Ildefonso, Santa Clara, San Juan, Taos, and Tesuque). The population in the six-county area is diverse, comprising approximately $60 \%$ white, $7 \%$ American Indians, and $40 \%$ of Hispanic origin. African American comprise less than $1 \%$ of the population. Income and education levels vary widely. LANL and its activities

\footnotetext{
${ }^{1}$ Los Alamos National Laboratory Site Profile, U.S. Department of Energy, Office of Oversight, Safety, and Health, June 1998.
} 
were initially surrounded in secrecy, and the newly created scientific community developed in isolation from the rich Pueblo and Spanish heritage of the surrounding area.

Several of the persons whom were interviewed pointed to the ambivalence with which local persons view the LANL and their economic dependence on its continued activities. The legacy of secrecy, the transfer of privately owned land to create the laboratory, and the differences in cultures continue to affect relationships between the DOE/LANL, and nearby communities. Carlos Vasquez, principal investigator for the project Impact Los Alamos, describes the contrast between "the country's most advanced scientific and technological culture and traditional village cultures" as follows:

The fifth largest state in the union [New Mexico] is also among the poorest. The Peace Corps once used Chama and Taos in northern New Mexico to train recruits headed for the Third World because these towns most resembled the structural poverty trainees would encounter in their destined place of service. Santa $\mathrm{Fe}$, on the other hand, has one of the highest concentrations of conspicuous wealth in the world and has become a playground for the rich and famous. New Mexico has one of the poorest educational systems in the world, yet its smallest county, Los Alamos, offers its youngsters one of the best educations available in the United States and boasts one of the highest concentrations of Ph.D.s in the world. ${ }^{2}$

The $C A B$ faced a variety of challenges in terms of a complex web of contextual factors that this study has shown generally to influence development of a local SSAB. These factors include site mission, salience of the issues, diversity, and previous civic engagement. Specific factors that contributed to the difficulty at Los Alamos included the site's mission and associated national, regional, and local opposition to specific policies such as weapons production and continuing waste-generating activities; longstanding distrust and ambivalence about the economic dominance and technical expertise of LANL; equity concerns, both generally and specifically as they relate to hiring and firing; safety and management concerns; and negotiation over land transfers from DOE to Los Alamos County and San Ildefonso Pueblo under legislation passed in 1997.

On the positive side, in terms of the establishment of an effective board, issues related to environmental management are of growing salience to the local communities in Northern New Mexico. Of particular concern are issues related to management of legacy wastes, contamination of groundwater, and contamination of the aquifer. Reaching agreement on the scope of inquiry required to understand and address these environmental issues, however, has proved difficult, and, as at other sites with continuing missions and highly salient issues related to weapons production and stewardship, there has been strong competition and controversy over the definition of environment and safety and about the fundamental purpose and scope of the board. The fact that these mission-related issues

\footnotetext{
2u'Impact Los Alamos: Traditional New Mexico in a High Tech World, Overview of a Project and Symposia," New Mexico Historical Review, Volume 72, January 1997.
} 
are highly controversial at the national level further complicates the challenge facing the board.

A particular problem at Los Alamos has been reaching agreement on the agenda and scope of the board's activities, both among board members and between the board and DOE/LANL. When the board was first formed in 1995, multiple issues of concern to the community spilled over into board discussions of environmental issues and, in the absence of alternative forums, the board became a primary mechanism for expression of these various concerns. In part, the issues were related directly to the site's defense mission; in part, they were related to broader community concerns about DOE and LANL operations; and in part, they were reflections of community concerns about social and economic conditions. This placed a heavy load on the board - a load for which citizens, DOE, and LANL management were unprepared. As one person whom was interviewed noted, "This was the first real public involvement opportunity at the Los Alamos Laboratory and everyone tried to get through the door at once with their community concerns."

To narrow and obtain agreement on the scope and focus of the board's work required a two-step process of first forging agreement among the very diverse interests on the board and subsequently coming to agreement with DOE. Yet little foundation had been laid for collaborative problem solving among the various interests in the community and there was also limited experience among DOE and LANL personnel about the methods of public involvement. In particular, there was little DOE and LANL experience with ways of interacting effectively with stakeholders and assisting the board in developing effective operational processes and procedures.

\section{Board Composition}

Initial formation of the $\mathrm{CAB}$ occurred over a period of over two years, beginning with a stakeholders' group in May 1993. The board then operated from 1995-1997 before being restructured. The reconstituted board began meeting informally in October 1997 and resumed regular, public meetings in 1998. Interviews with current and former members and staff indicated conflicting interpretations of events that occurred in the first two years of operation.

Community interest, expressed in a meeting of 31 public interest groups in 1993, led to creation of a Formation Committee that was established by DOE as an independent group to recommend members of a Citizens' Advisory Board. The committee drafted a mission statement, operating procedures, and other documents that were distributed for public comment and undertook a recruitment process to identify and recommend for DOE approval 12-17 members representing community viewpoints. Methods included mailings to over 2,000 interested citizens; newspaper, radio and television announcements; meetings with interested groups and Tribal and governmental officials; and broadly advertised public meetings in several locations. 
Comments from the public emphasized the need for:

- Fair representation of the diverse community

- Board accountability to the public

- DOE and LANL commitment to consider and respond to all public comments and recommendations

- Autonomy of the board

- Long-term commitment by DOE to fund the board

- Avoidance of conflict of interest.

The proposed slate of members was approved by DOE in May 1995. The board held its first meeting in September of that year and met regularly until August 1997.

The CAB, like other local SSABs across the DOE complex, experienced a variety of developmental difficulties in establishing effective dialogue among members, DOE, and the community. The difficulties encountered by the initial Northern New Mexico Citizens' Advisory Board were not easily resolved.

In 1997, the Secretary of Energy decided to terminate the service of members whose twoyear terms of office were expiring in 1997. Amid considerable controversy, meetings were discontinued pending selection of replacement board members. DOE assumed responsibility for this process. To solicit nominations for the eight replacement members needed to bring the board back to full strength, DOE/HQ held meetings with, and distributed letters to, representatives of local governments, local Tribal governments, and area organizations. The Los Alamos Area Office then selected replacement members on the basis of (1) demonstrated interest in environmental management issues; (2) demonstrated ability to work in a team setting; (3) interest in LANL environmental issues; and (4) a history of community service. DOE also indicated that the Area Office would continue to be responsible for member recruitment and selection. Currently, the board chairperson has been participating in the recruitment and selection process started at the end of 1998.

Over the six months between the resumption of board operations and the site visits, several of the remaining former members resigned or drifted away. They and some of the previously terminated members have become a nucleus of disaffected citizens that are likely to be a continuing source of discontent in the community. Some of these members challenged DOE's actions in a lawsuit. Although the case has recently been dismissed and not appealed, these events significantly disrupted board activities for over a year and have left residual issues that continue to affect board operations.

The newly reconstituted board, consisting of some previously and some newly appointed members, has met regularly since the spring of 1998. As of November 1998, the month before the second site visit, the board had 13 members - eight newly appointed members and five members of the former board whose terms of office expire in December 1998. 
As part of its effort to recruit members to replace these five, DOE was seeking to recruit two additional members (for a total of seven new members) to bring the board to its preferred size of 15 (the board has since decided to expand the total membership). When the new members took office in January 1999, the board had experienced a $100 \%$ turnover in membership within a period of a year. Such a turnover is unique among the local SSABs.

At the time of the site visits, the board was ethnically diverse with a high proportion of Pueblo members (one San Ildefonso Pueblo, one Cochiti Pueblo, one Picuris Pueblo, and one Nambe Pueblo), as well as Hispanics and Anglos. However, there was limited balance in terms of perspectives related to DOE/LANL issues; governmental, and in particular DOE-related perspectives were predominant. In addition, there was a high proportion of members whose employment was funded by DOE: of the 13 members, three were currently employed by the LANL, one was a former LANL employee, and three were persons who are paid with DOE funds to serve on Tribal Environmental Departments. Several persons whom were interviewed expressed concerns about the transition of the board from a "citizens' board" to a "DOE board." They were critical of the credibility of a board selected by, and sympathetic to, DOE and LANL, as compared with a board that can provide independent advice on environmental issues of concern to the community.

\section{Purpose, Goals, and Commitment to Consensus}

At the time of the site visits in the fall and early winter of 1998, the newly restructured board was still in the process of establishing an identity and sense of purpose. During the interviews, newly appointed and some former members expressed a common goal of assisting DOE with cleanup activities. For many, also, corollary goals related to the board's role in the community; these included disseminating information to stakeholders, helping to educate the public about the complexity of the issues, and providing a sounding board or information source for citizens. Most new members expressed pride in the progress achieved to date. They believed that they had worked effectively to draw up and approve by-laws and a work plan that formed the basis for future progress. Several pointed to the progress already made by the Environmental Restoration Committee. Others noted that they were beginning to trust one another and develop a team spirit. Many emphasized their desire to move on to substantive issues of environmental management and cleanup.

Soon after its restructuring, the board made a decision not to use a consensus approach but to follow Robert's Rules of Order in conducting meetings and deciding on recommendations. Many members demonstrated an orientation to making decisions expeditiously rather than spending a lot of time and energy discussing alternative viewpoints and searching for agreement among diverse perspectives. However, following discussions with other board chairs at the SSAB Chairs' meeting in September 1998, the chair reevaluated that decision. Proposed amendments to the by-laws (not yet voted on) called for passage of recommendations by consensus rather than Robert's Rules of Order. 


\section{Internal Process and Functions}

In combination with respect for the value of diverse viewpoints, successful performance of the following functions has been found to contribute to effective board performance: agenda-building and issues management processes, leadership, facilitation, team building, and administrative and technical support. A noteworthy feature of the Northern New Mexico Citizens' Advisory Board is that the reconstituted board has made considerable progress in putting in place most of these functions, although some of the previous and long-term members lament the change in character of the board and feel that the communities have been significantly disempowered.

\section{Agenda Building and Issues Management}

An Outreach Committee and three issue committees Environmental Restoration, Waste Management, and Monitoring/Surveillance have been established. Agenda setting is initiated by the committee chairs working with the chair, co-chair and DOE; committee chairs reported that they identified priority issues on which their own committee wished to work. All members who attended the September retreat were involved in drawing up a work plan that formalized planned activities and criteria for evaluating progress after both six and twelve months. The work plan has subsequently been approved in a full meeting of the board.

Several members expressed concerns about the ability of the board to complete its planned schedule of activities. Concerns included the lack of involvement and motivation of all members, including some members of the former board who were still officially members; the limited time available to volunteers to devote to board work; and the need to prioritize and focus on a very limited number of issues (these problems have been very common across the sites).

\section{Leadership}

While recognizing that his affiliation with the LANL has posed a special challenge, the new chair has been playing a lead role in moving the board forward. His primary focus has been on promoting the interests of the board, and he treats members with respect as well as providing motivation and encouragement. Setting a conducive atmosphere for work and encouraging the development of a focused agenda have been priorities. Although there is no formal Executive Committee, he has been supported in this effort by guidance from the DOE Coordinator and by the committee chairs. In combination with informal networking with members, he has been helping to move the board forward in a constructive path.

\section{Facilitation}

The board does not currently have a facilitator to help in planning and conducting meetings. Most members did not appear to believe that such a role needed to be filled at this time. The chair is experienced in conducting meetings, and as one member noted, there are few disagreements among members - "the board is very compliant." A broader 
interpretation of the facilitation function includes the mediator or broker role in addressing interpersonal issues and interpretations of technical and policy issues both among board members and between the board and DOE or the board and regulators. Although this informal facilitation process appeared to be played effectively by the chair, some members (the DOE coordinator, and the administrator, the chair, and other members) expressed frustration with the amount of time and attention they are having to devote to process and administrative issues rather than substantive issues.

\section{Team Building}

Group retreats, consensus training, orientation for new members, process workshops, and self-evaluation are examples of the various formal techniques that boards have employed to promote self-reflection and team building. These techniques help facilitate the process of reflecting critically on successes and problems, providing self-correction and redirection where needed, and promoting a sense of group identity and shared purpose. To date, the focus of the restructured board has been on developing a sense of board identity and purpose, and on putting in place the needed administrative infrastructure for effective functioning, such as by-laws and a work plan. Members who attended the first retreat, held the month before the first site visit, emphasized the value of this process for team building as well as for completion of board administrative tasks. The board has expressed its intent to conduct a self-evaluation later in the year.

\section{Administrative and Technical Support}

Day-to-day administrative tasks have been performed by a full-time administrator who is employed by the DOE site contractor. Her tasks included note-taking and distribution, record-keeping, arranging meeting logistics, and responding to inquiries. Her role has also included executive-level support such as acting as a bridge between DOE and board members and taking a lead role in coordinating board meetings and activities. DOE has also employed an additional consultant to assist in public relations tasks for the Department and/or the board.

Several persons noted the need for DOE to make arrangements for public access to board records and documents that are currently kept in the administrator's (private) office. Since the visit in October 1998, DOE, recognizing this need, has arranged for one room on the first floor of the Los Alamos Area Office building to be reserved for a CAB library. Meanwhile the $C A B$ Administrator and public relations consultant will be located in an office adjoining the library that is accessible to the public. Opening of the library and relocation of CAB staff was scheduled for completion in early 1999.

Provision for technical support has been included in the budget. The Monitoring Committee chair has been currently developing plans to draw on some outside technical support to help structure the Committee's work. 


\section{Process Summary}

Board meetings are scheduled one evening per month for three hours. During observations of the October and December meetings, the meetings proceeded smoothly. During the first meeting, time was provided for public comments; by-laws, a budget, and a work plan were approved; and a high proportion of time was spent on discussion of committee activities. The Environmental Restoration Committee made several formal requests for information from DOE. Members interacted with civility and with humor little disagreement was evident. The focus of the discussion was on making decisions.

\section{Public Engagement}

Engagement of the public has been a stated priority for the board, as reflected by members' statements related to goals, board actions during the meetings that were observed, and the creation of an Outreach Committee. However, the board faces some major challenges in this arena.

\section{Outreach and Information Gathering}

The board has established an Outreach Committee whose members and activities are integrated with those of $\mathrm{DOE}$ and the Laboratory. At the time of the site visits, the committee was headed by a Pueblo member who was also a member of the initial board. In addition, the committee included the board chair and former vice-chair (who was employed in the LANL Community Relations Office), the DOE Coordinator, and another DOE staff person. The committee had developed a first newsletter to be distributed to the community and was working to insert positive articles about board activities in the local press. The chair of the Outreach Committee was also encouraging board members to engage others to become informed about and involved in board activities.

At this early stage of development, the board has not undertaken specific informationgathering activities such as a community survey to assist members' understanding of community views of the board and issues of public concern. However, survey questions were being developed for inclusion in the annual surveys of Northern New Mexico local and regional leaders and communities that have been conducted by the LANL Community Relations Office.

\section{Opportunities for Public Participation in Board Activities}

One of the most straightforward methods of public outreach is available when board members are selected to represent constituencies and organizations within the community and can report back directly to them in the course of their normal organizational activities. The representation of local governments in the Northern New Mexico Citizens' Advisory Board has assisted in reporting back through these channels.

Reporting back to the broader community both through local and Tribal governments and through non-governmental community organizations requires additional efforts by the board. 
The board has taken several actions to encourage participation in its meetings. Board meetings were being held in different communities to enhance area-wide participation and the meetings were advertised in local and regional newspapers. In addition, the board meetings observed were structured to encourage public input - time for public comment was included at the beginning of the meeting and comments were acknowledged by the chair in a positive, welcoming manner. Members stated that committee meetings have been also open to the public; however, to date, these have not been advertised.

Several factors indicated that the current board faces many challenges in establishing its credibility with the public - and ultimately its value to DOE as a guide to the diversity of community perspectives that must be addressed in developing viable policies.

The legacy of distrust of LANL activities, in combination with the negative experience of the previous board and the disaffection of members who feel that they have lost their voice in the community, has made establishing credibility a particularly difficult - yet essential - challenge for the board to meet. At the same time, some of the new board members expressed frustration that some segments of the community were not fairly evaluating the considerable effort that they had been devoting to furthering the board's work.

The continuing, prominent role of DOE in recruiting, selecting, as well as approving members of the board (which is unique among the board), and the integration of board outreach activities and staff with those of DOE and LANL are perceived by those outside of the board as structural impediments that, despite the integrity and good intentions of individual members, impact the board's independence and its ability to speak impartially for community interests.

Board members, in particular the chair and DOE Coordinator, were cognizant of this challenge as they attempted to recruit members to replace the retiring class of 1998. Over the previous year of transition, several of the former members had resigned or dropped out of active participation. Despite their limited numbers, the remaining members had worked hard to put in place by-laws and committees to enable the board to focus on its mission of providing advice to DOE from diverse community perspectives. They were anxious to maintain this momentum and, in their recruitment efforts, were placing emphasis on selecting members who are willing to commit sufficient time to ensure progress in providing advice to DOE on environmental management issues.

\section{DOE and Regulator Engagement}

\section{DOE Level of Participation}

Members interviewed expressed strong appreciation for the support of the current DOE Designated Federal Official, who was new to the site. They particularly valued her willingness and ability to be a "doer" in promoting the board's interests. More negative and skeptical views were expressed about the engagement of upper DOE and LANL 
management; several members questioned the limited attendance and/or commitment of upper management of both DOE and LANL to the board. One member emphasized the need for a Secretarial visit to demonstrate support for the board.

\section{Empowerment by DOE}

As discussed in the section on public engagement, empowerment does not appear to be an issue for the new board members at this time, as for members of some other local SSABs. However, the members viewed their request for information at the October meeting as a test of DOE/LANL's empowerment of the board. In addition, public comments received during the initial formation process in 1994 indicate that board empowerment and the associated ability to be autonomous and accountable to the public are matters of concern to the broader community. These are issues of particular concern to former board members who feel that they - and the community in general - have been disempowered and that DOE and the LANL are continuing, as in the past, to ignore their concerns.

\section{DOE Responsiveness}

DOE responses to board recommendations cannot be evaluated at this time, since the new board has only just begun to work on its substantive tasks. However, the board has discussed the need for tracking recommendations and responses, and one member has agreed to take responsibility for the task. Several members expressed reservations about the extent of DOE and LANL upper management commitment and indicated that they are watching how DOE and LANL respond to the information requests made at the October meeting as well as responsiveness to recommendations from the board.

\section{Role of the Regulators}

Members' comments indicated that the regulators have played a limited role to date; several expressed concern that DOE's supplementing of State resources limited the regulators' independent role. The board's by-laws require board recommendations to be provided solely to DOE and do not provide for recommendations to be given also to the regulators (recommendations may be sent to the New Mexico Environment Department regulator as a courtesy). No formal cleanup agreement is in place, such as the Hanford Tri-Party Agreement that legally binds DOE to specific actions, deadlines and associated penalties. It was not possible to evaluate the interaction between the board and regulators at the October meeting that was observed, the EPA regulator was not present and a substitute was attending for the State.

\section{Issues and Observations}

\section{Issues Raised by Members Concerning the Northern New Mexico CAB}

- A primary issue of concern focused on problems arising from member burnout and the need for full involvement and contributions from all members. Several 
members emphasized the need to prioritize and focus on a few key issues. Others expressed concern about the need to maintain the board's momentum, emphasizing that, with procedures and committees in place, the board needs to move forward in developing advice. However, many felt constrained by the low number of active members.

- A second primary issue was the need to address concerns created by the close affiliation of board members to the LANL. An associated concern was to ensure that the recruitment process does not systematically prevent the nomination of certain categories of potential participants (for example, some Pueblo governments will not nominate women to represent them).

- Several members expressed concern that senior DOE and LANL management have not provided the board a clear commitment to provide the information the board requests or to act on the board's recommendations.

- One member noted that stipends are needed for members whose participation would cause financial hardship (this provision does apply, within established guidelines, at some sites).

- An issue was also raised about lack of public access to records currently kept in the Administrator's private office (this issue is currently being addressed by DOE).

\section{Researchers' Assessment of the Primary Accomplishments and Challenges Facing the Northern New Mexico CAB}

\section{Accomplishments}

- The board has made substantial progress in defining its focus and direction under difficult circumstances - by-laws, budget, and a work plan have been approved and four committees have been established that are proceeding on the work of the board.

\section{Challenges}

- Although the reconstituted board is young, its past history seems to have given members a sense of urgency that they need to move past process discussions, such as organizational and management issues and incorporating different viewpoints, to substantive discussions about environmental remediation and waste management issues. This reluctance to deal with process issues could limit the board's effectiveness in identifying and articulating diverse community viewpoints and in forging recommendations that reflect those viewpoints and capture the greatest possible areas of agreement. A facilitator could help to maintain an unbiased process and help keep board discussions focused and constructive. 
- The relationship between the board and DOE is unclear to DOE staff members, board members, and the community, both in terms of what it is and what it should be. In the process of intervening to reconstitute the board, DOE has taken on roles with the Northern New Mexico CAB that it has typically not played at other boards and may not want to play with the Northern New Mexico CAB over the long-term. These relationship and role issues and their consequences in terms of board independence, empowerment and credibility are just now being identified and considered by board members and DOE. Because of the board's history, the current board members were unclear about their ability or interest in challenging DOE's roles, for example in the recruitment, selection, and approval process. DOE is unclear about how to transition out of its intervention posture. Some of these issues include:

- The recruitment, selection, and approval process is currently under the open and direct control of DOE and is without specific criteria or categories of interest (established in the by-laws or by DOE) to assure balance of viewpoints on the board. Together, these factors have the potential to erode rather than enhance the credibility of the board.

- The board has been facing a challenge not only of recruiting members who provide balance and independence, including those who can articulate viewpoints that are critical of DOE/LANL, but also those who will be active and informed participants in board activities. A reputation of ineffectiveness or perception of dependence will make it harder to recruit the type of members who can make the board successful.

- The current board has limited balance among community viewpoints: a high proportion of members are supportive of DOE interests and linked to DOE and LANL through employment and funding. Consequently, the fairness, openness, and outcome of the ongoing recruitment process is of great importance that will be closely scrutinized by the broader community, especially ex-members who believe that they have been disempowered by DOE's replacement of the original board.

- Public expectations about the board set during the establishment of the initial board are not being met by the new board, according to comments made by non-members and a review of comments made during the formation process. This is due in part to the changes in roles, responsibilities, and relationships that occurred when DOE intervened to terminate the old board.

- The close coordination and linkage between the board's outreach activities and DOE/LANL's public relations and outreach activities also poses issues of independence and credibility and limits the ability of the board to develop and express its own viewpoints and ideas.

- An issue of particular concern is that discussions with members revealed only limited awareness of the need for greater independence, the problem of community credibility as well as possible approaches to addressing it, and the value of including members who are critical of DOE. 
- The commitment of DOE and LANL managers will be demonstrated in their responsiveness to board comments, questions, and recommendations, particularly those that challenge the status quo. Many of the persons interviewed (including both former and current members) queried the commitment of senior DOE and LANL management to the SSAB process. As emphasized in the Overview report, the commitment and engagement of upper management is a key factor in enhancing board performance and confirming to members the value of their contributions.

- The discussions indicated that the challenges faced by the original board have not diminished - multiple issues of concern to the community could continue to place a heavy load on the board and reduce its effectiveness. DOE may wish to consider establishing additional mechanisms to address the concerns of citizens beyond those related specifically to environmental remediation and waste management that the board is designed to address. 
PNNL-12139

An Evaluation of the Effectiveness of Local SiteSpecific Advisory Boards for U.S. Department of Energy Environmental Restoration Programs:

\section{Oak Ridge Reservation Environmental Management Site-Specific Advisory Board}

Judith A. Bradbury

Kristi M. Branch

Pacific Northwest National Laboratory

February 1999 


\section{OAK RIDGE RESERVATION ENVIRONMENTAL MANAGEMENT SITE-SPECIFIC ADVISORY BOARD}

\section{Table of Contents}

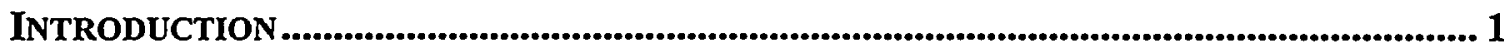

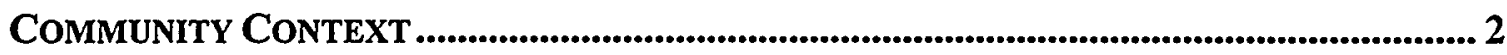

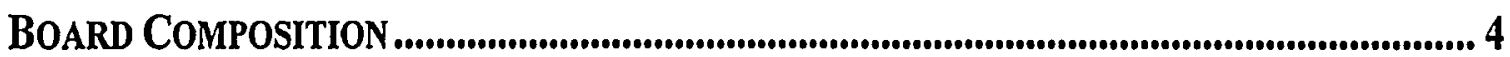

PURPOSE, GoALS, AND COMMITMENT TO CONSENSUS ................................................... 5

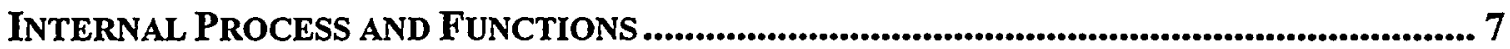

Agenda Building and Issues Management..................................................... 7

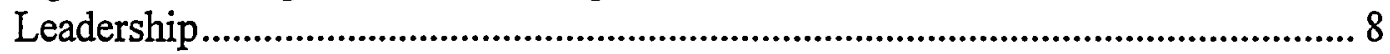

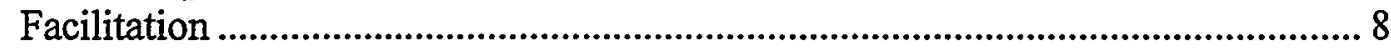

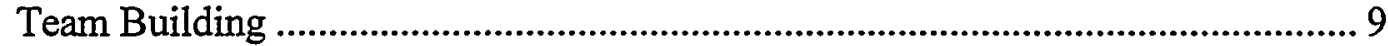

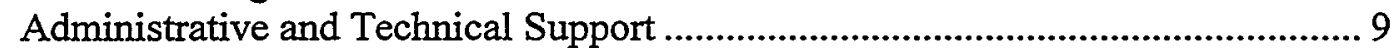

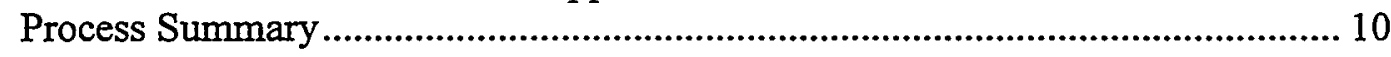

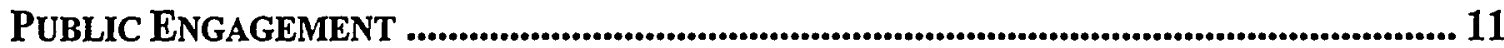

Outreach and Information Gathering ........................................................... 11

Opportunities for Public Participation in Board Activities................................. 11

DOE AND REGULATOR ENGAGEMENT................................................................... 12

DOE Level of Participation ......................................................................... 12

Empowerment by DOE...................................................................................... 12

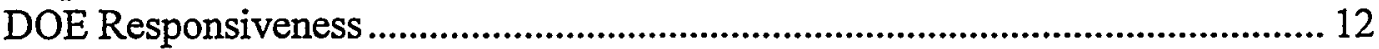

Role of the Regulators .................................................................................. 13

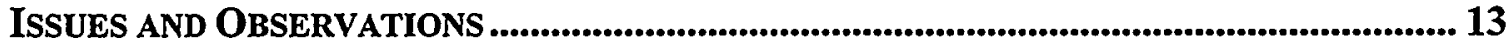

Issues Raised by Members Concerning the ORREMSSAB .............................. 13

Researchers' Assessment of the Primary Accomplishments and Challenges

Facing the ORREMSSAB ................................................................. 14 


\section{OAK RIDGE RESERVATION ENVIRONMENTAL MANAGEMENT SITE-SPECIFIC ADVISORY BOARD}

\section{Introduction}

This report details the results from the Oak Ridge portion of a U.S. Department of Energy (DOE) study that was initiated to understand factors contributing to the effectiveness of the DOE local Site-Specific Advisory Boards (SSABs) and to provide information useful for the boards and DOE in their continuing efforts at improvement. The Overview report that accompanies the individual site reports discusses findings across nine DOE sites and provides background on the goals, methodology, and rationale for the framework used in the study. It also serves as a template for the findings presented in this site report.

The report for the Oak Ridge Reservation Environmental Management Site-Specific Advisory Board (ORREMSSAB) is thus structured according to the six factors that were found to be important in assessing local SSAB effectiveness. As emphasized in the Overview, the study was designed to assist $\mathrm{DOE}$ and the boards in assessing how well the boards were fulfilling DOE's basic purpose in establishing the boards, and to provide information that would be useful to DOE and the boards in achieving this purpose. Specifically, DOE established the boards to obtain independent, consensus, policy advice and recommendations that drew on the range of local and regional stakeholder perspectives. The underlying rationale was that advice that reflected agreement among very different viewpoints would also be more likely to be acceptable to nearby communities and thus would provide a firm basis for developing policies that were not only technically sound but also could be implemented. Accordingly, the focus of the study was on board processes that enhanced the boards' ability to provide independent, broadly based policy advice, rather than on the recommendations per se.

This report describes the Oak Ridge board as it was operating at the time of the researchers' visits in August and November 1998. The description is provided in terms of the six factors found to contribute to board effectiveness (community context; board composition; purpose, goals, and commitment to consensus; internal processes and functions; and DOE and regulator engagement). It begins by highlighting key features of the site context that posed particular challenges to the Oak Ridge SSAB. The two subsequent sections discuss the board's composition, including diversity of viewpoints represented on the board, and the board's sense of purpose, goals, and commitment to consensus. The next section examines the board's internal processes and functions, including how board members accomplish agenda building, issues management, and team building; how leadership, facilitation, and brokering roles are taken and performed; and how administrative and technical support is provided. The following section, on public engagement, details the board's effectiveness in providing opportunities for public participation and in outreach and information gathering. The next section discusses the relationship between the board and DOE, and between the board and site regulators. The 
final section lists important issues that members identified and provides the researchers' assessment of the accomplishments and challenges facing the Oak Ridge SSAB.

As emphasized in the Overview, the purpose of this study is to provide an outsider's perspective, based on a review of boards across the DOE complex, and to encourage the boards to reflect on their own strengths and weaknesses and learn from one another's experience.

\section{Community Context}

The Oak Ridge Reservation (ORR or Reservation) lies in Anderson and Roane Counties and borders Knox and Loudon Counties across the Clinch River. The ORR lies almost entirely within the city of Oak Ridge, Tennessee (1990 population: 27,310$)$. It covers an area of 35,252 acres (600-800 acres outside of city limits) and is approximately 20 miles from Knoxville (1990 population: 335,749).

The area impacted by the Reservation from which members of the ORREMSSAB are drawn includes the city of Oak Ridge and a seven-county area. The 1990 population in the seven counties was 532,158 people; of these, almost two-thirds are from Knox County. The overall area population is $92 \%$ white and $6.5 \%$ African American. There is considerable variation among jurisdictions in terms of income, education, and occupation: Knox and Anderson Counties, as well as city of Oak Ridge residents have higher incomes and education and are more likely to be in managerial and professional occupations.

The Reservation currently provides employment for about 14,000 workers, including federal employees and contractors. Its total Fiscal Year 1998 budget was $\$ 1.8$ billion.

The Reservation's history dates back to World War II. In 1942, the federal government purchased land and named the new town Oak Ridge, where the Manhattan Project focused on the production of enriched uranium. In the 1950s and 1960s, the federal government reduced the Reservation boundaries by converting residential and commercial sections to private ownership. The Reservation includes three major facilities: The Y-12 weapons plant, whose continuing mission includes a variety of weapons-related activities such as the production of weapons components and assemblies; the Oak Ridge National Laboratory, which focuses on basic and applied research in a wide variety of areas; and the East Tennessee Technology Park (ETTP), formerly known as the gaseous diffusion plant, or K-25 facility. The K-25 facility terminated its uranium separation activities and was shut down in 1985. It is currently undergoing reindustrialization (recycling of material and industrial reuse of equipment, material, and facilities) as part of the site's environmental restoration and waste management program.

Environmental management is now the largest DOE Oak Ridge program. In addition to managing wastes produced by ongoing activities, DOE has large quantities of various types of waste to clean up and facilities to decontaminate. Portions of the reservation are 
contaminated with a variety of radioactive elements, mercury, PCBs, and industrial wastes that have contaminated areas downstream and down wind from the city and site.

The ORR presents a complex picture in terms of the contextual factors that this study has shown to influence development of a local SSAB (mission, salience of the issues, diversity, and previous civic engagement). The ORR has a continuing weapons production mission, other continuing research, and a large, complex environmental management program that collectively require the board to make many decisions about scope and focus. Because the site is not focused solely on restoration and waste management activities, issues not directly within the board's scope, yet of concern to the community and to board members, have the potential to spill over into board discussions and relationships. Because of the scale and complexity of the environmental management challenge at the site, it is difficult for board members to become sufficiently familiar with the issues to understand them well enough to develop priorities. As a result, the board faces greater challenges in agreeing on scope and priorities and on setting its agenda than boards at sites where the mission is focused solely on cleanup, and where the cleanup issues are less complex.

ORR activities have high national, regional, and local salience. The issues that the board is tasked to address (defined in the by-laws as "the full scope of ORR environmental and safety concerns") are already known and of central importance to the community. The initiative shown by area residents to express their interest in having a DOE local SiteSpecific Advisory Board is an indication of the salience of ORR activities to the community.

There is a diversity of views represented in the community; area residents are differentially impacted by, and have different perspectives on, ORR activities. While this provides a rich resource for the board, it adds to the board's challenge in ensuring that the membership adequately represents this diversity and that board processes facilitate effective communication and dialogue among those with differing, and sometimes opposing, viewpoints. The economic as well as potential environmental, health, and safety impacts are a particular concern for the city of Oak Ridge and neighboring communities, whose economic base is highly dependent on DOE. Economic impacts on more distant jurisdictions, though still.important, are moderated by distance and the relatively greater diversity of their economic bases.

In the past, the potential impacts of massive releases of mercury and radionuclides from the Y-12 weapons plant were a high priority issue for citizens. More recently, increased attention has been given to the potential health impacts on residents in the Scarboro community. Scarboro, which is predominantly African American, is located within the city of Oak Ridge, approximately one-half mile from the $\mathrm{Y}-12$ weapons plant. It houses many persons who have worked at the plant, primarily as service workers. In addition, reindustrialization of $\mathrm{K}-25$ and its conversion into a technology park is emerging as an issue of concern. There has also been continuing concern and controversy over operation of the TSCA hazardous waste incinerator. 
The city of Oak Ridge and surrounding communities have had a long history of active civic engagement in environmental issues on which they can draw for experience in establishing and operating a local SSAB. There has been little experience, however, of collaborative problem solving related to DOE issues among grass root citizen groups with differing viewpoints and from the different geographic areas included in the board. In the past, for example, much citizen engagement has tended to be citizen opposition to DOE activities. Opposition, has primarily developed outside of the city of Oak Ridge (the Oak Ridge Health Liaison appears to be an exception here). Primary examples include the precedent-setting LEAF court decision, brought by a Knoxville attorney, that established that DOE is not self-regulating with respect to non-radioactive toxic materials; opposition to, and widely publicized demonstrations against, $Y-12$ operations by a local peace organization with national links; and local and regional opposition to the TSCA incinerator. A factor complicating the establishment of the board within the organizational and political context of the community was the existence of the Local Oversight Committee (LOC), which is funded by DOE under the DOE/State of Tennessee Oversight Agreement. The LOC's Board of Directors includes the Oak Ridge City Mayor, the County Executive of each of nearby counties, and the chairs of the Oak Ridge Environmental Quality Advisory Board and Roane County Environmental Review Board. It is advised by a 15-member Citizen's Advisory Panel.

The initiative by local area residents to establish a local SSAB was controversial, strongly opposed by Oak Ridge City and the LOC itself. The decision to establish the ORREMSSAB was made by the DOE/HQ Assistant Secretary for Environmental Management after lengthy discussion with the involved parties. It was based on the latter's concern that "dissenting views in the community [do not believe that] the LOC represent[s] the diverse views within the Oak Ridge Community" (letter from Thomas Grumbly to Chairman Nephew, LOC Chair and Oak Ridge City Mayor, dated December 8 , 1994). The ORREMSSAB's relationship with the LOC, originally adversarial, has changed for the better in the intervening years as a result of continuing effort by members of the participating organizations. A board member serves as an informal bridge between the two organizations; another board member characterized current relationships as "excellent."

\section{Board Composition}

Formation of the ORREMSSAB occurred over a period of more than two years, beginning with a stakeholders' group in May 1993. Community interest led to formation of a Steering Committee in November 1993 that, through a series of meetings, developed a formal proposal for a local SSAB the following year. The official board formation process began in January 1995. Following extensive DOE publicity, an independent convener, assisted by a seven-member screening panel, screened applicants for diversity in backgrounds and demographics in a "blind" process. In addition, a representative from the Oak Ridge city council was included, at the city's request. The first meeting was held in September 1995. The board adopted by-laws in February 1996 and standing rules in May 1996. Officers were elected for Fiscal Year 1996 in February 1996. 
The board continues to play no role in recruiting and selecting members: members are screened and recommended to DOE for approval in a blind selection process that is unique among the local SSABs. Candidates are first recruited by DOE in a mailing of letters of invitation to local media and to community organizations in the seven-county area. An independent arbitrator selects a four-member selection panel that includes representatives of the city of Oak Ridge, the LOC, the environmental community, plus one ad hoc citizen. The selection panel agrees on the selection criteria and the relative weighting to be assigned to them. These are based on the seven-county demographics and discussions with ORREMSSAB and ex-officio members concerning priority issues from the public's perspective. The arbitrator does a blind match, which is followed by panel interviews with candidates to determine the level of interest and commitment.

A noteworthy feature of the process is that the criteria can change each time the candidate recruitment and selection process occurs. For example, greater weight was assigned in previous efforts to selecting members from downstream communities, since downstream impacts were of particular concern in the Records of Decision underway at that time. Now that attention has shifted to possible health impacts on the Scarboro community, within the city of Oak Ridge, it has been proposed that greater weight be assigned to criteria favoring selection from that community. As part of the current recruitment process, DOE is placing a priority on recruiting three additional members to replace the three representatives of environmental/health and peace activist viewpoints who resigned earlier in the year, and on recruiting a resident of Scarboro. Some board members expressed their disagreement with these changes in recruitment. The EPA supports efforts to ensure representation of these viewpoints on the board.

At the time of the site visits in August and November 1998, the ORREMSSAB had 15 members (one member has since resigned). As then constituted, the board did not represent the full diversity of views in the community. Nine of the fourteen members were, or had been, employed by companies involved in DOE activities. Eight were retired or not employed full time. Two were African American (this gave the board a higher proportion of African American members than the proportion in the seven-county area). The chair, DOE, the regulators, and many members recognized that the absence of some area perspectives was an important shortcoming that adversely affected the richness of the board's deliberations and the credibility of the board's work. These persons also supported DOE's goal of expanding the range of perspectives in the recruitment and selection process underway.

\section{Purpose, Goals, and Commitment to Consensus}

Members' comments, combined with a review of board records (Annual Reports, recommendations, and work plans), indicated that the board had experienced great difficulty in developing a shared sense of priorities, purpose, and approach. Although some board members have put in tremendous effort, searching for common areas of agreement did not appear to have been a central focus of the board as a group. One person whom we interviewed, for example, noted that "the dynamic from the very 
beginning was 'getting your own views on the agenda," rather than searching for areas of agreement that the board as a whole could share.

Most members with whom we spoke emphasized their interest in getting on with the analysis of issues framed to respond to DOE's (and regulators') decision-making process, seeing this as the way they could best help DOE proceed with cleanup efficiently and economically. Most wanted to avoid spending time and effort confronting fundamental assumptions or issues of focus and scope. The resignation of three members early in 1998 was described as "a turning point" for the board, though one that was interpreted quite differently by different members. Some believed that it had resulted in an improved understanding that "it is OK to have different agendas;" an alternative interpretation was that the board had been unable to effectively resolve issues of fundamentally different agendas or perspectives. At the same time, several members expressed relief that the board meetings had become less frustrating and contentious with its current, less diverse composition.

Early in 1998 the board held a special, one-day working session to discuss its decisionmaking process and to clarify issues associated with consensus versus majority voting. Following the meeting on decision making, members decided to change the by-laws to use Robert's Rules of Order and make decisions by voting rather than consensus. Most members with whom we spoke thought that the change had been beneficial. The consensus approach had appeared to them to foster interminable discussions and minority blocking, whereas Robert's Rules and voting reduced tension and anxiety, increased familiarity and comfort, improved efficiency, and provided a well-established and socially acceptable way to make decisions and allow the majority to rule. It was also seen as providing more direct accountability for board members to the public. As some noted, however, the point at issue was not which particular process to use but whether or not there was a basic agreement among members to try to come to agreement and to listen to one another. At the time of the resignations, no such basic agreement among was in place. Some members attributed the reduction in board dissention and incivility that has occurred to the resignation of members of "one faction," rather than to a more fundamental improvement in behavior or process management skills. Interviews indicated general agreement that the board's cohesiveness had been building over the previous year, although some questioned whether this was primarily due to the resignation of those who most directly challenged the majority viewpoints on the board.

Some of the most active board members, including the current chair, have placed a priority on building a more cohesive group and are credited with "refusing to allow the board to fail." Members pointed with pride to their innovative use of broadly based groups of members and non-members to develop policy recommendations that draw on a wide range of community views. As a result of this approach, two reports with important implications for the community's future were completed (Report of the Oak Ridge Reservation End Use Working Group and the Stakeholder Report on Stewardship). The reports' recommendations were subsequently incorporated into DOE's environmental program. 


\section{Internal Process and Functions}

In combination with respect for the value of diverse viewpoints, successful performance of the following functions have been found to contribute to board effectiveness: agendabuilding and issues management processes, leadership, facilitation, team building, and administrative and technical support. The interpretation of the following processes is based on observation of a facilitated special board session on procedures, particularly decision making; an Executive Committee meeting and a regularly scheduled board meeting; interviews with members, including former members; and review of board records. Through a variety of initiatives, the ORREMSSAB had been working to address board concerns and issues regarding some of these functions and had made several changes in the year of the site visit.

\section{Agenda Building and Issues Management}

In Fiscal Year 1998, the board reorganized its committee structure from "one that addressed broad subjects, such as Waste Management, Environmental Restoration, and Environmental Justice, to one that was more focused, with project teams addressing specific subjects, such as ETTP Remediation and Reindustrialization" (ORREMSSAB Annual Report p.1). As with all the boards, setting and keeping to an agenda has been an ongoing challenge for the ORREMSSAB.

Each year, the board has conducted a self-assessment that provides input to the goals and work plan for the following year. Agenda setting has typically been initiated by a request to DOE, the regulators, and each of the five committees (termed teams) to identify issues that they think are important. Individual members are also invited to identify such issues. Board members play a major role in selecting and approving issues to be assigned to the teams for further examination and detailed study, if deemed a priority. The work plan that is drawn up is flexible: a team or non-team member can bring forward new issues which, after discussion at a board meeting, may be approved and assigned to a team.

As a result of recent discussions, the board has been developing the use of a summary sheet/check list to be attached to all recommendations that are included in the board package that is distributed to members prior to a board meeting. The purpose is to provide a summary of key issues that will assist members in their discussion. It will include information on the background of the recommendation, its purpose, and associated pros and cons.

As noted above, after some adjustment, in Fiscal Year 1998, the board established standing project teams to review issues concerning five topics. In addition, special teams were formed to address by-laws, end use, health studies, public outreach, and waste cell management. Interviews revealed widespread agreement that the board would be more effective if it could further prioritize, focus, and streamline its discussions. Changes have recently been made to address this challenge (a very common one across all boards). Despite this ongoing challenge, members reported that the board was beginning to use its teams more effectively, thus enhancing the efficiency of board meetings. The board's small size and time limitations, especially for members with full- or part-time jobs, were 
cited by some as further reasons that the board needed to focus on a few key issues so that it could produce quality recommendations.

One reason given for the success of the group process resulting in the End Use and Stewardship reports and their adoption by DOE was the "narrow, understandable, and urgent" focus provided by this approach. The work had been sponsored by the board and supported by DOE. The End Use Working Group included members of the public (approximately 20-30 participants, of whom 20 participated regularly). Five current members of the ORREMSSAB participated intensively and played a leadership role; two additional board members, now resigned from the board, also played an active role. The group met for approximately 3-4 hours every other week for a period of one and a half years and employed the services of a professional technical advisor/facilitator.

The Working Group sought to identify and develop areas of agreement among all the participants; members who agreed with the results of the Working Group signed the recommendations as individuals, to be consistent with the Federal Advisory Committee Act. Those who disagreed did not sign and were free to develop minority reports. The process was praised both for the product it produced and for its effectiveness - it was described as focused and effective in bringing together different perspectives among the city and adjacent counties. The ORREMSSAB addressed the results of the Working Group by having the board deliberate on the Working Group's guidelines and recommendations, which were approved and submitted to DOE. Both board members and DOE indicated that this process resulted in recommendations that had high utility.

\section{Leadership}

Recognizing the evolutionary process of building an effective board and the need to overcome obstacles, the chair and members of the executive committee have worked hard to make the board succeed and to provide the leadership essential to board effectiveness. The chair is conscious of his responsibility to play a lead role in modeling the particular combination of attributes needed for effective operation of a local SSAB: treating members with respect, providing motivation and encouragement, setting a conducive atmosphere for work, and encouraging the development and execution of a focused agenda. He has been supported in this effort by guidance from the DOE coordinator and an Executive Committee that includes the vice chair, secretary, and each of the five team leaders. In combination with the informal networking among members, between DOE and the board and between the regulators and the board, these steps have helped the board move forward on a constructive path. As with several other boards, the leaders on the ORREMSSAB are facing the challenge of providing strong leadership without dominating the board.

\section{Facilitation}

Although most boards have employed the use of an independent facilitator to assist with meeting planning and group process management, the ORREMSSAB decided to manage its group process internally rather than obtaining the services of a professional facilitator. In part, this decision was based on concern that a facilitator would take control away 
from the board itself. Particularly during 1997, this strategy did not seem to work well. A number of problems occurred, including a focus on disagreements, lack of civility and respect for the views of others (including personal attacks on members), marginalization of those whose views differed from the mainstream, polarization of the board, lack of progress in developing consensus advice, and a feeling of being tyrannized by "the other side" (some by the minority, others by the majority). The board's process management methods were not able to halt these destructive actions, which contributed to all-around frustration and the resignation of board members - although this was not the only reason for the resignations. Some members believed that a facilitator could have helped manage this situation and that a facilitator would be valuable in preventing similar problems from occurring in the future, especially if the board's composition changes; others believed that a facilitator would only have caused additional problems.

A broader interpretation of the facilitation function includes the mediator or broker role addressing interpersonal issues and interpretations of technical and policy issues both among board members and between the board and DOE or the board and regulators. This informal facilitation process appears to be played effectively by the chair, the vice-chair, some members, and the DOE coordinator; however, in the past these informal brokering efforts were insufficient to prevent polarization of the board.

\section{Team Building}

The board has utilized several team-building techniques. It conducts an annual selfevaluation, arranges tours of the site and DOE facilities for new members (and others who might want to join them), as well as holding a one-day session on decision making. At the time of the site visit, it was planning to hold a one-day retreat/workshop to discuss process and relationship issues as well as to prioritize issues for the coming year.

The board's schedule (single-day meetings) and geographic area (small enough for members to drive back and forth on the day of the meeting) do not create the built-in opportunities for informal gathering that boards with two-day schedules and rotating locations have found contribute to team building. Particularly during Fiscal Year 1997, the board struggled with factionalism and lack of civility in interaction that, though terminated by the resignation of the three members, were not resolved within the board.

\section{Administrative and Technical Support}

Two persons, a coordinator and assistant who are employed by the Public Affairs Office of the DOE site contractor, currently provide full-time support to the board. Over the past year, as she had been provided with additional assistance, the coordinator focused increasingly on providing executive-level support. She works closely with the chair to develop agendas for board meetings and other activities such as the annual workshop. She also coordinates and facilitates interactions between the board, DOE, and the DOE contractor. Her assistant, who has only recently been employed full-time on board work, is primarily responsible for providing assistance with team meetings - coordination, taking and distributing meeting notes, and gathering and distributing information.

Several members commented that DOE has been supportive of the board's efforts to 
obtain these services and, indeed, has increased the level of support over the past year. Previously, the coordinator had sole responsibility for administrative tasks. The good quality of the support is reflected in the record of board activities - meeting minutes and other records are well organized, timely, and readily available.

The board has not usually obtained outside technical support, either for independent peer review or to provide assistance, primarily for non-technical members. Members did engage the services of an independent expert to give a presentation on the TSCA incinerator and also approved continuing support to address this issue; however, the decision became moot when the issue was addressed by a Governor's Task Force, rather than the board. Former members highlighted the lack of technical support as a contributing factor in their decision to resign. Some current members, however, emphasized that these persons did not openly articulate their concerns in board meetings. Some also indicated that there is allowance in the budget for technical support and attributed lack of agreement among members about who could/should provide appropriate technical support and/or how the hiring should be undertaken (since the board can not hire), as the reason for not proceeding.

Members' views on the need for and appropriateness of such a support function varied. Some believed that an independent viewpoint is always of value and, more specifically, would have helped prevent some of the bitter disagreement that occurred in the health study discussions. Another believed that it is inappropriate to substitute the ideas of a technical assistant for those of the board members. Others expressed the viewpoint that the knowledge and experience of the board's technical members and the support provided by the board's Coordinator and by the DOE and contractor staff who support the teams are adequate.

Some members who favored a technical support function cited concern that the community perceives the board to be too closely aligned with DOE (several members referred to this perception as a problem for the board's credibility). Others expressed concern that non-technical members (1) are too ready to accept the views of the comembers who have both technical training and knowledge about DOE sites and processes as well as time to devote to studying the issues; and (2) feel unable to fully participate and, as a result, become apathetic or intimidated. They believed that these problems would be reduced if the board had someone to distill key points in documents, provide summaries of material, explain issues, and respond to questions - support that would also help members whose work obligations leave them pressed for time.

\section{Process Summary}

The board meets one evening per month for approximately three hours. During the site visit to the board meeting in November 1998, the meeting was facilitated by the chair and ran smoothly and on schedule. Interactions were civil. Adequate support was provided, and handouts were readily available - these included copies of the agenda and background information on items for discussion. Members of the public were encouraged to speak, and, in addition, a mid-meeting break with light refreshments provided an opportunity for members and non-members to interact informally. 


\section{Public Engagement}

Recent board actions indicated that engagement of and communication with the public have become a high priority for the board. Some members pointed out that efforts over the previous year to "get the message out" were in place prior to public pressure from EPA and dissatisfaction expressed by members who had resigned.

In general, board members are selected to represent themselves, not a specific constituency or organization. Consequently, members are relatively "on their own" in determining how, when, and with whom to discuss board activities. The extent of reporting back and gaining input from the community is variable, depending on the member's existing links and also on individual preference.

\section{Outreach and Information Gathering}

The board has been placing greater emphasis on increasing community awareness of its activities. Responsibility has been assigned to an Outreach Committee, composed of active members and a newly appointed leader. This person, who is also a member of the LOC, recently attended a workshop for DOE staff on public participation that was conducted by an internationally known public involvement specialist. The board has recently completed a video and viewgraph presentation of board activities and has drawn up a list of community organizations, including an initial target list of ten, to whom presentations will be offered. Several presentations have already been given.

Regular outreach activities include:

- Quarterly newsletters

- Annual report

- Advertisements of meetings, including team meetings, in local newspapers

- Telephone call-in line providing an update on all meetings

- DOE monthly announcements of all DOE site activities, including board activities

- Website.

The board recently administered a mail-out survey to approximately 750 people ( 25 percent response rate). Names were obtained from DOE's master list of community organizations and contacts, supplemented by board records of interested persons, for example, persons who had attended meetings or called for information. In part, this was in response to a concern that the board should base its agenda on issues that are a priority to the community. Generally, board members expressed the belief that the board is in good contact with the community through its members' extensive informal networking.

\section{Opportunities for Public Participation in Board Activities}

The board provides copies of handouts to members of the public who attend their meetings and encourages them to bring issues to the board. The public was made to feel 
welcome, and opportunities were provided for members of the public to ask questions and make comments, by raising their hands or coming to a microphone during the meeting. Team meetings are open to the public. During 1998, meetings were held during lunch, late afternoon, or evenings.

It is clear from comments about the effectiveness of the End Use Working Group that most members viewed the approach as a model for effective interactions with the public. Interest has been expressed in identifying additional topics that could be discussed in the format of a working group sponsored by the board. This has been identified as a way to address concerns about the responsiveness of the board to the broader community, and vice versa. Some members cautioned, however, that the working group approach requires issues that are clearly defined, salient, and urgent.

\section{DOE and Regulator Engagement}

\section{DOE Level of Participation}

DOE actions indicated a very high level of support for the board. The Assistant Manager for Environmental Management has attended all monthly board meetings and was regarded by members as open to citizen input and views. A DOE staff person and contractor have been assigned to each team to attend team meetings and provide information and other assistance where needed. The coordinator's link to technical managers within the Department and her recognition (and support) of the need to establish a more diverse board and to be attentive to values and processes have been valuable to the board.

\section{Empowerment by DOE}

Empowerment did not appear to be an issue for Oak Ridge board members as it has been for members of some other local SSABs. For example, issues raised by members of other boards such as the need for board control of staff hiring or for holding meetings in non-DOE facilities were not mentioned. However, the DOE coordinator is aware of the community perception - mentioned by several members - that the board is too influenced by DOE. She recognizes that DOE must be especially careful to strike a balance in its guidance of the board, providing enough structure to ensure fair treatment and prevent personal attacks on members but not so much that the board feels controlled by DOE.

\section{DOE Responsiveness}

DOE's responsiveness to board recommendations, which had been reported in previous written surveys as having been a problem, received more favorable ratings in the interviews conducted for this study. According to the majority of those interviewed, the former "thanks for your comments" notes have been replaced by more detailed responses. DOE has also emphasized to the board that it is unlikely to see the full impact of its recommendations until after publication of a formal Record of Decision. One member 
noted that the board has also played an informal advisory role that is not well documented, yet seems to be effective.

\section{Role of the Regulators}

In the past, the regulators' role on the board has been limited. The board's original bylaws required board recommendations to be provided solely to DOE and had a history of high turnover of personnel and inconsistent attendance at board meetings. Revisions of the by-laws that call for recommendations to be provided to regulators as well as DOE have been match by an agreement by the regulators to play a more active role relative to the board and to provide written comments to board recommendations. As part of this increased involvement, and reflecting the national emphasis on environmental justice, EPA has advocated greater diversity of representation, especially from minority and lowincome communities in impacted areas such as the Scarboro community.

\section{Issues and Observations}

\section{Issues Raised by Members Concerning the ORREMSSAB}

- The credibility of the ORREMSSAB was raised as a concern - specifically, that the community perceives the board as too technically oriented and influenced by DOE.

- The resignations of three members early in 1998 was identified as an issue by many board members, although with widely differing interpretations.

- Several members were concerned that some members on the board do not have the time or interest to make appropriate contributions. They want the recruitment process to pay special attention to the motivations, capabilities, interests and time availability of candidates.

- Concern was also expressed that non-technical members do not participate fully in the board's substantive discussions; some non-technical members feel at a disadvantage relative to technically trained, retired members who devote much time and effort to board issues.

- Several members emphasized that public outreach needs to be a higher priority, with the board placing greater emphasis on being accessible and responsive to the community's issues and priorities. 


\section{Researchers' Assessment of the Primary Accomplishments and Challenges Facing the ORREMSSAB}

\section{Accomplishments}

- Over the past year, the chair has taken the next steps in establishing effective procedures, developing and providing leadership, and team building. Considerable thought and hard work have been devoted to changes designed to help the board move forward on to a constructive path.

- In sponsoring the End Use Working Group, the board has developed an innovative mechanism for providing focus and obtaining greater community participation. This mechanism, which was successful in its own right, may be applicable to other topics at ORR and, potentially, at other sites.

- DOE staff are very supportive and are active participants in helping the board to clarify and work through problems; the board is willing to accept this help.

- There is a high interest in cross-site issues and in working with other boards and sites.

\section{Challenges}

- The complexity of issues and diversity of opinions offer a challenging, yet valuable, opportunity for community learning and collaborative problem solving across diverse citizen groups in the affected area.

- The effectiveness of changes in decision method (to Robert's Rules of Order) and meeting procedures will be tested if the board is successful in recruiting members from the Scarboro community and with an activist environmental perspective generally opposed to DOE. Creating a constructive dialogue under these circumstances will be a challenge.

- Members have varying understandings of the consensus process and how it differs from Robert's Rules of Order. The board has found it difficult to come to terms with how to deal with dissent. Board members have widely differing interpretations of what happened with the three members who resigned, why, and what difference it made to the board.

- The board faces a management problem common to several boards: How can the board best capitalize on the valuable resources offered by members with time, technical expertise, and knowledge of the site, without overwhelming other members who have less time, technical expertise, and/or knowledge? 
PNNL-12139

An Evaluation of the Effectiveness of Local SiteSpecific Advisory Boards for U.S. Department of Energy Environmental Restoration Programs:

\section{Paducah Gaseous Diffusion Plant Site-Specific Advisory Board}

Judith A. Bradbury

Kristi M. Branch

Pacific Northwest National Laboratory

February 1999 


\section{PADUCAH Gaseous Diffusion PLANT SITE-SPECIFIC ADVISORY BOARD}

\section{Table of Contents}

INTRODUCTION

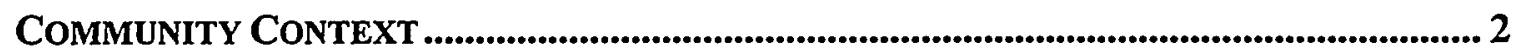

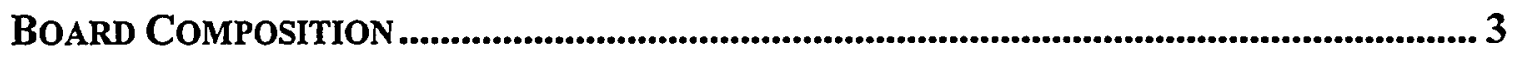

Purpose, Goals, and Commitment to Consensus ................................................ 4

INTERNAL PROCESS AND FUNCTIONS ...................................................................... 4

Agenda Building and Issues Management....................................................... 5

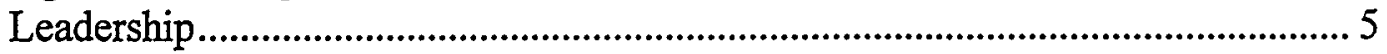

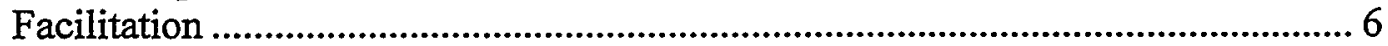

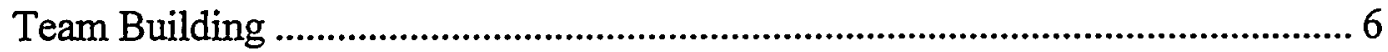

Administrative and Technical Support ......................................................... 7

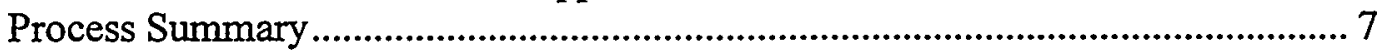

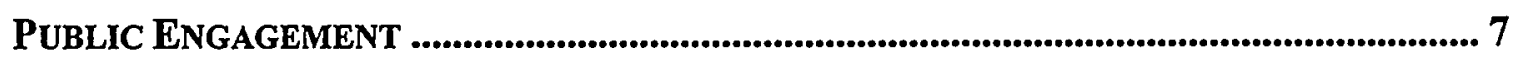

Outreach and Information Gathering .............................................................. 7

Opportunities for Public Participation in Board Activities.................................... 8

DOE AND REGULATOR ENGAGEMENT................................................................................. 8

DOE Level of Participation ........................................................................ 8

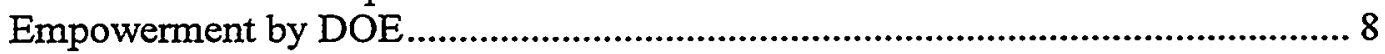

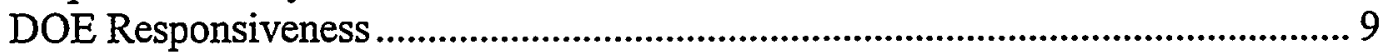

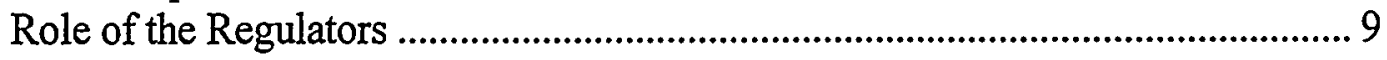

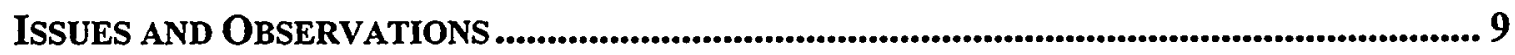

Issues Raised by Members Concerning the Paducah Gaseous Diffusion Plant

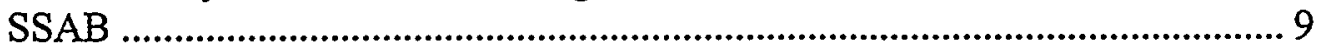

Researchers' Assessment of Primary Accomplishments and Challenges Facing the

Paducah Gaseous Diffusion Plant SSAB .................................................. 10 


\section{Paducah Gaseous DifFusion Plant SITE-SPECIFIC ADVISORY BOARD}

\section{Introduction}

This report details the results from the Paducah portion of a U.S. Department of Energy (DOE) study that was initiated to understand factors contributing to the effectiveness of the DOE local Site-Specific Advisory Boards (SSABs) and to provide information useful for the boards and DOE in their continuing efforts at improvement. The Overview report that accompanies the individual site reports discusses findings across nine DOE sites and provides background on the goals, methodology, and rationale for the framework used in the study. It also serves as a template for the findings presented in this site report.

The report for the Paducah Gaseous Diffusion Plant SSAB is thus structured according to the six factors that were found to be important in assessing local SSAB effectiveness. As emphasized in the Overview, the study was designed to assist DOE and the boards in assessing how well the boards were fulfilling DOE's basic purpose in establishing the boards, and to provide information that would be useful to DOE and the boards in achieving this purpose. Specifically, DOE established the boards to obtain independent, consensus, policy advice and recommendations that drew on the range of local and regional stakeholder perspectives. The underlying rationale was that advice that reflected agreement among very different viewpoints would also be more likely to be acceptable to nearby communities and thus would provide a firm basis for developing policies that were not only technically sound but also could be implemented. Accordingly, the focus of the study was on board processes that enhanced the boards' ability to provide independent, broadly based policy advice, rather than on the recommendations per se.

This report describes the Paducah Gaseous Diffusion Plant SSAB as it was operating at the time of the researchers' visit in July 1998. The description is provided in terms of the six factors found to contribute to board effectiveness (community context; board composition; purpose, goals, and commitment to consensus; internal processes and functions; public engagement; and DOE and regulator engagement). It begins by highlighting key features of the site context that pose particular challenges facing the Paducah SSAB. The two subsequent sections discuss the board's composition, including diversity of viewpoints represented on the board, and the board's sense of purpose, goals, and commitment to consensus. The next section examines the board's internal processes and functions, including how board members accomplish agenda building, issues management, and team building; how facilitation, brokering, and leadership roles are taken and performed; and how administrative and technical support is provided. The following section, on public engagement, details the board's effectiveness in providing opportunities for public participation and in outreach and information gathering. The next section discusses the relationship between the board and DOE, and between the board and site regulators. The final section lists important issues that members 
mentioned and provides the researchers' assessment of the accomplishments and challenges facing the Paducah SSAB.

As emphasized in the Overview, the purpose of this study is to provide an outsider's perspective, based on a review of boards across the complex, and to encourage the boards to reflect on their own strengths and weaknesses and learn from one another's accomplishments and challenges.

\section{Community Context}

The Paducah Gaseous Diffusion Plant (PGDP) is located approximately 15 miles west of the City of Paducah, which sits on the southern bank of the Ohio River in McCracken County, Western Kentucky. DOE property consists of 3,600 acres of which 750 sit inside the PGDP security fence. The area population is predominantly blue collar, mostly employed in light industry and service jobs.

The gaseous diffusion plant is a significant employer in the region, although its activities were largely unacknowledged from commencement of operations in 1952 until the 1970s. The uranium enrichment activities at Paducah have recently been privatized under the 1992 Energy Policy Act and are now the responsibility of the United States Enrichment Corporation (USEC) and its Management and Integration (M\&I) contractor, Lockheed Martin Utility Services, which employs 1,718 people in enrichment activities. An additional 133 Bechtel Jacobs Company LLC employees and about 100 of their subcontractors work for DOE's Environmental Management and Enrichment Facilities Program. DOE maintains a small site office administered by the Oak Ridge Operations Office. The Paducah office of DOE has stewardship responsibility for a large residue of depleted uranium hexafluoride that is contained in approximately 35,000 cylinders (more than at any other DOE site) and for supervision of site monitoring, decontamination, and restoration activities.

The Paducah SSAB faces several challenges in terms of the contextual factors that the study has shown to influence development of a SSAB (mission, salience of the issues, diversity, and previous civic engagement). Mission, to date, does not appear to have posed problems such as those at other sites, where issues of concern to the community related to continuing production, yet not within the board's scope, have spilled over into board discussions and relationships. Other factors, however, do pose a challenge to the board's development. A particular problem is the relatively low salience (i.e., central importance) of issues to the community that makes it difficult to recruit and maintain membership interest. In addition, a lack of previous community experience and knowledge of DOE issues and government procedures provides a limited foundation in collaborative problem solving. Paducah also reports to the Oak Ridge Office of DOE, which introduces an additional set of decision makers who are not residents of the local area.

Site activities achieved salience for the local population in the 1980s when it was revealed that groundwater pollution from the plant was affecting the well-water supply of 
some local residents. This concern was assuaged by DOE providing alternative city water supplies to the affected properties. Attention was also focused on possible loss of jobs at the plant in the mid-1980s when it was under consideration for closure. The continuing operation of uranium enrichment activities provides employment that is valued by many in the community.

Current issues are the disposition of the cylinders containing depleted uranium hexafluoride, migration of the contaminated groundwater towards the Ohio River, and the Vortec waste vitrification process to convert solid waste into a glass product. However, board members, DOE staff, and M\&I contractor employees all agreed that these issues do not seem to have attracted very much attention in the surrounding communities at large. Although business and philanthropic civic organizations function in the area, there has been limited political or environmental activism in the community, particularly in relation to DOE activities. Paducah SSAB members who were interviewed reported that most of the environmental interest that has occurred in the region seems to have been focused on industrial pollution at Calvert City and forest management issues.

Prior to formation of the Paducah SSAB, DOE at Paducah had established two organizations: a Neighborhood Council (established as a result of the well-water issues) to keep local residents informed of plant activities that could affect the local area, and a panel of regional academic advisors. The Neighborhood Council still functions under the auspices of Lockheed Martin Utility Services and USEC. Although the Council is not a DOE or Bechtel Jacobs organization, DOE or its M\&I contractor attend meetings, answer questions, and present regular updates of DOE activities at the site. These DOE and community interactions provided limited experience in collaborative problem solving. The SSAB provides a valuable opportunity for individual and community learning; however, this learning process has started later than at some sites where a foundation of citizen organization had already been laid. In Paducah, the majority of members have had to become knowledgeable about the plant and government procedures and regulations as well as developing effective working relationships with other members, DOE, and the regulators, after becoming members of the board.

\section{Board Composition}

Recruitment represents a hybrid of organizational, demographic, and individual approaches. The SSAB was set up using a working group (recruited largely through advertisements and a mailing list) and a paid facilitator hired by DOE. This group generated a charter for the SSAB and invited volunteers to join the board. Initially it was proposed to recruit representatives from existing local area organizations; however, this proved to be impracticable as there were not many such organizations interested in the site management issues. It was therefore proposed that the board be recruited to be representative of 15 demographic and interest categories such as county officials, business persons, environmental activists, health professionals, ethnic minorities, and union members. The process of establishing the board took almost one and a half years, beginning in May of 1995. The board was chartered in September 1996 and held its first official meeting in October 1996. 
Recruitment proved to be - and remains - a challenge, and five members of the working group have continued to the present time as SSAB members. In particular, it has proven difficult to recruit an elected public official to the board (the sole public official who was a member at the time of the site visit in July has now resigned) or to retain the participation of the local business community. Recent recruitment has mostly been through personal networking by current board members. Board meeting attendance is uneven.

There is moderate diversity in demographics and viewpoints. At the time of the site visit, the board consisted of 12 members - three were associated with the plant (one is a union worker), eight were male, and one was black. Two members had contact with a network in the environmental community. Two members were "plant neighbors" who were personally affected by the well-water contamination that was discovered in the 1980 s, and three members lived across the river in southern Illinois, in close proximity to air emissions from the plant.

\section{Purpose, Goals, and Commitment to Consensus}

Many of the participants expressed similar goals for the board, although these goals are in no sense shared or arrived at by common process of deliberation or consensus. Expressed goals were largely individual and community consciousness raising and learning how to become an effective, independent advisor and watchdog for DOE. Both DOE and the board members emphasized that the board was in an early stage of development and had yet to generate a track record of shared achievements around which members can coalesce.

The board's charter calls for members to attempt to reach consensus on all issues and to include dissenting views in its recommendations. At least three of the board's five sets of recommendations indicate consensus. However, a search for common areas of agreement did not appear to be a priority for most members interviewed.

\section{Internal Process and Functions}

A number of functions must be fulfilled for a group of people to work together effectively, particularly when they are convened to represent different perspectives. These include agenda building and issues management processes that emphasize searching for common areas of agreement among diverse views; leadership, particularly by the chair and/or executive committee; facilitation, both for meeting planning and implementation and for brokering technical and interpersonal issues; team-building processes, which may be formal or informal; and administrative and technical support, including technical assistance to facilitate participation by non-technical members and reduce members' workload. 


\section{Agenda Building and Issues Management}

The development of an agenda that meets the priorities of the members and focuses the work of the board makes an essential contribution to effectiveness. The Paducah SSAB's agenda is currently based on a 12-month rolling work plan that was developed at a planning session held as part of a regular meeting. The current work plan contains 28 items, for which a dozen items carry expected board actions of reviewing documents, monitoring, and advising "as appropriate." Board members described it as "mostly a hodgepodge." The agenda for future meetings is reviewed and modified by the board at each meeting. Members suggest issues for the agenda. Several issues proposed by one of the co-chairs have been adopted, but in the absence of agreed-on criteria for prioritization and a committee structure to promote follow through, prioritization seems to be ad hoc.

The board does not have a differentiated committee structure, but, prompted by criticism from one of the regulators, three individuals have recently adopted the role of "issue managers." These persons have agreed to take responsibility for researching and monitoring issues on behalf of the board. This development provides an opportunity to enhance the board's focus. It also provides an opportunity to expand the number of members who are knowledgeable about the issues and can bring different perspectives to bear on them during focussed discussions. It also enables the board to use its leverage as a SSAB to engage DOE more effectively.

As of July 1998, the board had issued five sets of recommendations to DOE, mostly concerned with procedural issues of public information and consultation. In a May 5 , 1998 , recommendation, the SSAB proposed that DOE not use a "Finding of No Significant Impact" (FONSI) determination pursuant to the Vortec Environmental Assessment to proceed with the 30-day Vortec system demonstration, but instead develop an Environmental Impact Statement that will include cumulative impacts from other sources. No system is in place at this stage of the board's development to track the status of board recommendations and DOE responses.

\section{Leadership}

Key functions of leadership for the advisory boards include emphasizing values; searching for agreement; maintaining the balance between technical and policy orientations; setting a conducive atmosphere for work; and networking. The Paducah SSAB does not have the benefit of strong unifying leadership to perform these essential leadership functions, but has attempted to provide a balance of power between those who oppose and those who support (or defend) DOE, by having two co-chairs.

The board appointed co-chairs are drawn from the opponents and supporters of DOE in an effort to provide balance among different viewpoints. However, the polarization persists. One co-chair is an articulate advocate of positions that are opposed to DOE based on its past performance, particularly on issues of informing the public and issues of governance; the other co-chair supports DOE and in fact is employed by the M\&I contractor. The chairs do not work directly with each other to establish a consensual 
agenda and do not interact outside of board meetings. One of the co-chairs has raised conflict of interest concerns about the other's employment by the M\&I contractor. These have not been fully resolved.

The Paducah SSAB has no executive committee to help plan strategy or to mediate between the positions of the co-chairs. To date, no other formal leadership has emerged.

\section{Facilitation}

The board has the benefit of a professional facilitator who has been involved in the development of the SSAB from the beginning of the working group, although there is a perception among some board members that he is too close to DOE and too distant from the local community. The facilitator manages the meeting process well, keeping to schedule, and ensuring that all who wished to be heard have ample opportunity to do so. However, his attempts to expand his scope to play a mediator role, intervening outside of meetings to regulate the tone of email exchanges, was perceived among some members as exceeding his legitimate role. There appears to be no other person to fulfill the role of acting as broker on interpersonal issues or differing interpretations of technical and policy issues.

\section{Team Building}

The board has not engaged in any formal or organized team building activities such as consensus training or group retreats, and has not conducted a self-evaluation. Such techniques, especially when used in combination with self-evaluation, can help facilitate the process of reflecting critically on successes and problems, providing self-correction and redirection where needed, and promoting a sense of group identity and shared purpose. One interviewee commented that members' reported sense of isolation could be alleviated by attendance at other SSABs' meetings and discussion about processes used effectively elsewhere.

Opportunities for informal social interaction are limited by the short meeting time - since meetings are scheduled once a month in the evening, members do not have the opportunity for interaction that is available to members of boards where meetings are scheduled over a two-day period with an overnight stay. One member, however, observed that DOE should make a greater effort to provide refreshments to members, most of whom come to board meetings straight from work to contribute many hours of volunteer time.

Most interviewees reported that the board essentially functioned more like a focus group of concerned individuals and some commented on the limited communication among members outside of board meetings. In this sense, the board may be close to being a "stable operating system," but it is far from operating as an integrated team - one interviewee emphasized the need for members and board officers to engage in discussion of members' roles and responsibilities and clarification of board goals. Team building has not been enhanced by disputes between the co-chairs over conflict of interest concerns. 


\section{Administrative and Technical Support}

The board's administrative and technical support has been provided by M\&I contractor personnel. Some members see this support as questionable; in response, DOE has recently provided funding for the board to hire its own secretary and open its own office space in premises not under the control of DOE or an M\&I contractor.

There is no independent technical assistance presently available for the board. Members have discussed the possibility of hiring a technical consultant to provide independent peer review; however, no action has been taken, in part because of the difficulty of finding a suitable candidate. The board apparently has not discussed hiring a technical assistant to review technical documents, identify key issues, and prepare and distill information to help members get up to speed.

\section{Process Summary}

Observation of the meeting, combined with a review of the meeting minutes, indicate that the quality of discourse and the ability of the board to effectively advise DOE is constrained by several factors. Limited community experience with environmental activism or participatory political processes reduces the available pool of potential board members already possessing the skills necessary for the advisory board to operate effectively - these skills are having to be learned more or less from scratch. The majority of members has had no previous knowledge of $\mathrm{DOE}$ processes and procedures and is unfamiliar with the technical and policy issues related to the site. As a result, introduction and detailed discussion of issues related to a particular topic often are left primarily to one member who has more understanding of technical issues. Since this member is opposed to DOE, the focus of discussion is what DOE is doing wrong, rather than working collaboratively as a group.

There is little awareness among board members about how to translate objections to DOE actions (or inaction) into board recommendations to DOE. What is needed, and what is perhaps emerging, is leadership that is capable of combining the two perspectives represented on the board into a single agenda around which members can unite and on which they can focus. The appointment of issue managers to monitor and provide feedback to the board on key projects may help provide more balance in members' ability to contribute to board discussions. One interviewee also suggested that this process may be aided by the facilitator encouraging members to voice their views.

\section{Public Engagement}

\section{Outreach and Information Gathering}

All participants in the SSAB process, be they members, DOE staff, or M\&I contractor personnel, agreed that the Paducah SSAB had not yet reached the state of operational development that would enable it to engage in successful public outreach. DOE staff emphasized, however, that this would be essential for the board to be able to perform the 
role DOE envisaged for it. From DOE's perspective, a group composed of individuals who are not representative of and responsive to the public offers no substantial improvement over existing mechanisms for individual public comment. This view is not necessarily shared by DOE's opponents on the board, who tend to regard their role as more of a public watchdog or oversight committee at least as much as an advisory group seeking consensual solutions.

The extent of seeking input and reporting back to civic organizations appears to be limited. The board does not have an operational mailing list of interested individuals, a newsletter, website, or public comment line.

\section{Opportunities for Public Participation in Board Activities}

Although board meetings are open to the public, attendance by non-members is almost unheard of. There are no committee meetings in which the public can participate. Indeed, given the difficulties encountered in recruiting members to the board, public interest in participation may be minimal unless or until some kind of precipitating event occurs (such as the groundwater contamination issue in the 1980s).

\section{DOE and Regulator Engagement}

The environmental restoration program is the major concern of the DOE site office. DOE has continued to provide support for the board processes, while expressing the view (in common with board members) that the board is still in its formative stages and that its true value remains a potential to be fully realized. The site office has a limited number of staff, and participation in the SSAB represents a proportionately larger effort than at larger DOE sites.

\section{DOE Level of Participation}

DOE is represented at SSAB meetings by its most senior Paducah official as well as by its Communications Department, although, because of other responsibilities, the senior official cannot always attend meetings. He and his staff respond openly to questions and requests for information, while apparently taking care to keep relationships on an appropriately formal level. An issue for some members is that the Paducah site is administered by the Oak Ridge Operations Office and subject to an additional bureaucratic layer. They believe that the local office has limited influence on many of the key decisions related to budget and prioritization of projects.

\section{Empowerment by DOE}

DOE has attempted to balance the board's desire for independence with agency bureaucratic procedures and needs. In response to members' concerns about undue DOE influence, DOE has supported opening an office in separate premises and hiring a parttime secretary who is not an M\&I employee. 


\section{DOE Responsiveness}

At the time of the site visit, five sets of board recommendations had been issued (a sixth one has since been issued). DOE initially responded orally to recommendations but has since begun responding in writing. There is a feeling among some members that DOE is slow and not very explicit in responding to these substantive issues; this may be attributable, in part, to personnel changes at DOE. In addition to opening an office and hiring a secretary, DOE has shown responsiveness by making changes in DOE presentations, when some board members complained that DOE had previously overwhelmed the board with technical presentations, described by one member as "viewgraph culture," the number and scope of technical presentations were reduced.

\section{Role of the Regulators}

The regulators who usually participate in board meetings were not present during the observation of the board meeting in July. Therefore it was impossible to observe the level and type of interaction that usually occurs. Members gave mixed assessments of the regulators' role. Some observed that the State of Kentucky had strongly supported establishment of a SSAB and that the state regulator had contributed, through his criticism of the board, to the decision to appoint the issue managers.

\section{Issues and Observations}

\section{Issues Raised by Members Concerning the Paducah Gaseous Diffusion Plant SSAB}

- Although it has been in existence for two years, the board was frequently referred to as being "in the early days." Its real value was viewed as a potential one.

- Several persons interviewed expressed concern about the board being polarized.

- Several persons also highlighted a problem of lack of trust in DOE that prevents the board from moving forward.

- Some of the board members expressed strong concern about an appearance of conflict of interest.

- Uneven attendance by some members causes problems in continuity.

- Several members expressed a sense of isolation and concern that decisions about Paducah are made by the Oak Ridge Operations Office. 


\section{Researchers' Assessment of Primary Accomplishments and Challenges Facing the Paducah Gaseous Diffusion Plant SSAB}

\section{Accomplishments}

- The board provides a useful mechanism for citizen input and information that was not previously available. It may also be viewed as a prototype for community dialogue, providing indirect benefit to the community as well as to DOE.

- There is strong DOE support for the board processes.

- Board meetings are well run by a professional facilitator who helps keep the board moving forward.

- The appointment of issue managers provides an opportunity to balance members' knowledge levels and contributions, as well as providing more focus on issues.

\section{Challenges}

- Several contextual factors pose a particular challenge for the Paducah board. In particular:

- the absence of strongly salient issues results in difficulty in recruiting and maintaining a high level of interest as well as obtaining feedback from the community

- the community has very limited experience in public involvement, particularly in collaborative problem-solving approaches that provide a foundation for the SSAB

- there is limited prior knowledge of DOE issues and government procedures.

- There is limited awareness among members about how to leverage the board's legitimacy with DOE to affect DOE policy and procedures.

- Lack of leadership to unify competing agendas is a serious constraint.

- The facilitator lacks legitimacy to fill the leadership gap. 
PNNL-12139

An Evaluation of the Effectiveness of Local SiteSpecific Advisory Boards for U.S. Department of Energy Environmental Restoration Programs:

Pantex Plant Citizens' Advisory Board

Judith A. Bradbury

Kristi M. Branch

Pacific Northwest National Laboratory

February 1999 


\section{Pantex Plant Citizens' AdVisory BoARd}

\section{Table of Contents}

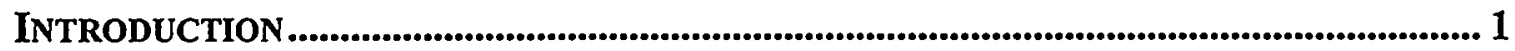

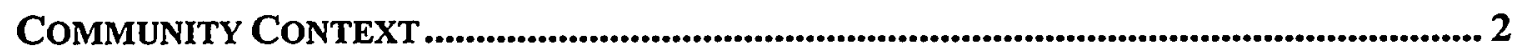

BOARD COMPOSITION ................................................................................................................ 3

PuRPose, GoAls, ANd Commitment to Consensus...................................................... 5

INTERNAL PROCESS AND FUNCTIONS ....................................................................... 5

Agenda Building and Issues Management.................................................... 6

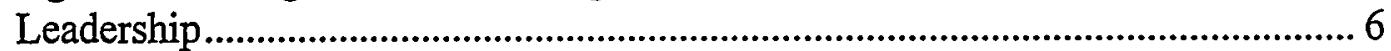

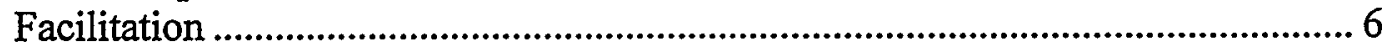

Team Building ................................................................................................ 7

Administrative and Technical Support ......................................................... 8

Process Summary ............................................................................................... 8

Public Engagement ................................................................................................... 9

Outreach and Information Gathering ............................................................ 9

Opportunities for Public Participation in Board Activities................................... 9

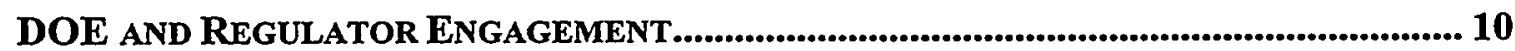

DOE Level of Participation .......................................................................... 10

Empowerment by DOE.................................................................................. 10

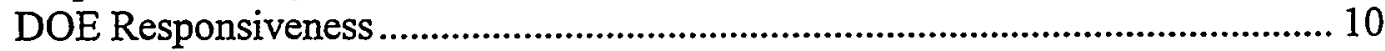

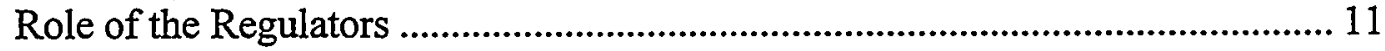

ISSUES AND OBSERVATIONS ......................................................................................... 12

Issues Raised by Members Concerning the Pantex Plant CAB ........................... 12

Researchers' Assessment of Primary Accomplishments and Challenges Facing the

Pantex Plant $\mathrm{CAB}$.................................................................................. 12 


\section{Pantex Plant Citizens' Advisory BoARd}

\section{Introduction}

This report details the results from the Pantex portion of a U.S. Department of Energy (DOE) study that was initiated to understand factors contributing to the effectiveness of the DOE local Site-Specific Advisory Boards (SSABs) and to provide information useful for the boards and DOE in their continuing efforts at improvement. The Overview report that accompanies the individual site reports discusses findings across nine DOE sites and provides background on the goals, methodology, and rationale for the framework used in the study. It also serves as a template for the findings presented in this site report.

The report for Pantex Plant Citizens' Advisory Board (CAB) is thus structured according to the six factors that were found to be important in assessing local SSAB effectiveness. As emphasized in the Overview, the study was designed to assist DOE and the boards in assessing how well the boards were fulfilling DOE's basic purpose in establishing the boards, and to provide information that would be useful to DOE and the boards in achieving this purpose. Specifically, DOE established the boards to obtain independent, consensus, policy advice and recommendations that drew on the range of local and regional stakeholder perspectives. The underlying rationale was that advice that reflected agreement among very different viewpoints would also be more likely to be acceptable to nearby communities and thus would provide a firm basis for developing policies that were not only technically sound but also could be implemented. Accordingly, the focus of the study was on board processes that enhanced the boards' ability to provide independent, broadly based policy advice, rather than on the recommendations per se.

This report describes the Pantex Plant $C A B$ as it was operating at the time of the researchers' visit in May 1998. The description is provided in terms of the six factors found to contribute to board effectiveness (community context; board composition; purpose, goals, and commitment to consensus; internal processes and functions; public engagement; and DOE and regulator engagement). It begins by highlighting key features of the site context that pose particular challenges facing the $C A B$. The two subsequent sections discuss the board's composition, including diversity of viewpoints represented on the board, and the board's sense of purpose, goals, and commitment to consensus. The next section examines the board's internal processes and functions, including how board members accomplish agenda building, issues management, and team building; how facilitation, brokering, and leadership roles are taken and performed; and how administrative and technical support is provided. The following section, on public engagement, details the board's effectiveness in providing opportunities for public participation and in outreach and information gathering. The next section discusses the relationship between the board and DOE, and between the board and site regulators. The final section lists important issues that members mentioned and provides the researchers' assessment of the accomplishments and challenges facing the $\mathrm{CAB}$. 
As emphasized in the Overview, the purpose of this study is to provide an outsider's perspective, based on a review of boards across the complex, and to encourage the boards to reflect on their own strengths and weaknesses and learn from one another's accomplishments and challenges.

\section{Community Context}

The Pantex Plant site is located approximately 17 miles northeast of Amarillo, Texas, in the heart of the Texas Panhandle. The 16,000-acre site in Carson County is located above the Ogallala aquifer. Amarillo is the home of several large industries (Levi Strauss, Affiliated Foods, ASARCO, St. Anthony's Health Systems, Burlington Northern Santa Fe RR, Corporate Systems Ltd., IBP, Owens Corning, and Southwest Public Service), a university (West Texas A\&M) and a community college (Amarillo); the surrounding area is primarily ranchland. Amarillo is a small city of approximately 171,000 (metropolitan area: approximately 215,000 ) population. The city has a substantial Hispanic (14\%) and black (5\%) population. The area is known for its conservatism and pro-business orientation. Median household income in 1989 was $\$ 25,425$.

Several aspects of the Pantex Plant and mission create a challenging context for the development of a SSAB. Pantex is a DOE Defense Program (DP) site, actively involved with nuclear weapons. In the past, the site assembled nuclear weapons and fabricated chemical explosives for nuclear weapons in addition to its ongoing mission of nuclear weapons disassembly; demilitarization; sanitation of weapon components from dismantlement activities; and the interim storage of plutonium components from retired weapons. DOE, Mason \& Hanger (the managing and operating contractor), and the community's business leadership are aggressively seeking new defense missions for the plant. Because of its DP mission, much of the plant's activity remains classified. This status makes many in the surrounding highly patriotic communities uneasy about pushing too hard about site-related issues. The plant's environmental management program is small, compared to the DP program (\$20 million compared to $\$ 275$ million in 1997) and has a relatively low profile.

Though more open than previously, when many of the area residents did not know what was being done at the site, Pantex is not nearly as open to the public as the DOE Environmental Management (EM) sites are. In addition, Pantex reports to the Albuquerque Operations Office of DOE, which introduces an additional set of decision makers who are not residents of the local area. Prior civic activity related to the site has focused on opposition to its nuclear weapons activities. This opposition involved a national and international network, some of whose participants moved to the local area specifically to further the anti-nuclear or peace cause. Diverse viewpoints are not well represented in the public discourse of the community.

Although the area has a substantial number of business, cultural, and philanthropic civic organizations, and does have League of Women Voters (LWV) and NAACP chapters, there is limited tolerance for activism. This increases the difficulty of recruiting members 
who are able and willing to represent diverse views, particularly those critical of DOE. This has placed a heavy burden on the relatively small number of organizations representing environmental, ethnic, and governance interests relative to the Pantex Plant.

Although the Pantex Plant has been directly involved in weapons production, it has never been involved in plutonium production or chemical processing. This has limited both the extent and severity of the environmental problems at the site, though its continued work with nuclear weapons components creates continuing concern about environmental and public safety and health. The site has a burning ground where explosives, explosive components, and explosive-contaminated materials and waste are disposed through controlled open burning. Community concerns focus on potential contamination of wells and groundwater, airborne contamination and monitoring, and safe operations, handling, storage, and shipment of the nuclear materials (including worker protection).

In 1990, DOE entered into an Agreement in Principle with the State of Texas. The Agreement focuses on waste management, emergency response, and environmental monitoring and restoration. The agreement involves four state agencies and four county governments. In 1994, the EPA determined that the Pantex Plant was a Superfund site and added Pantex to the National Priorities List. The Texas Natural Resource Conservation Commission (TNRCC) has RCRA regulatory oversight responsibility for Pantex Environmental Restoration activities.

The Pantex Plant has high, and increasing local and national salience. It is the area's largest employer (about 3,600), and is playing a singular and important role in the national weapons program. It has been the focus of anti-nuclear, peace protests for many years, gaining national visibility as the origin of the "white trains" carrying nuclear warheads assembled at the site. The environmental and good governance organizations actively involved in Pantex issues at the local level over the past decade include the Peace Farm, STAND, and STAR.

The economic impact of DOE activities on the local economy is exaggerated by the size and geographic isolation of the local economic base. Potential adverse impacts on the local economy from cutbacks at the site have high local salience and evoke a strong proDOE response from local business and political leaders. This creates tension with environmental and peace groups, who are concerned that economic interests may prevent the community from protecting its environmental, safety, and health interests.

The $\mathrm{CAB}$ is the only DOE-related community-based advisory body active in the local area.

\section{Board Composition}

The $\mathrm{CAB}$, was formed in response to stakeholder requests and with the direct intervention by the Secretary of DOE (Hazel O'Leary). In 1993, when public meetings sponsored by the Office of the Governor, DOE, and EPA were held to explore community interest and support for a citizens' advisory board to address Pantex issues, 
well over 100 residents participated from Amarillo - a very strong community demonstration of interest. The Keystone Committee worked with the community and DOE in 16 public meetings over a nine month period to determine the stakeholder categories, ex-officio non-voting members, and purview of the board. The first board meeting was held on May 10, 1994. Although chartered in May 1994 under the SSAB scope, the CAB's scope was expanded to include all past, present, and future Pantex Plant operations.

Recently, board membership has fluctuated between 14 and 17. In early 1998, the board had 15 members and seven ex-officio members. The ex-officio members represent DOE, EPA, and several state agencies (Texas Natural Resources Conservation Commission, The Texas Department of Health/Bureau of Radiation Control, the Governor's Office, and the State Attorney General's Office). The original membership of the board was 20, with nine ex-officio representatives. The board does not have representatives from local government, and the by-laws explicitly prohibit members from serving as formal representatives of an organization. Although the board has experienced some difficulty with recruitment and retention, it has succeeded in recruiting new candidates and was in the process of reviewing and voting on new members at the time of the study. The membership subcommittee oversees the process of recruiting new candidates, which is governed by careful attention to selection criteria. Candidates are interviewed by the board, recommended to the Designated Federal Official (DFO) by the board, and, following DFO review and comment, finally selected through a two-vote process of the board. Consensus is required for selection of new members. There have been instances where the caucuses have acted to block acceptance of proposed members.

The board has succeeded in maintaining participation by strong representatives of both the local business community and the environmental/peace activist organizations. Board members are.organized into caucuses, commonly referred to as the "boosters" and the "critics," which play an important role in board activities and informal processes. Recently, after extensive discussion, the board has included a number of "neutral" members. The board uses a system of co-chairs, selected to balance viewpoints, which means that one co-chair has been from each caucus over the history of the board. Recruitment is a mix of the individual and organizational approaches, although members serve as individuals rather than as representatives of an organization. Members are selected from various categories, which are carefully observed. Attention is paid to gender balance and representation from the black and Hispanic population, and from residents proximate to the site. Members include representatives from the Amarillo economic development corporation, union site workers, site neighbors, area residents, and activist groups.

The board is noteworthy for its success in maintaining the participation of minority viewpoints, the role of caucuses, and for its adherence to a consensus process that was designed specifically to prevent marginalization of minority viewpoints. However, members note that the polarization of the board, as represented by the two caucuses, is a barrier to productive work. The board's inability to identify topics of shared interest and importance is a basis of continuing frustration that has not been successfully addressed. 
Members attributed this situation to different causes. Some members expressed hope that the recent addition of a "neutral" category will help provide a bridge between the two opposing caucuses, although some expressed concern that the conservatism of the local community might prevent public expression of diverse viewpoints. Others expressed concern that the addition of neutral members would gradually marginalize minority viewpoints. The new facilitation team is working with the co-chairs and the board on these issues.

\section{Purpose, Goals, and Commitment to Consensus}

The scope, agenda, and purpose of the board have been topics of great focus and debate since the original convening meetings. Although the board's charter makes an explicit commitment to a consensus process, which the board follows in making decisions of all types, disagreements over priorities and purpose have not been resolved, and the $\mathrm{CAB}$ has struggled to identify areas where it can work together to address shared issues and identify areas of common agreement. The inability to resolve the issues of focus and priority has created a sense of frustration among board members, who recognize that they have achieved only a limited ability to work together to address shared concerns and provide clear advice to DOE or the other ex-officio members.

The $\mathrm{CAB}$ has revisited its by-laws and procedures several times, and spends a considerable amount of time on process issues. The fundamental structure of the board, which is designed to provide balance between the two caucuses, is challenged by the probusiness caucus on the grounds that it is proportionately unrepresentative of the viewpoints of the community. The feasibility, and hence the value, of a board where "tough" discussions among members with diverse and divergent viewpoints lead to the identification or creation of areas of common agreement was not clear for many members, who therefore do not understand the purpose and benefits of strong representation of the diverse viewpoints. Indeed, attempting to forge areas of common agreement from among diverse viewpoints has not become an organizing principle for the board, and the importance of processes to prevent the marginalization of viewpoints is continually challenged. Despite these difficulties, the board has maintained a balance and an adherence to the consensus process that has kept both sides in the discussion. The interviews indicated that some members feel that reflection on the process and consequence of polarization is providing insight that may allow more constructive engagement in the future.

\section{Internal Process and Functions}

A number of functions must be fulfilled for a group of people to work together effectively, particularly when they are convened to represent different perspectives. These include agenda-building and issues management processes that emphasize searching for common areas of agreement among diverse views; leadership, particularly by the chair(s) and executive committee; facilitation, both for meeting planning and implementation and for brokering technical and interpersonal issues; team building processes, which may be formal or informal; and administrative and technical support, 
including technical assistance to facilitate participation by non-technical members and reduce members' workload. 


\section{Agenda Building and Issues Management}

The development of an agenda that meets the priorities of the members and focuses the work of the board makes an essential contribution to the board's effectiveness. The $C A B$ 's agenda is set by the co-chairs, who work with the facilitators to arrange the process of assigning issues to subcommittees and task forces. The board solicits expressions of issues, upcoming decisions/activities, and needs from DOE and the other ex-officio members as input to an annual process for developing a work plan. All members work as a whole board to prioritize issues and areas of focus, which are then grouped into categories. The co-chairs then assign these categories of issues to task forces, creating new task forces if necessary. The task forces then determine how the issues will be addressed and suggest a schedule, bringing this information back to the board. This information is then organized into an annual work plan.

Task forces and subcommittees select their own chairs, who then work with the co-chairs and facilitators to structure presentations and board meetings. Participation in task forces and some subcommittees is open to members of the board and to the public, although the chairs must be board members. As new issues emerge over the year, the work of the subcommittees and task forces is modified based on board meetings and discussions with the co-chairs. Focus is maintained by reference to the agreed-upon work plan and board discussions, with recognition of the need to balance the interests of the opposing caucuses. The facilitators help with this process. Issues are worked at the subcommittee and task force level, which then bring recommendations to the whole board. If agreement cannot be reached, the issue is referred back to the subcommittee or task force for further work, sometimes more than once.

\section{Leadership}

Key functions of leadership for the advisory boards include emphasizing values; searching for agreement; maintaining the balance between technical and policy orientations; setting a conducive atmosphere for work; and networking. Situations in which co-chairs are required to provide a balance of power between opposing factions make it very difficult for such leadership to emerge. Historically, much of the energy of the co-chairs has been focused on managing the tensions between the two caucuses. However, the new chair-co-chair combination is reported to be working well, and there is hope that this will enable the board to be more effective in both its own and the community's eyes. Subcommittee and task force chairs organize and lead efforts to articulate and analyze issues and bring proposed recommendations before the board. The $\mathrm{CAB}$ does not have a formal executive board, although communication among the cochairs and the subcommittee and task forces chairs is frequent.

\section{Facilitation}

The board has always had professional facilitation support, considered essential to help the board manage the tensions between the caucuses. Responding to a perceived problem with the facilitation, but without consulting the board, in late $1996 \mathrm{DOE}$ took the 
unilateral action of changing the facilitation team, explaining to the board that it felt it was DOE's responsibility to ensure effective facilitation for the board. Controversy over this action consumed much of the energy of the board for several months, and created a significant challenge for the new facilitation team, who are faculty at the local university. The board agreed to accept the new facilitation team on a trial basis, conducting an evaluation of the facilitators at the end of every meeting. The facilitation team has been working with the board, especially the co-chairs and chairs of the subcommittees and task forces, to develop the agenda and structure for the board meetings and move forward. The observed meeting was facilitated in an effective partnership between the facilitator and co-chairs. The facilitator played an active role, reminded members of the importance of politeness, and took the initiative to summarize the discussion, identifying potential areas of agreement that the board could consider. The meeting ran to schedule.

The new facilitation team's role with the $C A B$ is evolving, but includes assistance with agenda setting, meeting structure and process, and advice to board and subcommittee/task force chairs. It is too soon to tell what role the facilitation team will be able to play in supporting informal communications among board members and with DOE and the other ex-officio members. At this time it is also too soon to tell whether the facilitators will be able to work effectively across the caucuses to mediate among board members on interpersonal issues and between the board and DOE on interpretations of technical and policy issues.

\section{Team Building}

Despite the extensive work during the convening period, $\mathrm{CAB}$ members generally expressed little sense of the board as a team. Members' affiliation was oriented toward their caucus rather than the whole board. Members in the neutral category expressed a sense of isolation, since they were not included as members of either of the two caucuses. The board has not succeeded in developing informal positive relationships between members in the two caucuses and has structured few opportunities for social interaction outside of board meetings. The board conducted a day-long informal retreat in 1995 to address organizational issues and focus on interactions among board members, and it held an orientation and training session on consensus in 1996. A recent field trip to Los Alamos, several members noted, provided some positive opportunities for informal interactions, though not enough to overcome the longstanding tension that has built up between some members. The issue over the change in the facilitation and fiscal management team (see below) hampered the facilitation team's ability to assist effectively with team-building activities, but this issue seems to have been moderated over time, enabling the facilitation team to provide more assistance to the board and to plan some team-building activities.

Despite considerable initial discussion about consensus decision-making and subsequent training, current board members indicated that they do not share a common understanding of or commitment to the consensus process. Although task forces and subcommittees sometimes poll the members to determine their viewpoints, the board does not regularly conduct a self-evaluation. The facilitators have provided feedback and observations to the board on several occasions, and DOE has periodically discussed the 
board's purpose and focus with them. New members receive an orientation packet from 
the office manager, with assistance offered by the co-chairs, facilitators, and office manager to help them become familiar with the issues and the procedures of the board.

\section{Administrative and Technical Support}

As part of the change in facilitation support, DOE also changed fiscal management for the board to the local university, which now tracks the board's budget and provides information to the board. The board has a full-time staff person who manages the $C A B$ office, which is located in downtown Amarillo. In addition, Mason \& Hanger provides a person to support the board and its activities. In the early days of the board, EPA also provided a resource person to the board. Discussions indicate that the board places considerable importance on its authority to control the hiring of support and technical staff. Typical administrative and technical support activities include staffing the $C A B$ office, performing day to-day administrative tasks, overseeing meeting logistics, keeping the board's records, and coordinating the various board functions. The records of the board are in good order, and are kept at the board's office in downtown Amarillo. The board does not have anyone assigned specifically to provide technical assistance, though it does have budget and scope to acquire independent technical consultants. For example, at the observed meeting, the board had arranged a presentation by the consultants who had reviewed the Rocky Flats monitoring program.

In addition to the controversy about facilitation and fiscal management support, there has also been a longstanding disagreement about the recording of board meetings: video, audio, or only notes. Currently, the meetings are not recorded on video or audio tape. The board members interviewed generally were withholding judgment about the new support staff, though several noted the adverse impact on the board of the controversy associated with the termination of the previous support staff.

\section{Process Summary}

Because the $\mathrm{CAB}$ has succeeded in retaining representation of the strongest community voices regarding Pantex, it has the potential to provide consensus advice that identifies common concerns, captures areas of agreement, and reaches out to all aspects of the community. Given the differences in perspective represented on the board, this would be a significant achievement and could result in powerful advice. Observation of the meeting, combined with a review of the meeting minutes, indicate that the board has not yet been able to focus on finding this common ground, with the result that board members report frustration with their meetings and discussions. Disagreements about agenda, focus, and purpose, which have been reflected in arguments about details, has prevented the board from really digging into issues of interest to individual board members, and has limited the board's ability to provide consensus advice on substantive issues. It should be noted, however, that the board has provided consensus advice to both DOE and the TNRCC.

Board meetings are held once a month (except December) for approximately four hours. The board experimented with meeting at different times of the day to allow the public to attend, but adopted a mid-day time because of low public attendance. The observed 
meeting proceeded smoothly, with active participation by most members. Non-technical staff participated fully in the discussions, which integrated technical and value-related considerations. Interactions were civil and respectful, though somewhat formal, with a reminder given about politeness, when needed. Effective facilitation encouraged adherence to the agenda and moving past points of disagreement. A round-robin of updates from DOE and the other ex-officio members did not reflect an ongoing effort to frame issues and problems in a way that would help the board develop a focused and impactful agenda.

\section{Public Engagement}

Members' discussions indicated that engagement of the public is not currently a top priority of the board, in part because they are still struggling with internal relationship building and communication issues. However, the board did commission a survey of community values, completed in 1996. Also in 1996, the board prepared a fact sheet on a site-related EIS for distribution to the public, and board members staffed a booth at the Pantex Community Information Fair. The board does not publish a newsletter or an annual report.

Although the board has not collected any specific data on board visibility, several members commented that they did not believe many community residents knew about the board. Despite the fact that the board was initiated in response to stakeholder requests and the community expressed a high degree of interest at the initial meetings, board meetings have not been well attended by the public. Board members viewed this with mixed feelings; they did believe that the board should serve as a forum for information exchange with the public, but many did not feel that the board had been functioning well enough to fulfill this role effectively.

\section{Outreach and Information Gathering}

The board has a public outreach subcommittee, and there has been some discussion about how the board should be encouraging information exchange with the public. However, few of the proposed activities have taken place. Ongoing outreach primarily occurs through individual board members' efforts to discuss board activities and issues with their acquaintances and organizations. Some members have organizations to which they regularly report; others discuss board activities with a more informal network of acquaintances. The board has also demonstrated its willingness to contract for studies to gather information about community attitudes and knowledge.

\section{Opportunities for Public Participation in Board Activities}

The $\mathrm{CAB}$ meetings are structured to allow public input as topics of interest to the public are raised. In the observed meeting, a member of the public played a key role in raising questions relative to the agenda topic and providing technical information to the board. Information pertinent to the discussion and meeting was readily available to non-board attendees. However, directions to the meeting and signs identifying the location were not posted for newcomers. Meetings allowed for comment both during specific comment 
periods and during discussions.

Task forces and some subcommittee meetings (which were not observed) are open to the public, both for observation/comment and more active participation as a member of the working group. The board meetings are advertised in the local newspaper (as well as the Federal Register) and both board and committee meetings are advertised through a mailing list and the caucus's network.

\section{DOE and Regulator Engagement}

The board's by-laws indicate that the board's principal focus is to provide informed advice to DOE but that it may also advise the other ex-officio members. The board has provided advice to the TNRCC, and received responses from the TNRCC.

\section{DOE Level of Participation}

Although the $\mathrm{DOE}$ site manager originally attended the $\mathrm{CAB}$ meetings, this was no longer the case at the time of the study. However, DOE representatives publicly express strong support for the value of the board and fulfill their responsibility to have a representative attend board meetings, though the individual serving this function has varied over time. DOE and Mason \& Hanger arrange for regular presentations to be made to the board on a variety of topics in which the board has expressed interest - for example, occurrence and monitoring reports - and have agreed to a scope for the board that extends beyond environmental management. Board members have access to DOE contacts, and DOE and its contractors have made themselves available to make presentations to the board on a variety of topics. Board members reported no difficulty arranging $\mathrm{DOE} /$ contractor presentations.

\section{Empowerment by DOE}

Board independence, an important issue for some members of the board, lies behind some of the careful procedures established to guide board operations and member selection processes. However, board members have not hesitated to call upon DOE to intervene on issues concerning process. Staff at the DOE Amarillo Area Office have not hesitated to take action in response to these requests when they observe problems that are affecting the effectiveness of the board (e.g., replacement of the facilitator), even when they know that their actions will cause controversy. These actions indicate that DOE does take responsibility for the effectiveness of the board. On the other hand DOE staff do not appear to structure their interactions with the board to frame issues in a way that makes clear how board advice could help DOE make decisions about important issues. Board members and DOE representatives agree that DOE is prepared to provide support to the board when it is needed.

\section{DOE Responsiveness}

The board's relationship to DOE is ambivalent. The fact that the board was created as a result of citizen initiative and Hazel O'Leary's intervention was mentioned by a number 
of members, though with opposing interpretations. Some board members believed that the board did not (and perhaps should not) have a privileged relationship to DOE in terms of access to information and acceptance of advice, noting that DOE regularly briefs and consults with local governmental officials. Others commented that DOE did not bring issues early, clearly, and comprehensively to the board. Still others commented that the board's relationship with DOE was improving and that they were making progress on agreeing to roles that were mutually acceptable and obtaining the support they needed.

Some board members expressed frustration at the difficulty of obtaining clear and responsive information from DOE and the regulators. This may, in part be due to DOE's policy to treat any request for information that requires them to assemble data as a Freedom of Information Act (FOIA) request, requiring the board to submit a formal FOIA request, unless DOE determines that the data would be valuable to itself. This obviously slows down the information exchange process and affects the board's perception of DOE responsiveness.

Board recommendations to DOE are sent as letters. Neither DOE nor the board maintains a tracking system for board recommendations or information requests and responses. However, the board records show that $\mathrm{DOE}$ does provide written responses. Review of the record indicates that some responses have been received several months following DOE's receipt of a recommendation, though the number of recommendations has been sufficiently few that generalizations about response time can not be reliably made.

\section{Role of the Regulators}

The CAB has a greater variety of ex-officio members than any other SSAB. All of the ex-officio members except the TNRCC representative are located outside the region, either in Austin or Dallas, which means that considerable effort is required for them to attend board meetings. The board is authorized to, and does, provide advice to the state regulators, particularly TNRCC. Board discussion indicated that instability within the state regulatory agencies has affected their ability to participate consistently and to represent agency positions clearly, particularly the TNRCC.

Board discussions and interviews indicated that the regulators have specifically requested board advice and comment on issues, for example the continuance of air monitoring. There is widespread agreement that the board and the regulators have had difficulty developing a mutually satisfactory exchange of information and input. The board has had difficulty reaching consensus in time to provided input within the decision schedule of the regulators. The board has also had difficulty formulating clear and strong information requests and for holding the regulators accountable for providing the desired information. Review of board meeting minutes and interviews indicate that some questions have been raised repeatedly over many months without a clear response by the agencies. The board does not seem to have an effective mechanism to address these problems, which are a source of frustration for both board members and regulators. 


\section{Issues and Observations}

\section{Issues Raised by Members Concerning the Pantex Plant CAB}

- Fundamental disagreements and polarization of the board create frustrating stalemates and limit the effectiveness of the board.

- Site-related issues are not presented early, clearly, and comprehensively by DOE or the ex-officio members, and the board has not coalesced on a shared agenda.

- Recruiting, seating, and maintaining members has been difficult and frustrating.

- The pro-business caucus (boosters) does not value the board or the viewpoint of the "critics."

- The critics' caucus has not been able or willing to attend to a focused set of issues.

- For all these reasons, the board has difficulty taking action in a timely way, and providing recommendations or comments within the decision time frame.

\section{Researchers' Assessment of Primary Accomplishments and Challenges Facing the Pantex Plant $C A B$}

\section{Accomplishments}

- The community has fulfilled its desire to establish a SSAB, and has succeeded in obtaining support for a SSAB from a DP site.

- The board successfully negotiated a charter and scope that was adapted to the issues and characteristics of the site and its ongoing activities.

- The board has succeeded in maintaining participation by strong representatives of both the local business community and the environmental/peace activist organizations and has succeeded in recruiting replacement members.

- The board has survived several transitions in leadership, both within the board, from DOE, and with their support/facilitation staff.

- Expert and strong facilitation is essential, given the polarization of the board. This need has been recognized by both the board and DOE and the board has had access to professional facilitators.

\section{Challenges}

- Board members have had a hard time successfully framing issues to obtain the information and response they are seeking from $\mathrm{DOE}$ and the ex-officio members. They do not appear to have mechanisms to identify these situations and raise them 
to $\mathrm{DOE} /$ the ex-officios as a board. Rather they remain as requests by individual members.

- The board has not succeeded in gaining widespread commitment among its members to a search for areas of agreement, thus leading to a persistent sense of conflict and lack of shared purpose that adversely affects both formal and informal interactions.

- The mechanisms to protect against marginalization of the minority viewpoints that the board has instituted are important, given the characteristics of the community. However, unless a strong majority of board members understand and accept the value and legitimacy of having these viewpoints represented, it will be difficult for the board to develop the sense of shared purpose that is a prerequisite for constructive dialogue.

- The board faces a challenge in maintaining the participation of its members. It is important for DOE and ex-officio members to continue emphasizing the value the board can bring to their decisions and encouraging board members to focus on seeking areas of agreement regarding issues important to upcoming decisions. 
PNNL-12139

An Evaluation of the Effectiveness of Local SiteSpecific Advisory Boards for U.S. Department of Energy Environmental Restoration Programs:

Rocky Flats Citizens Advisory Board

Judith A. Bradbury

Kristi M. Branch

Pacific Northwest National Laboratory

February 1999 


\section{ROCKY FLATS CITIZENS ADVISORY BOARD}

\section{Table of Contents}

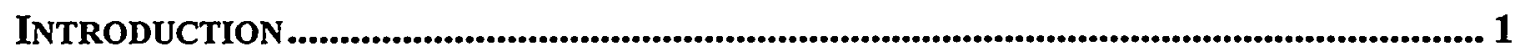

CoMmUNITY CONTEXT ............................................................................................................... 2

BOARD COMPOSITION ..................................................................................................................... 3

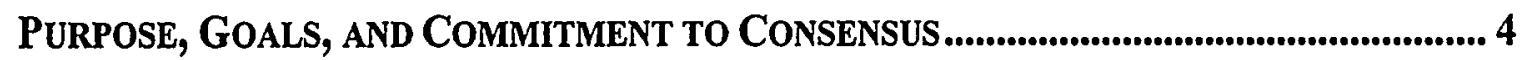

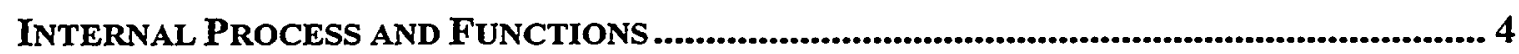

Agenda Building and Issues Management........................................................ 5

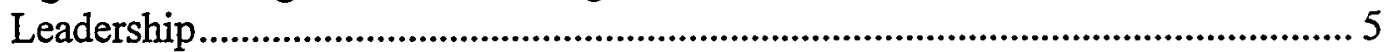

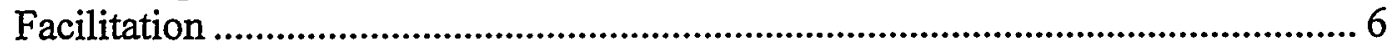

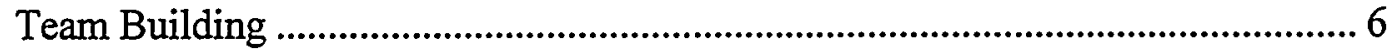

Administrative and Technical Support ........................................................ 6

Process Summary .............................................................................................. 7

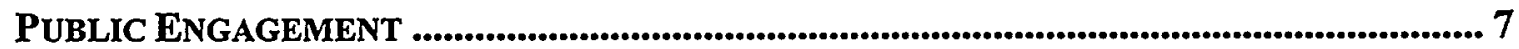

Outreach and Information Gathering ........................................................ 7

Opportunities for Public Participation in Board Activities................................. 8

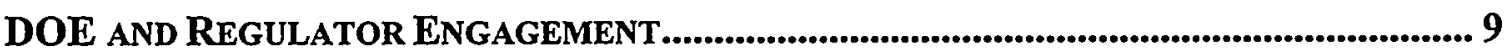

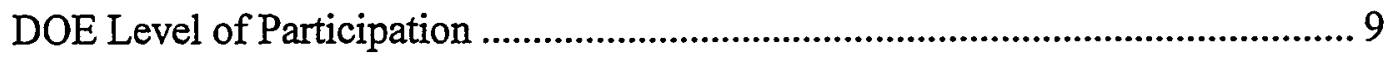

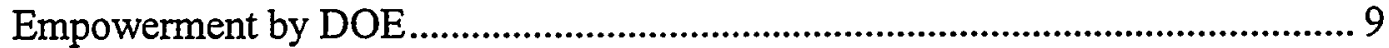

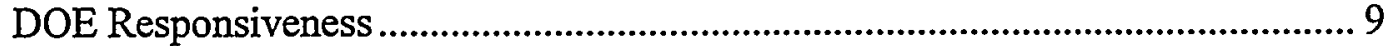

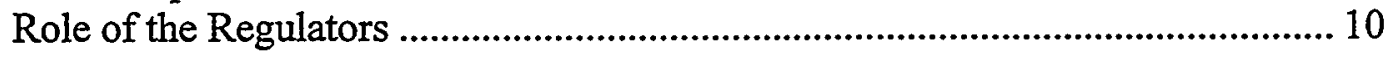

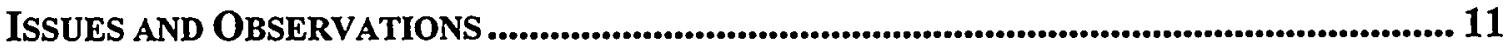

Issues Raised by Members Concerning the Rocky Flats CAB ............................ 11

Researchers' Assessment of Primary Accomplishments and Challenges

Facing the Rocky Flats $\mathrm{CAB}$............................................................. 11 


\section{ROCKY FLATS CITIZENS ADVISORY BOARD}

\section{Introduction}

This report details the results from the Rocky Flats portion of a U.S. Department of Energy (DOE) study that was initiated to understand factors contributing to the effectiveness of the DOE local Site-Specific Advisory Boards (SSABs) and to provide information useful for the boards and DOE in their continuing efforts at improvement. The Overview report that accompanies the individual site reports discusses findings across nine DOE sites and provides background on the goals, methodology, and rationale for the framework used in the study. It also serves as a template for the findings presented in this site report.

The report for the Rocky Flats Citizens Advisory Board (CAB) is thus structured according to the six factors that were found to be important in assessing local SSAB effectiveness. As emphasized in the Overview, the study was designed to assist DOE and the boards in assessing how well the boards were fulfilling DOE's basic purpose in establishing the boards, and to provide information that would be useful to DOE and the boards in achieving this purpose. Specifically, DOE established the boards to obtain independent, consensus, policy advice and recommendations that drew on the range of local and regional stakeholder perspectives. The underlying rationale was that advice that reflected agreement among very different viewpoints would also be more likely to be acceptable to nearby communities and thus would provide a firm basis for developing policies that were not only technically sound but also could be implemented. Accordingly, the focus of the study was on board processes that enhanced the boards' ability to provide independent, broadly based policy advice, rather than on the recommendations per se.

This report describes the Rocky Flats $\mathrm{CAB}$ as it was operating at the time of the researchers' visit in August 1998. The description is provided in terms of the six factors found to contribute to board effectiveness (community context; board composition; purpose, goals, and commitment to consensus; internal processes and functions; public engagement; and DOE and regulator engagement). It begins by highlighting key features of the site context that pose particular challenges facing the $\mathrm{CAB}$. The two subsequent sections discuss the board's composition, including diversity of viewpoints represented on the board, and the board's sense of purpose, goals, and commitment to consensus. The next section examines the board's internal processes and functions, including how board members accomplish agenda building, issues management, and team building; how facilitation, brokering, and leadership roles are taken and performed; and how administrative and technical support is provided. The following section, on public engagement, details the board's effectiveness in providing opportunities for public participation and in outreach and information gathering. The next section discusses the relationship between the board and DOE, and between the board and site regulators. The 
final section lists important issues that members mentioned and provides the researchers' assessment of the accomplishments and challenges facing the $\mathrm{CAB}$.

As emphasized in the Overview, the purpose of this study is to provide an outsider's perspective, based on a review of boards across the complex, and to encourage the boards to reflect on their own strengths and weaknesses and learn from one another's accomplishments and challenges.

\section{Community Context}

Officially known as the Rocky Flats Environmental Technology Site, Rocky Flats is located approximately 16 miles northwest of Denver, Colorado (1990 population: $467,610)$ and about 12 miles north of Boulder City (1990 population: 83,312). The site is a 350-acre industrial area, surrounded by a buffer zone of 6,100 acres. Area growth has resulted in the spread of suburban development toward the site. There are seven contiguous local governments. Although the nearby metropolitan area is demographically diverse, population in these nearby jurisdictions is primarily white.

Several aspects of the Rocky Flats site and mission provide a favorable context for the development of a SSAB: scope and agenda are focused on cleanup and closure; the issues are salient, with key dimensions already articulated; prior civic activity, including DOE-related activity, has laid a foundation for public involvement; and there is sufficient diversity and organizational activity to provide a broad base for recruitment of members with diverse views.

Currently, the sole mission of the site is cleanup, waste management, decommissioning, and closure. Weapons component production - Rocky Flats' former mission - ceased in 1989. The site was designated as an Accelerated Closure Site in 1997. Under this pilot program, the site receives its funds from a special account and cleanup is scheduled for completion in the 2006 to 2010 time frame.

When weapons component production ended, the site retained a large inventory of plutonium and highly enriched uranium in a variety of forms, some of which pose high risks and are not suitable for extended storage. Work is well advanced on treating plutonium solutions; uranium solutions have been shipped off-site. Other key tasks to be undertaken that pose a threat to the environment include plutonium soils cleanup; groundwater containment; and the decontamination, decommissioning, and demolition of over 100 buildings associated with former production activities.

Site activities have high local, regional, and national salience (i.e., central importance). Rocky Flats gained national prominence in 1989 when an FBI raid occurred. This event and subsequent disclosures about the extent of contamination problems served as a wakeup call for neighboring jurisdictions and their inhabitants. Regional chapters of environmental organizations that have been actively involved in Rocky Flats issues over the past decade include the Sierra Club, Greenpeace, and Physicians for Social 
Responsibility. The site has been the location of highly publicized peace demonstrations, engaging several regional groups with national affiliations.

There is national, state, and local agreement on the cleanup and closure mission, and DOE is bound by the collaborative Rocky Flats Cleanup Agreement, signed by DOE, EPA, and the State of Colorado in 1996. Although approximately 3600 workers are currently employed at the site, the economic impact of DOE activities on the local economy is moderated by the diversity of the regional economic base. Potential environmental impacts and future site uses (including shipment of all wastes off site), however, are of high salience for the surrounding population and raise contentious issues for nearby local governments; for the State of Colorado; and for local, regional, and national activist groups. Local jurisdictions, which are differentially affected by potential air and groundwater contamination, have different stakes in the level of cleanup and have conflicting views on how the site should be used following closure. Differing views are also evident on the issue of removing TRU and other wastes: off-site shipment is strongly supported by state and local governments, but is opposed by the peace movement.

The $\mathrm{CAB}$ is only one of several DOE-related groups active in the local area. In addition to the direct, active involvement of nearby local governments, the Rocky Flats Local Impacts Initiative (RFLII), which was formed in 1991, works with DOE to mitigate socioeconomic impacts of the changed site mission. The RFLII includes representatives from surrounding jurisdictions, business, and interest groups.

\section{Board Composition}

Formation of a citizen board to improve public involvement in the cleanup of federal facilities, recommended by the Federal Facilities Dialogue Committee (Keystone Committee) in 1993, was supported by the State Governor and the local Congressman who requested the Colorado Department of Health and EPA Region VIII to jointly work together in its formation. This approach was favored by area citizens, who had pressed for establishment of a citizens' advisory board to represent community views on a broader set of issues than those examined by the RFLII. The CAB was established as a nonprofit, 501(c)(3) organization in November 1993 and subsumed in 1994 under the umbrella Environmental Management Site-Specific Advisory Board, for purposes of the Federal Advisory Committee Act (FACA). It is the only local SSAB structured as a nonprofit organization, and several aspects of the board's development and independent status continue to influence board operations and its interactions with $\mathrm{DOE}$.

At the time of the site visit in the summer of 1998 , the board was composed of 16 members and was seeking additional recruits (seven new members have since joined the board). The membership range has been 15-25, with a goal of 25. Initially, EPA and the State of Colorado selected a core group of six to select members. Members are now selected by the board, on the recommendation of the membership committee. The board was broadly representative of the community in terms of demographics and viewpoints, although perhaps with limited representation of business viewpoints. Members included representatives from two local governments, union site workers, and activist groups, as 
well as a variety of other citizens. The chairperson was a member of the Rocky Mountain Peace Center (a new chair has taken office since the site visit and the former chair is now the vice chair).

Recruitment is a mix of the individual and organizational approaches. Members are selected from various categories, drawing on community organizations and interest groups. Categories are carefully observed (academic, business, health care, environmental and public interest, Rocky Flats employees, and community and local government representatives). In addition, individual attributes are also emphasized, with particular attention to the candidate's time availability, ability to contribute to the work of the board, and also a commitment to work towards consensus.

The study found that, although disputes over scope and agenda are less severe at sites whose primary mission is cleanup, there are nevertheless issues at most sites that have the potential for polarizing the board. An effective strategy is to focus on issues that have the potential for gaining broad agreement and to delay addressing polarizing issues either indefinitely or at least until the board is sufficiently sturdy to survive the disagreement. At Rocky Flats, a latent issue has been the planned off-site shipment of TRU wastes to the Waste Isolation Pilot Plant (WIPP) in New Mexico. The board has only recently begun to discuss the various aspects of this issue.

\section{Purpose, Goals, and Commitment to Consensus}

The board presented a unified sense of purpose and searches for areas of agreement among diverse views. Members expressed pride in their ability to provide an independent perspective on site activities. Although several members referred to the changes in emphasis that have occurred as new members have joined the board, members generally agreed on the need for a watchdog role in relation to site activities and were committed to applying community values to site decisions and issues. Several members pointed with pride to their role in working with others in the community to persuade DOE to agree to fund an independent review panel on site cleanup levels for soil (interim levels agreed to by the regulators and DOE were perceived to be higher than levels set for other sites). The board's very strong commitment to consensus permeated both the board meetings and the interviews with members. The search for common areas of agreement appeared to be a central focus of the board's work.

\section{Internal Process and Functions}

Board processes operated very smoothly. Provision had been made for the various functions that support effective discourse. In combination with the diversity of viewpoints represented on the board, the successful performance of these functions contributed to the effectiveness of the discourse that was demonstrated during the board meeting. These functions include agenda-building and issues management processes, team building, leadership, facilitation, and administrative and technical support. 


\section{Agenda Building and Issues Management}

Agenda-setting is initiated during the summer, when EPA and the State of Colorado are invited to provide a list of activities that they would like the $C A B$ to consider. $D O E$ is also asked to present its list of priorities to the board. The board's subcommittees (called focus groups) also submit suggestions. $C A B$ members, members of the public, ex-officio members, and DOE are surveyed to determine their top ten issues from this consolidated list. Members vote on a final list at the board's annual retreat, and the results are recorded in the board's annual work plan. Issues are divided between "tracking" issues, which are assigned to support staff for monitoring, and focus areas, which are delegated to board committees (termed focus groups) for detailed evaluation and discussion. In addition, as new issues emerge over the year, committees may wish to add or change their tasks; suggested changes may be discussed among the committee chairs. The board's overall focus is maintained by reference to the agreed-upon work plan, supported by the informal networking process and values commitment among core members to the Keystone process.

In dividing issues between tracking and focus issues, the board attempted to resolve a common problem among all of the boards - how to strike a balance between detailed study of a few issues and less detailed review of a wide variety of issues that are important to the community. However, the problem appeared not to have been resolved in view of concern expressed about the board's tendency to stretch itself too thin rather than selecting and concentrating on a few, key issues. Since the site visit, the board suspended the focus group meetings for a period of six months so that the whole board could spend time working on a vision for the $\mathrm{CAB}$. To accomplish this, the board is meeting twice a month and devoting the entire meeting to discussion of this topic.

\section{Leadership}

Effective leadership that focuses on enhancing the effectiveness of board discourse and the interest of the board was clearly in evidence. The chair has played a key role in filling the various leadership functions - placing a priority on enhancing the board's effectiveness, emphasizing values, searching for agreement, and maintaining the balance between technical and policy orientations; setting a conducive atmosphere for work; and networking. He was strongly supported by a group of core members who formed the executive committee (chair, vice-chair, secretary, and treasurer) and who were very committed to the values espoused in the Keystone Committee report.

Leadership was reflected in the behaviors demonstrated in the board meeting that was attended and also in the minutes of previous meetings. For example, the chair placed particular emphasis on encouraging articulation of, and attention to, all viewpoints and stood back from pushing his own personal views. Technical and policy orientations are balanced. The board focus is guided toward attempting to reach agreement, informally taking the pulse of members prior to bringing an issue to the board, and referring issues back to committee for further work where agreement is not present. Interactions with the public indicated respect for public input (see section on public engagement, below). Comments from other members indicated the extensive informal networking that 
underlies board decisions and also the ability of the chair to take off his "organizational hat" in discussions with the board.

\section{Facilitation}

Observation of the $\mathrm{CAB}$ August meeting showed that the meeting was facilitated in an effective partnership between the independent facilitator (hired by the board) and chairperson. The facilitator managed the meeting process, while referring final decisions about schedule changes or substance to the chair and the board. Members were reminded that respect for one another should be the "bottom line" for interactions among board members and between the board and public attendees (this was stated upfront and reaffirmed during the meeting). The meeting ran to schedule.

The facilitator's role at Rocky Flats was limited to meeting facilitation. Other persons are available to fulfill the broker role that is part of the facilitator's job at some sites. A key actor in this important, behind-scenes work is the lead administrator/technical assistant who mediates among board members on interpersonal issues and among board and DOE on interpretations of technical and policy issues.

\section{Team Building}

Board members acknowledged the importance of team building, both in establishing and maintaining a shared sense of purpose and board identity. Promoting a shared sense of purpose was singled out as a particularly important task for the board as membership changes. Team-building processes are also important in facilitating the informal networks that enhance group effectiveness. And, as one member noted, the social interactions forged during the early years helped the board "get through tough times and difficult discussions."

New members undergo an orientation process that includes provision of two information notebooks, one about the site and the board - its history and procedures - and one that includes a list of all previous board recommendations and DOE responses. New members also participate in a 90-minute discussion of key features such as agency relationships, consensus decision making, and overall board structure and functions. The annual retreat is designed as a key part of the team-building process. It provides also an opportunity to develop the coming year's work plan and to assess future directions. The board undertakes a self-evaluation as part of this process - to help members reflect on what they have achieved, what is working and not working, and where changes may be needed. Training in consensus decision making was provided during the early years of the board and, most recently, earlier this year.

\section{Administrative and Technical Support}

Support is provided by a four-member team, hired by the board, that addresses the full range of support tasks. These include staffing the $\mathrm{CAB}$ office, including response to citizen hotline calls; performing day-to-day administrative tasks; overseeing meeting logistics; keeping the board's records; and coordinating the various board functions. The 
lead administrator has played a particularly key role in providing technical assistance (in addition, as noted above, to fulfilling a mediator function). In this role, he distills, synthesizes and summarizes information for members; explains technical issues; and provides mentoring where needed. In fulfilling this function, he has been able to lessen the workload on members and to facilitate non-technical members' understanding and contribution to discussions.

All of the persons interviewed spoke very highly of the support staff and expressed appreciation for the multifaceted support provided. They praised, in particular, the staff's dedication and sensitivity to their support role in ensuring smooth operation of board functions and simplifying members' tasks. The high quality of the support was also reflected in the record of board activities - meeting minutes, bi-weekly updates, and other records are detailed, precise, and understandable.

\section{Process Summary}

The diversity of the board, in combination with the commitment to consensus that underlay the effective performance of the key board functions discussed above, contributed to the effectiveness of the discourse that was observed during the meeting. These factors also contributed to the ability of the board to provide advice that articulated the implications of technical issues in terms of values and reflects diverse public views, as shown in its recommendations.

Board meetings are scheduled one evening per month for approximately four hours. During observation of the August meeting, the discourse proceeded in a smooth, unhurried manner, with a high proportion of time spent on substantive discussion. There was active participation by most members, including two new members - one interviewee observed that there was an unspoken agreement that members prepare for the meetings. Interactions were very civil and respectful, with a reminder given to a member of the public, when needed. Effective facilitation and the leadership role of the chair, as noted previously, emphasized and encouraged articulation of different views and a focus on reaching agreement.

\section{Public Engagement}

Members' discussions indicated that engagement of the public is high on the board's agenda, and board members expressed a strong sense of its responsibility to the public. One member, for example, observed that the board's legitimacy is derived from the community. There was general agreement that the board serves as a forum for expression of public views and the board's activities demonstrate interest in both providing outreach and in developing better understanding of public views through community and opinion surveys.

\section{Outreach and Information Gathering}

The extent of seeking input and reporting back to civic organizations by members is variable, depending both on the individual and whether he or she has a discrete group 
with which to interact. The administrative staff is responsible for outreach and information-gathering, under the direction of an outreach committee that meets on an ad hoc basis.

Regular outreach activities include:

- Advertisements of monthly board meetings and announcements in the local community events section of local newspapers

- Mailing list of approximately 650 persons, who receive a monthly postcard listing committee (focus group) meetings and topics to be discussed in the upcoming board meeting

- Distribution of a quarterly newsletter to 3,500 regular recipients and, periodically, to every household in a targeted area

- Website, updated regularly

- 24-hour public comment line.

At the time of the site visit, the board had just approved developing a speakers' bureau to give presentations about the $\mathrm{CAB}$ to community organizations. Plans for a community forum were put on hold, pending experience with the speakers' bureau and stronger expressions of interest and support by board members. In addition, the board hired two summer interns to help develop information targeted to residents who have recently moved into the area and who may have concerns about the safety of the site. The interns were developing an eight-page booklet on the history, impacts, and monitoring activities at the site that is designed to address residents' question, "Is it safe to live around Rocky Flats?" They were also completing a series of fact sheets on contaminants of concern.

The board takes seriously its responsibility to learn about public views. A Community Needs Assessment, conducted in 1996, examined the concerns and wishes associated with Rocky Flats that were held by local residents. More recently, the board completed a survey of public awareness of the board in an area near the site. The survey gathered information about awareness, perceptions of risk, and sources of information about the site as well as awareness of the $\mathrm{CAB}$ and the degree to which respondents wished to be involved in board activities. Information gathered in these surveys about issues of concern will be used to help target informational products more effectively.

\section{Opportunities for Public Participation in Board Activities}

Several actions were taken during the board meeting to indicate that the public's input was valued. Information was readily available, although directions to the meeting were not posted for newcomers. Meetings allowed for comment both during specific comment periods and during discussions. Public views were woven into the overall dialogue. One member observed that he had learned to appreciate the chairperson's emphasis on addressing every public comment, no matter how trivial, as a way of demonstrating the value of including the public. 
Committee meetings (which were not observed) are open to the public. Meetings are advertised through a mailing list (see below).

One non-board member commented favorably on the long-term value of the board to the community. In her view, the board had contributed to an effective learning process on the part of the public and DOE and the regulators - a learning process in constructive dialogue that extended beyond the board itself.

\section{DOE and Regulator Engagement}

\section{DOE Level of Participation}

The relationship between the DOE site office and the board is complicated at Rocky Flats by the existence of two groups (RFLII as well as the CAB) that are funded by DOE and by the independent status of the $C A B$. The two $D O E$ groups have different orientations and viewpoints, which contributes to DOE's stated position that it views the $C A B$ as one of a number of community groups from whom it obtains input.

Responsibility for the board is delegated, as at other sites, to the Communications Department. The Site Manager rarely attends meetings, but has met with the executive committee. A representative of senior management attends regularly, although there has been turnover in fulfilling this role. At the observed meeting, the DOE representative responded openly to questions. Although, information provided by the persons interviewed indicated that the engagement of upper management appears to have been limited, other DOE and contractor staff (mid-level managers and communications staff) have been very supportive of, and interact frequently with, the $\mathrm{CAB}$. These persons have provided considerable time and resources in meeting board needs.

\section{Empowerment by DOE}

The board is the most independent of all SSABs, being the only board established as a nonprofit organization. The board has its own office and hires all of its own staff, including administrative, technical and support staff. Members expressed pride in this independence and the ability it provides to offer a critical perspective on DOE activities and framework.

\section{DOE Responsiveness}

Board recommendations to DOE are produced in a clear, standard format. The board does not maintain a formal matrix but tracks recommendations and responses, although there was no policy in place to deal with delay or non-receipt of responses. A summary of recommendations is listed in the annual report.

Responsiveness to board needs by communications staff was appreciated by the members. However, several members expressed concern that positive feedback from upper DOE site management was less than expected. One member expressed 
disappointment that the board had been unable to achieve its larger goal of "sitting down and having an honest discussion" with DOE. Several commented that the lack of positive reinforcement and the perceived perfunctory nature of $\mathrm{DOE}$ response caused them to question the value of their contributions - even to the extent of causing some members to withdraw. However, some noted that DOE had been making an effort to improve responsiveness in recent months, both in terms of speed of response and also in explaining why board advice may not be taken.

Despite these tensions, both board and DOE discussions indicated similarities in assessment of the board's achievements. There was awareness that the challenges posed by an activist board to the DOE way of doing business, though painful at times, had nevertheless had some very positive results for the community. Members primarily emphasized the role of the board in opening the information process - of obtaining information and distilling it so that the broader public could give more meaningful input. A DOE official emphasized the role played by the board in forcing the agency to reexamine its assumptions and to take into account issues that the agency would otherwise have overlooked. This person emphasized that both $\mathrm{DOE}$ and the community at large had benefited from the example set by the $\mathrm{CAB}$ for community discourse. DOE had learned to take into consideration and interact more effectively with the public, while the community had learned how to participate effectively on policy issues.

\section{Role of the Regulators}

Relationships with the regulators at Rocky Flats are influenced by the collaborative approach between EPA, the State of Colorado, and DOE that is specified in the Rocky Flats Cleanup Agreement. The regulators appeared to work closely together.

The board's by-laws allow for recommendations to be provided to both regulators and to DOE. However, a review of the 15 recommendations itemized in the 1997 annual report indicates that only one recommendation was addressed and responded to by regulators (state regulator).

Both regulators (especially the state regulator) participated actively in the discussion during the board meeting, although their primary role appeared to be limited to providing information. As noted by one person who was interviewed, this reflected the board's preference that officials only speak "officially."

As with DOE, input from the board is regarded as only one source of input. At the state level, for example, the Governor listens to other community inputs, especially from local officials. Informal interaction occurs between meetings, especially with the State regulator. The executive committee recently met informally with both regulators to discuss their roles and participation at board meetings. 


\section{Issues and Observations}

\section{Issues Raised by Members Concerning the Rocky Flats CAB}

- Several members raised the issue of the disappointing relationship with upper DOE site management.

- An additional concern, which was noted as being one that may increasingly affect all of the boards was the difficulty of maintaining a shared sense of purpose as membership changes - many of earlier recommendations may not be acceptable to current members.

- Also an issue was the difficulty in recruiting new members (however, the board seems to have been successful in overcoming this difficulty in its most recent recruitment effort).

- Improving public engagement is an issue of continuing concern.

Researchers' Assessment of Primary Accomplishments and Challenges Facing the Rocky Flats $C A B$

\section{Accomplishments}

- The board is notable for members' commitment to consensus and the effectiveness of its processes. The value of diversity in membership, combined with commitment to searching for agreement, and effective leadership, facilitation and team building is demonstrated in the quality discourse among members. A core group of members is committed to fulfilling the purpose of the SSAB Initiative.

- Although members expressed some disappointment concerning their relationship with DOE, the board appears to have had a positive influence on interactions between the public and DOE.

- The board is very aware and committed to fulfilling the board's responsibility to the public.

\section{Challenges}

- Several persons referred to a negative perception of the CAB as an activist organization, perhaps stemming from its origin as an independent organization, with broad representation of citizen views.

- Engaging upper DOE management and the regulators appears to be a continuing challenge. 
PNNL-12139

An Evaluation of the Effectiveness of Local SiteSpecific Advisory Boards for U.S. Department of Energy Environmental Restoration Programs:

\section{Savannah River Site \\ Citizens Advisory Board}

Judith A. Bradbury

Kristi M. Branch

Pacific Northwest National Laboratory

February 1999 


\section{SAVANNAH RIVER SITE \\ CITIZENS ADVISORY BOARD}

\section{Table of Contents}

INTRODUCTION ........................................................................................................................................ 1

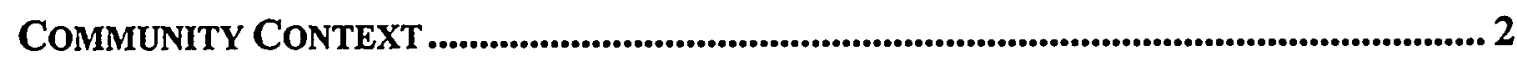

BOARD COMPOSITION ............................................................................................................... 3

PURPoSE, GoALS, AND COMMITMENT TO CONSENSUS............................................................. 4

INTERNAL PROCESS AND FUNCTIONS .............................................................................. 4

Agenda Building and Issues Management.......................................................... 4

Leadership ........................................................................................................ 5

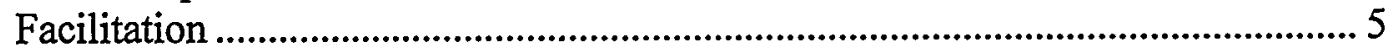

Team Building ..................................................................................................... 6

Administrative and Technical Support ...................................................................... 6

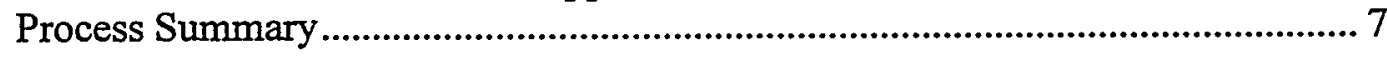

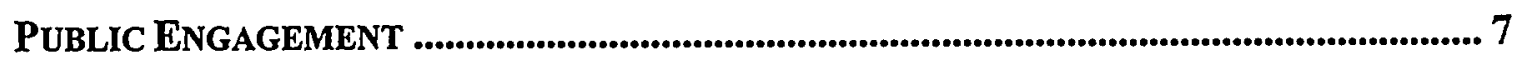

Outreach and Information Gathering ............................................................... 7

Opportunities for Public Participation in Board Activities...................................... 8

DOE AND REGULATOR ENGAGEMENT.................................................................................... 8

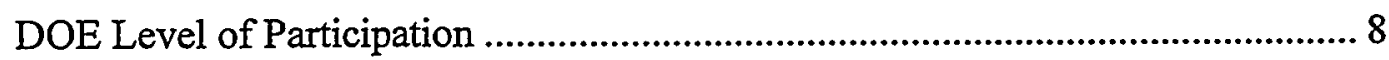

Empowerment by DOE....................................................................................... 9

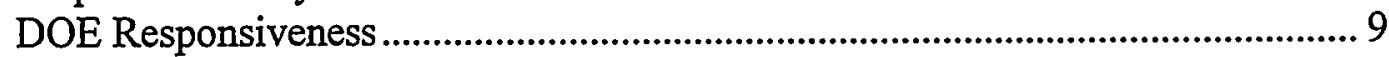

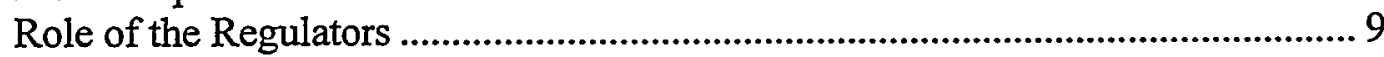

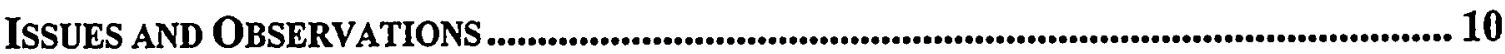

Issues Raised by Members Concerning the Savannah River Site CAB ............... 10 Researchers' Assessment of Primary Accomplishments and Challenges

Facing the Savannah River Site CAB ............................................................... 10 


\section{SAVANNAH RIVER SITE CITIZENS ADVISORY BOARD}

\section{Introduction}

This report details the results from the Savannah River Site portion of a U.S. Department of Energy (DOE) study that was initiated to understand factors contributing to the effectiveness of the DOE local Site-Specific Advisory Boards (SSABs) and to provide information useful for the boards and DOE in their continuing efforts at improvement. The Overview report that accompanies the individual site reports discusses findings across nine DOE sites and provides background on the goals, methodology, and rationale for the framework used in the study. It also serves as a template for the findings presented in this site report.

The report for the Savannah River Site Citizens Advisory Board (CAB) is thus structured according to the six factors that were found to be important in assessing local SSAB effectiveness. As emphasized in the Overview, the study was designed to assist DOE and the boards in assessing how well the boards were fulfilling DOE's basic purpose in establishing the boards, and to provide information that would be useful to DOE and the boards in achieving this purpose. Specifically, DOE established the boards to obtain independent, consensus, policy advice and recommendations that drew on the range of local and regional stakeholder perspectives. The underlying rationale was that advice that reflected agreement among very different viewpoints would also be more likely to be acceptable to nearby communities and thus would provide a firm basis for developing policies that were not only technically sound but also could be implemented.

Accordingly, the focus of the study was on board processes that enhanced the boards' ability to provide independent, broadly based policy advice, rather than on the recommendations per se.

This report describes the Savannah River Site $C A B$ as it was operating at the time of the researchers' visit in March 1998. The description is provided in terms of the six factors found to contribute to board effectiveness (community context; board composition; purpose, goals, and commitment to consensus; internal processes and functions; public engagement; and DOE and regulator engagement). It begins by highlighting key features of the site context that pose particular challenges facing the $\mathrm{CAB}$. The two subsequent sections discuss the board's composition, including diversity of viewpoints represented on the board, and the board's sense of purpose, goals, and commitment to consensus. The next section examines the board's internal processes and functions, including how board members accomplish agenda building, issues management, and team building; how facilitation, brokering, and leadership roles are taken and performed; and how administrative and technical support is provided. The following section, on public engagement, details the board's effectiveness in providing opportunities for public participation and in outreach and information gathering. The next section discusses the relationship between the board and DOE, and between the board and site regulators. The 
final section lists important issues that members mentioned and provides the researchers' assessment of the accomplishments and challenges facing the $\mathrm{CAB}$.

As emphasized in the Overview, the purpose of this study is to provide an outsider's perspective, based on a review of boards across the complex, and to encourage the boards to reflect on their own strengths and weaknesses and learn from one another's accomplishments and challenges.

\section{Community Context}

The Savannah River Site is located approximately 20 miles from Augusta, Georgia, in a rural area of South Carolina, bordering the Savannah River. Workers are dispersed over a wide area, including small rural communities surrounding the site. Nearby urban areas include Augusta, Georgia (1990 city population: 44,639), North Augusta, South Carolina (1990 city population: 15,351) and Aiken, South Carolina (1990 city population: 19,872). The area affected by the site extends to two states (South Carolina and Georgia) and includes six counties: Aiken, Barnwell, and Allendale in South Carolina; and Columbia, Richmond, and Burke Counties in Georgia. The population in the six-county area is primarily white, but with a relatively high proportion of African Americans.

Approximately 14,000 people are employed at the site, making it one of the largest employers in South Carolina. The site has played a major role in national defense. In addition to remediation, site activities include production, waste processing and management of a variety of nuclear materials. The environmental and safety issues associated with the site are great and highly salient (i.e., of high importance). The Savannah River Site's original mission was production of materials used in fabrication of nuclear weapons, primarily tritium and plutonium-239. Five reactors and support facilities, including chemical separation facilities, or "canyons," were built on site. Although the reactors are no longer operating, several on-going production activities continue (production of plutonium-238 for deep space probes and tritium unloading, mixing, and loading). Future missions include fabrication of mixed oxide fuel (mox) from decommissioned nuclear warhead material and, potentially, plutonium disposition. Waste management activities include the Defense Waste Processing Facility, which will vitrify the 35 million gallons of high-level waste currently stored in tanks on site. Two research centers are also located at Savannah River - a timber and forestry research center operated by the U.S. Forest Service and an environmental research center operated for DOE by the University of Georgia.

A primary factor that has posed a challenge to development of a local SSAB at some sites has been lack of agreement on scope and agenda. Disagreement is especially likely to arise at sites where DOE's mission includes current production (including weaponsrelated) and waste processing activities as well as environmental cleanup. At the Savannah River Site, although potential water contamination is of concern to downriver communities, the site's continuing and future mission has not been subject to controversy, and hence has not affected the CAB's ability to develop its scope and agenda. 
A particular challenge for the $\mathrm{CAB}$ has been the limited interaction between $\mathrm{DOE}$ and the community. Until recently, site activities were shrouded in secrecy. Regional activism related to environmental justice issues is evident. However, the culture is generally conservative, and local environmental activists opposed to DOE nuclear activities and with links to national movements do not appear to have gained widespread local support. The $C A B$ has therefore had little foundation for embarking on the collaborative problemsolving approach envisaged for the SSAB Initiative. As one observer commented, "The board was the first attempt of DOE to break out into openness." The CAB may be viewed as a prototype for community dialogue, providing indirect benefit to the community as well as to individual members and DOE.

\section{Board Composition}

The $\mathrm{CAB}$, which has 25 members, held its first meeting in 1994. A public working group of 16 citizens developed a charter and membership selection process following a year long effort that included 11 public meetings. They also established a seven-member panel from the general public that selected the initial members.

The board now recruits, screens, and selects its own members, using a very open and carefully designed approach. A major recruitment effort is undertaken every two years. The board advertises extensively, using newspapers, radio and cable network, contacts with community organizations, coupon mailings, flyers, the site's general mailing list, the $\mathrm{CAB}$ newsletter, news releases, employee notification, and the internet. Candidates are invited to attend board meetings to introduce themselves prior to board elections (all members vote); if not elected, they are retained on a waiting list for two years and used to replace members during annual elections. The effectiveness of this approach is demonstrated by the results; although the board had some difficulty in recruiting in previous years, the most recent (1998) campaign resulted in a large pool of qualified candidates for membership.

$\mathrm{CAB}$ recruitment demonstrates an individual approach. It is specifically designed to reflect the demographic diversity of the communities that surround the site and are impacted by the site. Members are chosen from the following categories: public officials, business, academia, labor, general public, minority issues, and environmental representatives. Cross-cutting criteria of gender, race, and geographic location are used to develop a balanced board. In addition, financial assistance is provided to some members to assist in maintaining economic diversity. The categories and cross-cutting criteria have been strictly applied from the outset.

Board composition at the time of the site visit in early spring showed a board that was demographically and geographically balanced. Viewpoints, characterized by one observer as "mainstream," included five members who represented an environmental viewpoint, although they did not include the viewpoint of persons who are closely linked with environmental organizations or organizations that are opposed to nuclear activities. This viewpoint has been missing since the resignation of a key representative early in the 
board's development. Current and ex-site-related employees played lead roles on the technical issues committees (termed subcommittees); responsibility for other committee work was allocated among non-technical members. The chair was female, white, and active in community affairs, including membership in a local county council. The vicechair was an African American businesswoman, also active in community affairs.

\section{Purpose, Goals, and Commitment to Consensus}

The $\mathrm{CAB}$ adopted Robert's Rules of Order several years ago under the previous chair and has continued with this decision-making approach since that time. There appeared to have been limited commitment - and strongly held philosophical opposition on the part of one member - to the value of a consensus approach. In part, this may be attributed to the absence of members generally opposed to DOE's nuclear activities and thus a reduced emphasis on the need to search for common areas of agreement among very divergent views. In part, also, it reflected agreement among members on the board's technically oriented purpose and goals. Several members emphasized that although consensus was not used formally, most decisions that came before the board reflected considerable "behind the scenes" networking and discussion to obtain agreement on key issues. Minority reports have been used when agreement cannot be obtained; however, agreement appears to have been the norm, with only three minority reports filed out of a total of 78 board recommendations since the board's inception.

Discussions with board members revealed that, although there were some differences in emphasis, there was a shared sense of purpose: members agreed on the need for community input to ensure faster, better cleanup and the safety of the workers and communities. They pointed with pride to the number and quality of recommendations as a measure of their board's worth and drew on the expertise of current and former siterelated workers, including peer technical review, to establish the credibility for their work. Agreement on scope and agenda (initially, environmental remediation, waste management, and future use of the site, but expanded to include nuclear materials) was evident; as one member noted in a matter-of-fact way, "Other issues are outside of the purview."

\section{Internal Process and Functions}

The study of board processes across the complex highlighted the importance of providing for the functions that, in combination with diversity on the board, contributed to smooth functioning of the board. These functions include agenda-building and issues management processes, team building, leadership, facilitation, and administrative and technical support. As described below, these functions, which were generally well provided, were oriented to facilitating the technical work of the $C A B$.

\section{Agenda Building and Issues Management}

The board's agenda-building and issues management work was primarily performed in the subcommittees. Subcommittee chairs are elected by all board members and, with 
input from subcommittee members, select priority topics to be studied. DOE also provides a list of issues for the board to consider; the regulators review these issues and are provided an opportunity to comment on these, or add issues. An issues matrix, showing the important issues for each of the three parties (DOE, regulators, and board), is used as a general guide, although the specific list of topics is fluid. Subcommittees are open to members of the public; the Environmental Remediation Subcommittee, in particular, had a number of regular non-members - primarily site-related retirees who were familiar with DOE and regulatory processes and site issues - who participated as members of the subcommittee.

Members expressed no concerns about maintaining focus. The technical subcommittees - nuclear materials management, risk management and future use, and environmental remediation - were chaired by members who were able and willing to devote a large proportion of their time to the work. Under their direction, issues were discussed in detail and recommendations brought back to the board for further discussion and approval. The smooth functioning of the issues management process was enhanced by the clear understanding of roles and responsibilities in board operations, as discussed under the leadership function below. In addition, the length of the board meetings, which were scheduled for two concentrated days at bi-monthly intervals, offered an opportunity for board discussion without the pressure felt at sites where meetings are scheduled for only one evening. This also allowed longer time between meetings for the subcommittees to do their work.

The schedule for the two-day meetings was arranged so that subcommittee meetings and executive committee meetings could be held in the same location. This enhanced the efficient use of time and allowed members who were widely distributed over the large six-county area to meet in person rather than by phone. The subcommittee meetings and an open session for the public were held the night before the board meeting.

\section{Leadership}

Effective leadership was clearly in evidence. The chair played a leading role in setting a conducive atmosphere for work, demonstrating and modeling respect for all members and emphasizing the value of each member's contribution. Her primary focus was on promoting the board's interests and facilitating members' interactions. She emphasized the smooth working of board operations, orchestrating productive board meetings, ensuring that organizational functions were performed, and supporting the technical focus of the substantive issue subcommittees. The chair was supported by an executive committee, comprising the chair, vice-chair, and subcommittee chairs, which met approximately three times a year. The roles and responsibilities of these members appeared to be have been clearly defined and assigned, thus promoting smooth operation of their various tasks.

\section{Facilitation}

The chair played a leading role in meeting facilitation (the meeting that was observed was the final meeting of the facilitator who has now been replaced). She emphasized civility 
in interactions and participation of members who wished to contribute. The meeting ran smoothly and on schedule.

The broker role of mediating among board members on interpersonal issues is played by a variety of persons: the chair, vice-chair, several members, and also the lead administrative staff person who has worked with the board for many years and who is a trusted contributor to the board's effectiveness. Brokering on technical issues appeared to be primarily conducted as part of the technical discussions in subcommittee meetings, and, according to several members, by subcommittee chairs between meetings.

\section{Team Building}

The distribution of members over a two-state, six-county area makes it difficult to communicate between meetings. The board has held two retreats and self-evaluation is conducted, although none of the members mentioned this as being an important function to be performed. The systematic scheduling of board meetings in different locations of the two-state area, which requires an overnight stay, provided an opportunity for social interactions. The effectiveness of these interactions in forging informal bonds and networks was clearly revealed in comments from several members from different social and racial backgrounds who referred to the board as "family." New members receive a one-day orientation that includes a one-day site tour and half-day briefings and introductions to key DOE staff working with the $\mathrm{CAB}$, as well as an information packet about the site.

\section{Administrative and Technical Support}

Currently, support functions are provided by two full-time $M \& O$ contractor staff. The support staff fulfill both day-by-day administrative functions (staff the $\mathrm{CAB}$ office, provide day-to-day meeting and logistics support, keep records and distribute information) and executive coordination functions. The staff were rated highly by members as being dedicated to supporting the smooth functioning of the board and simplifying the work load on members. The high quality of the support was reflected in the record-keeping - meeting minutes and other records were detailed, understandable and clearly organized.

The board has a technical coordinator who participated actively in committee meetings to assist members in identifying key technical issues, and distilled and summarized information (since the site visit, his role has expanded to include coordinating the development of motions for board consideration). Understanding the technical issues was not cited as a problem for the non-technical members whom were interviewed. One person, for example, observed that she and others expected - and indeed insisted - that technical members explain issues and answer their questions. One of the subcommittees contracted with the University of Washington to perform peer review of various site programs, including a groundwater program. 


\section{Process Summary}

The board and subcommittee discussions that were observed reflected a strong focus on reaching agreement on technical issues. A small, technically oriented proportion of members participates in the substantive discussions. This technical focus appeared to be reinforced by the important role of the committees in the overall board structure and the smooth operation of other supporting board processes. The trust of other members, perhaps developed through the social interactions facilitated by the two-day meetings, seemed to facilitate deferral by non-technical members to the expertise of the more technically trained, provided that the latter answered questions and explained the issues. Notably, the sense of achievement in developing well-thought-out and carefully researched recommendations and comments was expressed by both technical and nontechnical members.

\section{Public Engagement}

Variability was apparent in the priority level members assigned to interaction with the public. For some, outreach activities were very important; for others, this was relatively low on the agenda. This is in keeping with the general division of responsibility among board members.

\section{Outreach and Information Gathering}

The extent of seeking input and reporting back to civic organizations by members was limited. Although this was done by some members, it did not appear to be common practice and reflected the difficulty for members recruited through an individual approach. As one member observed, "How do I know who the public is whose views I am supposed to represent?"

The board had not sponsored any information-gathering activities, but had undertaken a variety of outreach activities. Some members favored an expanded approach to public outreach, emphasizing the board's need to visit locations such as churches, schools, and civic organizations where the public is most likely to be found and where members are already known. The outreach committee was planning to develop a speakers' bureau. Training in public speaking was to be provided by the staff in the site communications department. The board also conducts a variety of outreach activities on a regular basis:

- Meeting advertisements in local newspapers (described as "down-home" approaches)

- Newsletters, fact sheets, and brochures

- Exhibits, displayed in business expos and malls and at other area events

- Working with the local media to increase the number of newspaper editorials and participating in local cable talk shows

- Website

- Annual plan. 
In addition to these activities, the board sponsored educational forums on plutonium disposition and spent nuclear fuel in Georgia and in South Carolina in 1996 and 1997. In 1996, the Risk Management and Future Use Subcommittee board hosted a series of five well-attended public meetings, in which participants rank-ordered criteria to be used in the 1999 budget prioritization process.

\section{Opportunities for Public Participation in Board Activities}

Board meetings are systematically rotated around the two-state area to facilitate greater public access to meetings. The meeting that was observed was held in the hotel where members stayed overnight; the venue afforded ample opportunity for public input. Although open to the public, few non-members attended the subcommittee meetings. However, attendance was reported to be greater when they are held between meetings at a location closer to the site and a group of non-members (mostly retirees formerly associated with the site) regularly participate. A postcard mailing is used to notify these regular attendees and others who have previously shown an interest in the various subcommittees. Since the site visit, the board has also established public focus groups-ad hoc teams comprising non-board members as well as board members that act independently of the board to study a particular problem in detail.

A session for the public was held before the subcommittee meetings which were held the evening before the board meeting. Public attendance was limited both at that session and for the two-day board meeting. Board meetings are widely advertised through a site mailing list of approximately 3,000, and through local media (newspapers and radio spots). The board showed a welcoming attitude to public attendees, responding to comments and questions raised during the public comment periods held at intervals during the board meeting. Information was readily available for public review.

\section{DOE and Regulator Engagement}

The $\mathrm{CAB}$ provides advice to DOE and the regulators, although most advice is directed to DOE. Both DOE and the regulators are very engaged in board activities. The board is a high priority for the site and is the primary mechanism for public involvement; the regulators participate actively.

\section{DOE Level of Participation}

Clear directions and written guidelines issued to all site staff by the Acting Savannah River Site manager signal very clearly to DOE and contractor staff the high priority placed on interactions with the CAB. DOE participation was evident both at the highest management level (the site manager, appointed shortly after the site visit, has attended several meetings over the past year) and among staff at the working level. $C A B$ contractor staff are rated regularly on their performance. The SSAB Coordinator plays a key role in ensuring close coordination among the various staff involved with SSAB activities - the administrator, contractor staff, DOE technical staff, and upper management - to ensure that the process functions effectively. 
Responsibility for the board is assigned to the Assistant Manager for Environmental Programs, who has held this role since the board's inception. The value he and his superiors place on the board has been demonstrated to members by his regular attendance at board meetings, his expectation that his staff will also attend, and the high level of responsiveness to board recommendations, as outlined below. New members are introduced to him as part of their initial site orientation. DOE and contractor are assigned to each of the board's subcommittees to provide assistance as needed. Although the Assistant Manager was unable to attend on the evening of the site visit, a senior official substituted for him, and many DOE and contractor staff were active participants in the subcommittee and board meetings. Members appreciated the value placed on their contributions; several noted that DOE's attitude had changed over time from one of "tolerating" the board to realizing that members are knowledgeable and have much to contribute.

\section{Empowerment by DOE}

The issue of empowerment did not appear to be of concern. The M\&O contractor provides both administrative support and extras such as paying for board refreshments extras that as one person observed "make the meetings fun." Two full-time M\&O staff attend to $C A B$ affairs; they can also draw on the larger resources of the public involvement staff. The board hires its own facilitator, drawing up criteria, issuing RFPs, and screening and selecting a candidate; and selects and hires its own technical reviewer.

\section{DOE Responsiveness}

DOE's guidelines for staff interactions with the $C A B$ specify very clearly the high level of importance paid to being responsive to $\mathrm{CAB}$ recommendations. A particular requirement is that $\mathrm{DOE}$ responses should be made within 10 calendar days of their receipt. The Site Manager requires that he be involved in meetings to discuss responses to board recommendations. The DOE Coordinator, who is tasked to perform follow-up functions, schedules meetings with technical staff within a few days of each board meeting to ensure prompt response. Recommendations and responses, including dates, are listed on a tracking system to monitor the status of each recommendation. The high priority placed on responsiveness is further demonstrated by the recommendations status list that hangs by the AM/EM's office.

\section{Role of the Regulators}

As with the DOE officials, both EPA and state regulators have been associated with the board since its inception (a state regulator participated in the Charter Committee) and have developed effective working relationships. While recognizing that the board is primarily accountable to DOE (who foots the bill), the regulators nevertheless had a sense of responsibility for the board's development. They participate actively in board meetings, playing an important role in offering an alternative perspective on site activities, and encouraging members to examine issues that they may otherwise have 
ignored. As noted by one regulator, this approach of providing encouragement and moral support goes considerably beyond the typical regulator's role.

\section{Issues and Observations}

\section{Issues Raised by Members Concerning the Savannah River Site CAB}

- Several members emphasized that there is a need for greater public involvement, going out to people on their territory rather than expecting them to come to the board.

- Concern was expressed by some members that they are bearing the load for others.

- There is a very steep learning curve for members not familiar with the site.

- How can members with limited time (i.e., have other jobs) become engaged in technical/policy issues?

\section{Researchers' Assessment of Primary Accomplishments and Challenges Facing the Savannah River Site CAB}

\section{Accomplishments}

- A shared sense of purpose, pride in the board, camaraderie, and sense of family were very evident.

- The board has placed a priority on ensuring demographic diversity and membership has provided a major personal growth opportunity for many members.

- Well-functioning processes are in place and there is an effective, experienced chair. The chair focused on effective board functioning and moving things along. She modeled respect for all members and made sure everyone had an opportunity to contribute to the functioning of the board.

- DOE is very committed. The board is a high priority for DOE; responsiveness and support at all levels was very strong.

- The regulators are very engaged and demonstrated a sense of responsibility for ensuring the effectiveness of the board. They are a particularly important source of input to the board in helping provide a different perspective.

\section{Challenges}

- An activist, anti-nuclear viewpoint is missing; most members appeared to be supportive of DOE's mission. 
- There was a strong focus on technical issues, which was reinforced by the strong committee structure, including chairs.

- A gap existed between those who come up to speed on site issues and those who do not.

- There was a small subset of members responsible for technical work. This poses a general question: how can one structure a board to balance the strong influence of members with time, very high interest, energy, technical training, and knowledge of the site? 